\title{
Otimização linear aplicada ao plantio sustentável de vegetais
}

\author{
Rafael Martins Gomes
}


SERVIÇO DE PÓS-GRADUAÇÃO DO ICMC-USP

Data de Depósito: 02.08.2011

Assinatura:

\title{
Otimização linear aplicada ao plantio sustentável de vegetais
}

\author{
Rafael Martins Gomes
}

Orientador: Prof. Dr. Marcos Nereu Arenales

Dissertação apresentada ao Instituto de Ciências Matemáticas e de Computação - ICMC-USP, como parte dos requisitos para obtenção do título de Mestre em Ciências - Ciências de Computação e Matemática Computacional. VERSÃO REVISADA.

USP - São Carlos

agosto de 2011 
Ficha catalográfica elaborada pela Biblioteca Prof. Achille Bassi e Seção Técnica de Informática, ICMC/USP, com os dados fornecidos pelo(a) autor(a)

Gomes, Rafael Martins
Otimização linear aplicada ao plantio sustentável
de vegetais / Rafael Martins Gomes; orientador
Marcos Nereu Arenales -- São Carlos, 2011.
88 p.
Dissertação (Mestrado - Programa de Pós-Graduação en
Ciências de Computação e Matemática Computacional) --
Instituto de Ciências Matemáticas e de Computação,
Universidade de São Paulo, 2011.
1. Rotação de culturas. 2. Otimização linear e
discreta. 3. Geração de colunas. 4. Agricultura
sustentável. I. Arenales, Marcos Nereu, orient. II.
Título.




\section{AGRADECIMENTOS}

Muitas pessoas estiveram envolvidas nessa fase de minha vida, e ajudaram a torná-la em uma das experiências mais amadurecedoras e especiais que tive até hoje. Espero conseguir mencionar todas essas pessoas, de alguma forma, sabendo que todas foram especiais a seu modo.

Agradeço primeiramente a Deus, por me dar a vida e os dons que possuo, permitindo que meus esforços e estudos me trouxessem a esse ponto.

Agradeço a minha mãe, Áurea Martins Gomes, por ser o pilar de sustentação da minha vida, minha inspiração, minha heroína. Sem sua dedicação e seu carinho, eu nunca me tornaria a pessoa que hoje sou. Lembrar dela sempre foi a forma que eu encontrava para obter motivação em me dedicar a tudo que fiz e continuo fazendo. Não há palavras que descrevam o quão especial é o amor de mãe. Desejo a ela toda a felicidade do mundo, e estarei a seu lado para todo o sempre, fazendo de tudo que estiver a meu alcance para que minha mãe tenha uma vida repleta de paz, felicidade e harmonia. Amo-te mais que tudo neste mundo, mãe!

Agradeço à minha família, mas preciso deixar uma menção honrosa à minha avó materna, Maria Boretti Martins, por preparar deliciosos almoços todos os sábados, entre outras iguarias clássicas de avós que adoram engordar seus netos. Um exemplo de disposição de dar inveja a muitos jovens, espero me tornar alguém tão inspirador como minha avó um dia.

Agradeço ao meu melhor amigo, Gustavo Monteiro Dias, pela amizade inabalável que nesta data passa dos 18 anos. A certeza de que encontraria um rosto amigo em São Carlos foi uma das razões que tive coragem de encarar a mudança para uma cidade desconhecida. Desejo ao Gustavo muito sucesso, mas não é como se ele não soubesse o quanto eu torço por ele.

Agradeço aos professores que participaram das bancas de qualificação e defesa, Alysson Machado Costa, Reinaldo Morabito e Vitória Pureza, por aceitarem o convite e compartilharem de sugestões de melhorias. Certamente muitas das lições que aprendi serão utilizadas no futuro em outras ocasiões, de alguma forma. 
Agradeço ao meu orientador, Marcos Nereu Arenales, com quem aprendi muito, principalmente a organizar minhas tarefas e responsabilidades. Não hesito em afirmar que hoje sou uma pessoa muito mais capacitada e auto-didata, e devo isto ao apoio do meu orientador. Saiba que seu último aluno adotado termina o mestrado mais responsável e com mais maturidade graças a você.

Agradeço às funcionárias da secretaria de pós-graduação do ICMC da USP de São Carlos, sempre muito atenciosas, pacientes e prestativas: sua ajuda por muitas vezes tornou os processos burocráticos necessários e exigidos pela faculdade uma tarefa menos árdua e de forma organizada. O agradecimento se estende aos funcionários de toda a USP de São Carlos, pelos serviços oferecidos.

Agradeço aos professores e alunos do Laboratório de Otimização do ICMC da USP de São Carlos, pela enorme amizade e apoio durante todo este tempo. Muitas foram as risadas, papos de todas as naturezas, pizzadas, temakis às quartas-feiras, jogatinas, almoços, jantares, amigo secreto, festas de aniversários com bolos da Maria Doces... inúmeras memórias agradáveis que levo no meu coração e lembrarei com muito carinho. Ver um grupo onde professores e alunos convivem e se socializam tão à vontade me faz querer visitar e participar de eventos com a turma em novas oportunidades. Desejo sucesso a todos!

Como alguém que encontrou no Kung $\mathrm{Fu}$ um estilo de vida, eu não poderia deixar de agradecer pessoas que foram e estão sendo importantes nessa caminhada. Seguindo a ordem cronológica, agradeço inicialmente ao meu niisan, meu irmão adotivo mais novo, Luiz Paulo M. Tempester, por ser mais que um amigo, ser o irmão que eu nunca tive. Seu apoio em uma fase crítica em minha vida foi fundamental para que eu superasse as dificuldades, o que só foi possível por eu ter conhecido o Kung Fu por intermédio dele. Por todo o apoio e reconhecimento do meu potencial em artes marciais, agradeço meu niisan e lhe desejo muito sucesso, e ratifico que superá-lo-ei como mestre em Kung Fu!

Agradeço ao Si Hing Rafael e Si Hing Juliano, instrutores da academia Tat Wong de Campinas, onde meus treinamentos iniciaram, antes do início do meu mestrado. Ambos perceberam em mim dedicação, empenho e potencial, e assim me incentivaram e apoiaram durante os treinos. Lembro de lágrimas escorrerem após meu 
último dia na academia. Sou grato a eles pela ajuda na fase inicial de meu treinamento, que se estende até hoje!

Agradeço à Associação Fei Lung Sin de Kung Fu de São Carlos e ao Si Sok Danilo Martins de Mello, por fornecer na faculdade treinos abertos e gratuitos, sempre com seriedade e dedicação. Altruísmo como este do Danilo, se responsabilzando por treinos sem exigir nada em troca enquanto se dedica à sua graduação, mostra o quão especial este grupo é. Por mais que eu voltasse dolorido, com hematomas e cansado, os treinos com o pessoal da AFLS eram a razão pela qual eu mal podia esperar pelo anoitecer. Agradeço todos os colegas de treino destes dois anos e meio pelos ótimos momentos juntos. Dentre os colegas deixo um agradecimento especial para o Sérgio Aparecido Zanchetta Jr., conhecido entre os amigos como Zanka, por ter sido como um padrinho de treino, também reconhecendo meu potencial e dedicação, e empenhando-se em me ensinar. Graças ao pessoal da AFLS de São Carlos, ganhei uma maturidade nas artes marciais que me ajudam em vários campos da vida até hoje.

Por fim, agradeço à União Long Fon Quan Kung Fu e Tai Chi Chuan de Mogi Mirim (minha cidade natal) e ao Jo Sz Marcos Braga, onde comecei a treinar neste último ano de mestrado e pretendo estabilizar. Desde que cheguei, pude ver que o Jo $\mathrm{Sz}$ reconheceu minha maturidade em artes marciais. Se estou evoluindo tão rapidamente dentro da LFQ, não posso negar que é devido ao empenho do pessoal da AFLS. Espero atender as espectativas do Jo Sz Marcos e poder adquirir o título de mestre em artes marciais com sua ajuda.

Na vivência em São Carlos, agradeço a Beth, funcionária da padaria que ficava ao lado da kitnet que morei no primeiro ano, por muitos cafés da manhã com papos super agradáveis, roscas de goiabada e cuecas-viradas que levava para casa (que não se limitaram ao primeiro ano!), e por ser um exemplo de determinação e garra. E agradeço também à Gisele Paladine Basílio Conquista, funcionária faz-tudo da temakeria que eu e colegas sempre íamos desfrutar de culinária japonesa: assim como a Beth, tive papos super agradáveis com a Gisele e pude conhecer mais uma pessoa que é exemplo de força e amor. Desejo muito sucesso e felicidade às duas!

Agradeço também amigos distantes, mas com quem converso ocasionalmente e me trazem memórias tão boas: Raquel Costa, Cristiane Gelatti e Ronaldo Campos, amigos desde os tempos do ensino médio; Camila Kamarad, Sílvia Murata e Sidney 
Abe, amigos da graduação; e Janaína Santos, Aline Miyuki, Juliana Moraes e Juliana Otaviani, amigas do meu antigo trabalho. Saudades de tempos que não voltam mais, mas que mostram o quão especial essas amizades são!

Agradeço ao professor de Educação Artística Avelino Francisco Dias Ferreira, conhecido como Kiko, colega de trabalho de minha mãe. Além de ter se tornado um grande amigo nosso, em um fim de semana de intensos testes na reta final do meu mestrado o carregador de meu notebook queimou, e foi o empréstimo do carregador do notebook do Kiko, que possuía um igual ao meu, que eu pude dar contuinidade e finalizar meus experimentos (que ainda duraram semanas a fio). Obrigado, Kiko, muito sucesso e felicidade!

Agradeço aos colegas das repúblicas que morei, Rep Capelinha e Rep 29, pelos papos descontraídos e risadas diárias. Apesar de eu me considerar o paizão da turma, por ser o único de pós-graduação, sempre me sentia à vontade com todos.

Agradeço ao $\mathrm{CNPq}$ pelo apoio financeiro fornecido durante meu mestrado, permitindo que este estudo fosse concluído e todas as memórias boas e agradecimentos aqui listados tenham se concretizado. 


\section{RESUMO}

O planejamento de rotações de culturas é um tema de interesse em ascensão por permitir uma redução significativa no uso de adubos industriais, agrotóxicos e outros produtos químicos no cultivo, permitindo a auto-sustentação e qualidade das terras cultivadas. Este trabalho centraliza em utilizar rotações para atender uma demanda periódica prédeterminada, respeitando as restrições relativas a aspectos ecológicos que auxiliam na estabilidade geral do solo para definir uma rotação de culturas factível. Modelos matemáticos que consideram um tamanho mínimo de lote a ser usado por uma rotação e métodos heurísticos, baseados em geração de colunas, são apresentados. Uma análise detalhada do comportamento dos métodos perante variações em diferentes parâmetros e critérios é realizada. A primeira heurística, denominada Algoritmo GC-BC, obteve resultados de melhor qualidade e de forma mais rápida que a segunda heurística, denominada Heurística Lote Fixo. Entretanto, combinando ambas heurísticas foi possível obter os resultados mais satisfatórios, ou seja, soluções que respeitam a condição de lote mínimo em um tempo computacional aceitável para um planejamento anual, cujos valores são próximos a um limitante superior. A ideia subjacente de gerar colunas adicionais para um problema mestre restrito produz soluções de qualidade, o que pode vir a ser aplicado em outras áreas de pesquisa que necessitam da geração de colunas para uma resolução em tempo computacional viável.

Palavras-chave: rotação de culturas, otimização linear e discreta, geração de colunas, agricultura sustentável 



\begin{abstract}
The crop rotation planning is a rising topic for providing a significative reduction on the usage of industrial fertilizers, pesticides and other chemical, allowing the soil to selfsustain. This study focus on using rotations to meet a periodic and pre-defined demand while ecologic restrictions, that help sustain the soil's stability, define a valid crop rotation. Mathematical models that consider a minimum size of a used lot associated with a given rotation and heuristic resolution methods, based on column generation, are presented. A detailed analysis of the methods behaviour before changes on parameters and criteria is performed. The first heuristic, called GC-BC Algorithm, achieved better and faster results compared to the second heuristic, called Fixed Lot Heuristic. However, combining both heuristics produced even better results, that is, solutions that respect the minimum lot sizing restrictions in good execution time for an annual planning. The idea behind of generating additional columns to the restricted master problem produces good quality solutions, which may be applicable in other research areas that require column generation for their resolution with a reasonable execution time.
\end{abstract}

Keywords: crop rotation, linear and combinatorial optimization, column generation, sustainable agriculture 



\section{SUMÁRIO}

$\begin{array}{ll}\text { Introdução } & 01\end{array}$

Revisão bibliográfica $\quad 05$

Modelos matemáticos $\quad 09$

Modelo base de rotação 11

Modelo de otimização linear com atendimento de demanda 19

Modelo de otimização inteira para o problema de atendimento de demanda e 23

lote mínimo

Métodos heurísticos de resolução

Heurística GC-BC 27

Heurística Lote Fixo $\quad 30$

Testes computacionais

$\begin{array}{ll}\text { Testes heurística GC-BC } & 37\end{array}$

$\begin{array}{ll}\text { Testes preliminares } & 37\end{array}$

Testes ponderação- $\alpha$

Testes conjunto de restrições (3.6) 47

Testes curva de eficiência $\quad 50$

Testes critério de parada relaxado 53

Testes simetria $\quad 57$

Testes lote mínimo $\quad 60$

Testes heurística Lote Fixo 63

Testes fixa lote pequeno 63

Testes fixa lotes grandes $\quad 67$

$\begin{array}{ll}\text { Testes fixa dois lotes } & 70\end{array}$

Testes fixa maior demanda $\quad 72$

Comparativo final $\quad 76$

$\begin{array}{lr}\text { Conclusões e Perspectivas } & 81\end{array}$

Referências bibliográficas $\quad 85$

$\begin{array}{ll}\text { Apêndice } & 87\end{array}$ 



\section{INTRODUÇÃO}

Uma prática comum na agricultura e altamente notável no Brasil, devido à sua tradição histórica no cultivo de cana-de-açúcar, é a monocultura: com administração relativamente fácil no constante plantio de uma única cultura, os custos totais dos alimentos são reduzidos, embora seja alta a utilização de agrotóxicos e fertilizantes sintéticos, entre outros produtos e recursos industriais que são poluentes e não renováveis. Apesar de possuir um custo final menor, a monocultura acarreta em uma perda gradativa das propriedades físicas e químicas do solo devido ao uso intensivo dos produtos industriais, podendo até tornar-se improdutivo em caso de má administração. Parte da poluição pode ser levada às águas locais, ao solo e alimentos, trazendo danos à saúde humana e alterando as condições ambientais da região. Há um custo incalculável que vem sendo desprezado. Surge neste contexto a necessidade de novas abordagens para melhor sustentabilidade ambiental e financeira de pequenos e médios agricultores, os quais não possuem capital para manutenção e investimentos com produtos industriais e gerar produções mínimas para viabilidade econômica (Gliessman, 2000).

A consciência ambiental é, hoje em dia, mais difundida. Nota-se a preocupação com o desenvolvimento sustentável entre a população e nos meios industrial, político e governamental. Por exemplo, limites para a emissão de poluentes e demais cuidados como tratamento e purificação, mesmo que acarretem em um investimento maior, são implantados em indústrias, visando melhor cuidar do meio ambiente e de outras questões sociais. Já no setor da agricultura, o acesso de pequenos produtores ao mercado e cuidados ecológicos, como a redução do uso de pesticidas, ganham destaque no ponto de vista econômico e sustentável. Neste contexto, uma medida que pode atender estas expectativas no meio agrícola é a rotação de culturas.

A rotação de culturas traz diversidade vegetal na terra em que é aplicada: diversidade esta, que foi mostrada em estudos ecológicos e agronômicos, capaz de melhorar a exploração dos recursos produtivos do solo, além de auxiliar no controle de pragas e pestes com uso reduzido de inseticidas e outros produtos industriais, aumentando a estabilidade do solo defronte pressões ambientais e estendendo assim sua vida útil (Altieri et al., 1995; Vandenmeer, 1992). Para os produtores, uma maior variedade de produção ajuda a manter uma estabilidade econômica, reduzindo o impacto causado por oscilações nos preços e no mercado de oferta e demanda, caso 
estes venham a ocorrer. Vemos uma sustentabilidade não só agrícola e ecológica, mas também econômica com o uso de rotações de culturas.

Porém, pequenos e médios produtores possuem uma área de plantio reduzida disponível e sua produção tende a ser descontínua e heterogênea. Associações e cooperativas atuam unindo estes produtores agrícolas para que haja uma produção constante e uniforme: na região Sudeste do Brasil temos, por exemplo, associações como Horta e Arte (SP) e Sítio do Moinho (RJ) (Campanhola e Valarini, 2001). Desta forma, os gastos administrativos, desde planejamento de plantio e conexões de mercado até empacotamento, deixam de ser uma tarefa individual e custosa, sendo feita em conjunto e padronizada. A inclusão de pequenos agricultores no mercado é de fundamental importância econômica, pois estimulam a compra e venda no comércio local e aumentam o número de empregos (Ong’Wen e Wright, 2007).

Neste contexto, este trabalho propõe modelagens matemáticas e métodos de solução que representem as decisões a serem tomadas por estas cooperativas, ou seja, o quê, quando e quanto será produzido por cada membro da associação, de forma a cumprir uma demanda de mercado periódico prevista ao longo do tempo. Com um planejamento adequado, garante-se o atendimento da demanda exigida com o melhor aproveitamento da terra, produzindo alimentos com redução no uso de fertilizantes e afins, aumentando a qualidade da produção.

Um planejamento de rotação de culturas consiste em repetir uma sequência de plantio após seu término. O período de tempo deste planejamento pode ser variado e, inclusive, ser um fator característico dos cultivos a serem usados: plantações de laranja, por exemplo, ocupam a terra por anos. Hortaliças, por sua vez, variam de algumas semanas a alguns meses. Ao definir um rotação de culturas, as características das plantações devem ser consideradas para um planejamento efetivo.

O devido planejamento do cultivo do solo pode ajudar a manter a fertilidade do solo naturalmente, garantindo um uso contínuo viável econômica e ecologicamente. O uso de uma adubação verde pelo plantio de uma leguminosa melhora a fertilidade e protege o solo, assim como um período sem nenhum cultivo permite o controle biológico de pragas e doenças e contribiu na reciclagem dos nutrientes da terra. (Altieri et al., 1995; Gliessman, 2000). Por estas razões, fatores ecológicos e agronômicos são considerados na maioria dos modelos matemáticos relacionados à rotação de culturas.

Quanto aos aspectos ecológicos, alguns a se levar em consideração no cultivo de hortaliças são: o não cultivo de culturas de mesma família botânica em sequência em 
um mesmo local, uma cultura para adubação verde (geralmente leguminosa) em algum período da rotação para auxiliar na fixação de nitrogênio, assim como um período de pousio (sem cultivo), para o descanso da terra. Estes critérios serão usados como restrições para definir uma rotação de cultura factível para o problema abordado neste estudo.

Na seção seguinte, é feita uma revisão bibliográfica sobre rotações de culturas, apontando alguns trabalhos e mostrando o desenvolvimento nesta área desde os primeiros trabalhos apresentados no final da década de 30. Um enfoque maior é dado nos trabalhos e tese de doutorado de Santos (2007, 2008, 2009, 2010a, 2010b), os quais serviram de base para este estudo e que utilizam critérios ecológicos como os mencionados acima em seus modelos.

Na Seção 3, o modelo matemático que representa os critérios ecológicos e definem uma rotação factível é apresentado. Junto a este, o modelo matemático referente ao problema de atendimento de demanda é discutido e demonstramos como ambos são unificados e caracterizados como um problema mestre e um subproblema. $\mathrm{O}$ problema mestre, originalmente formado por variáveis de decisão lineares a respeito do tamanho de lote a ser usado para cada rotação, é expandido com a inclusão de restrições de lote mínimo para as variáveis de decisão, determinando o modelo final inteiro-misto a ser estudado neste trabalho. O uso de um lote mínimo é interessante em aplicações práticas, já que o manuseio e administração de espaços muito pequenos de terra podem se tornar difíceis e até mesmo custosos, não justificando o uso destes lotes pequenos conforme a solução ótima de um modelo linear.

A Seção 4 discute a dificuldade da resolução por métodos exatos do modelo proposto da Seção 3, e detalha duas heurísticas criadas visando contornar tal dificuldade: a primeira, denominada Algoritmo GC-BC, é uma alternativa ao branchand-price, método de resolução intuitivo a um problema de geração de colunas que contém variáveis discretas, cuja ideia é realizar a geração de colunas e a resolução via branch-and-cut separadamente; a segunda proposta, a Heurística Lote Fixo, resolve o problema linear e define, pelo uso de algum critério de seleção, uma variável a ser fixada em um valor que satisfaça a condição de lote mínimo.

A Seção 5 consiste dos testes computacionais realizados, com diferentes enfoques de resolução e análise de comportamento do modelo perante mudanças de parâmetros para o Algoritmo GC-BC, como ponderações entre o lucro e a criação de lotes, diferentes valores de lote mínimo, entre outros. Para a Heurística Lote Fixo, 
avalia-se quatro diferentes critérios de escolha de variáveis. Todos os métodos são avaliados quanto ao tempo computacional e qualidade de solução em relação à resolução linear do modelo relaxado.

Por fim, a Seção 6 consiste de um sumário das conclusões ao analisar os resultados obtidos pelos testes realizados e descritos na Seção 5, e discute novas possibilidades de estudos futuros e aplicação das técnicas propostas em outras linhas de pesquisa. 


\section{REVISÃO BIBLIOGRÁFICA}

O tema planejamento de plantio de culturas existe há tempos na literatura, desde o trabalho pioneiro de Kantorovich (1939, traduzido do russo em 1960), o qual mostrou este tema como sendo tratável com ferramentas matemáticas em um modelo de otimização linear, com objetivo de maximizar a produção. Uma abordagem mais profunda foi apresentada em Chicago no primeiro congresso em aplicações de otimização linear, em 1949, por Hildreth e Reiter (artigo publicado em 1951), que propuseram um modelo para particionar uma área de plantio utilizando-se de rotações pré-definidas nessas partições, argumentando que assim os custos com manutenção (irrigação, mão-de-obra, entre outros) e os riscos econômicos seriam reduzidos. Os autores também argumentam sobre as vantagens das rotações de culturas em relação ao aumento da produção e melhor uso dos recursos. Nesse modelo, as variáveis de decisão eram o tamanho das áreas com cada rotação.

Rotações pré-definidas foram totalmente descartadas por El-Nazer e McCarl (1986), em que um problema de rotação era solucionado com sequências de culturas cultivadas uma após a outra anualmente, em áreas homogêneas. Um novo enfoque, com múltiplos plantios anuais e áreas heterogêneas, foi considerado posteriormente por Dogliotti et al. (2003), que desenvolveram uma ferramenta computacional capaz de gerar as rotações factíveis de um dado grupo de culturas de uma região do Uruguai, além de considerar restrições de plantio sequencial de uma mesma cultura na rotação.

El-Nazer e McCarl (1986) também consideram que a ordem das culturas cultivadas é de grande importância, supondo que a produtividade de uma cultura está diretamente relacionada à cultura precedente ao seu plantio no mesmo local, podendo essa produtividade ser afetada pelo cultivo de até quatro anos anteriores. Já se inicia, aqui, a possibilidade de proibir certas sequências previamente à resolução do modelo, seja por motivos ecológicos, agronômicos ou qualquer outro. Restrições quanto ao plantio são abordadas por Haneveld e Stegeman (2005), com as sequências de culturas definidas fortemente segundo as restrições impostas sobre o plantio, que consideram não apenas o que foi plantado nos últimos anos, mas também a duração de cada plantação. Os autores trabalham também com restrições de pousio inclusos nas rotações a serem definidas, dependendo do sequenciamento das culturas. 
Detlefsen e Jensen (2007) tomam uma abordagem diferente, focando a formação da seqüência de plantio conforme a quantidade de nitrogênio presente no solo utilizado para o cultivo das culturas plantadas nos anos precedentes: no caso do modelo proposto foram consideradas culturas anuais, referindo-se então ao cultivo dos últimos três anos. Os autores assumem que o tamanho dos lotes de terra a serem utilizados para cada cultivo é fixo e determinado previamente, o que permite que o problema seja resolvido como um problema de transporte.

Pouco se tratou, até então, a respeito de épocas de cultivo favoráveis: as rotações não consideravam o período do ano em que seriam aplicadas. Clarke (1989) trouxe tal consideração à tona, incluindo épocas propícias para o cultivo. Seu modelo, entretanto, não tratava de possíveis influências que uma cultura podia trazer aos cultivos seguintes.

Alfandari et al. (2009) consideram um problema aplicado em Madagascar, visando reduzir o desmatamento da região. Para preparar as terras para o cultivo, utilizase uma técnica que envolve a queimada da vegetação local, mas devido ao seu uso exaustivo e planejamento de curto prazo, as terras se tornam improdutivas. Desta forma, outros lotes de terra passam pelo mesmo processo para dar continuidade ao cultivo. Os autores propuseram um modelo que representa um planejamento a longo prazo, atendendo uma demanda e minimizando a área a ser cultivada, reduzindo assim o desmatamento contínuo e mantendo a fertilidade da terra.

No primeiro trabalho de Santos et al. (2007), o modelo proposto visa maximizar o uso de terra para cultivos respeitando restrições ecológicas juntamente de restrições de adjacências: uma área de cultivo previamente dividida em lotes fixos, cujas divisões podem ser representadas por um grafo de adjacência. Assim como duas culturas de mesma família botânica não podem ser cultivadas em sequência em uma mesma área, elas são proibidas de cultivo em lotes adjacentes em um mesmo período de tempo.

Em Santos et al. (2008), o problema de rotações de culturas com restrição de adjacência é expandido e explorado por reformulações, utilizando decomposição de Dantzig-Wolfe e geração de colunas em sua resolução. Neste trabalho, os autores exploram características de algumas distribuições espaciais comuns, como divisão em tabuleiro ou lado a lado. A partir dessas características, o modelo principal pode ser simplificado e a solução ótima obtida em um tempo computacional menor.

Santos (2009), em sua tese de doutorado, organiza os trabalhos para o problema de rotações de culturas com enfoque em adjacência dos trabalhos anteriores, e propõe uma proposta de resolução por branch-and-price é desenvolvida. O modelo com 
atendimento de demanda também é desenvolvido, e considerações são feitas sobre a minimização de lotes usados para o atendimento da demanda, assim como penalizações de demandas não atendidas e desconsideração de lotes muito pequenos.

Santos et al. (2010b) focam unicamente no modelo com atendimento de demanda, organizando e detalhando os esforços aplicados no problema descritos na tese de doutorado da autora. Em Costa et al. (2010), os autores expandem o modelo de demanda com a adição de estoques de produção. Porém, devido às características perecíveis de hortaliças, os estoques não podem exceder um determinado período, assim como parte do estoque é perdido ao longo do tempo. Além do método de resolução por geração de colunas, uma programação estocástica de dois estágios com recurso é proposta.

Por fim, em Santos et al. (2010a), os trabalhos anteriores da autora são organizados e sintetizados em um único artigo. A consideração de estoques para o problema de demanda é incluída, mas a extensão com estoques perecíveis de Costa et al. (2010) não é mencionada nesta síntese. 


\section{MODELOS MATEMÁTICOS}

A rotação de culturas consiste em definir uma sequência de plantio para uma dada área que se repetirá indefinidamente ao longo do tempo, ou seja, uma sequência de decisões que se repetem após ser realizada. Este intervalo de tempo necessário para que toda a sequência seja plantada é chamado de tamanho da rotação. Um exemplo simples para visualizar o conceito de rotação, consideremos uma rotação com tamanho de 1 ano, na qual uma cultura $\mathrm{A}$ é cultivada durante os 4 primeiros meses em toda a área de cultivo, seguidos de 5 meses cultivando-se uma cultura B, e por fim 3 meses cultivandose uma cultura C: temos então o ciclo A-B-C e, após o cultivo de C, retoma-se o cultivo da cultura A. Esta rotação é ilustrada na Figura 3.1 abaixo:

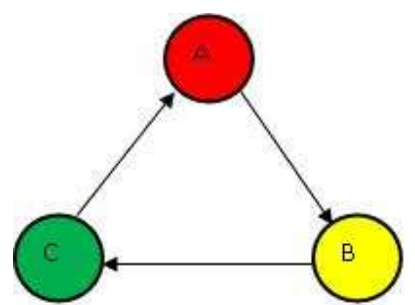

Figura 3.1: um exemplo de rotação das culturas A, B e C

O planejamento adequado do cultivo pode ajudar a manter a fertilidade do solo naturalmente, garantindo um uso contínuo viável econômica e ecologicamente, e também permite o controle biológico natural de pragas e doenças, minimizando o uso de agrotóxicos ou quaisquer outros produtos químicos, gerando uma maior estabilidade geral do solo e de suas características físicas, químicas e biológicas. Para isto, fatores ecológicos e agronômicos são considerados na maioria dos modelos matemáticos relacionados à rotação de culturas.

Dentre os aspectos ecológicos, três deles são considerados neste trabalho:

(a) culturas de mesma família botânica não são cultivadas em sequência em um mesmo local, evitando assim a proliferação de pragas e doenças: ressaltemos que organismos-pestes costumam atacar culturas de uma família botânica em comum;

(b) um cultivo de uma cultura para adubação verde (comumente realizado pelo plantio de leguminosas, sem colheita, visando estabilizar o nível de nitrogênio do solo) deve ser incluído no planejamento da rotação; 
(c) um tempo (de duração pré-determinada) chamado pousio, em que nada é cultivado e a terra tem sua vegetação espontânea crescendo durante este tempo, permitindo que o solo recupere sua estrutura (tanto física quanto biológica) e ajudando inclusive no controle biológico de alguns insetos e ácaros, também deve estar incluso no planejamento da rotação.

Os aspectos ecológicos listados acima são considerados no modelo proposto por Santos et al. (2007), que será o modelo base considerado neste trabalho. Diferentes considerações podem ser feitas ao determinar uma rotação: os critérios ecológicos (a)(c) listados acima aplicam-se bem à rotações de hortaliças, que são o objeto de estudo deste trabalho.

As sub-seções a seguir explicitam os modelos matemáticos usados neste estudo: primeiramente, define-se as restrições que caracterizam uma rotação, respeitando os critérios ecológicos (a)-(c) e outros aspectos técnicos, tais como período adequado de plantio e períodos de colheita. Na sequência, modela-se o problema abordado de atendimento de demanda e, por fim, ambos os modelos são reformulados em problema mestre e subproblema, para definir rotações para o cumprimento de demanda. 


\subsection{MODELO BASE DE ROTAÇÃO}

Para simplificar a modelagem, discretizamos o tamanho da rotação em unidades de tempo menores chamadas períodos, os quais definem os possíveis instantes para as tomadas de decisão, bem como os dados do problema. Por exemplo, uma rotação de um ano pode ser discretizada em 12 meses, de modo que as ações são do tipo: plante a cultura A no mês 3, a qual deve ser cultivada durante 5 meses. As demandas e colheitas são quantidades também descritas nesta discretização: por exemplo, a cultura A possui demanda de 50 unidades (que podem ser em $\mathrm{kg}$ ou outro unidade adequada de medida) no período 8.

Considere que o tamanho $T$ da rotação seja dividida em $M$ períodos. Por exemplo, $T=1$ ano pode ser dividido em $M=12$ meses. Uma programação de rotação de culturas de tamanho $M$ é um calendário de plantio das culturas da rotação. Para tomar esta decisão, os critérios ecológicos (a)-(c) apresentados na seção anterior são considerados. Por simplicidade, relembramos de forma resumida estes critérios:

(a) Uma cultura não pode ser cultivada após uma outra de mesma família botânica;

(b) O plantio de uma cultura para a adubação verde deve ser incluída na rotação;

(c) Um pousio deve ser incluído na rotação, por um tempo pré-estabelecido.

Adicionalmente, há restrições técnicas que se deve levar em conta: a época de plantio e ciclo de cada cultura é variante entre elas. Cada hortaliça possui suas épocas específicas de plantio, além de requerer um respectivo tempo para que as colheitas sejas feitas. Essas restrições, que serão incluídas no modelo, são descritas como:

i. Cada cultura possui um conjunto de períodos favoráveis para seu plantio, os quais devem ser respeitados;

ii. O tempo entre plantio e as colheitas (ciclo) é variante entre as culturas.

Estes critérios e restrições técnicas definirão as restrições matemáticas do modelo. É importante relembrar que, por enquanto, a rotação de um único lote está em questão. 
Um exemplo (Santos, 2009) para ilustrar este modelo: considere três culturas e rotações de duração de 1 ano, divididas em períodos de 1 mês (totalizando assim 12 períodos). A cultura $X$, pertencente à família botânica 1 , possui ciclo de 5 meses e deve ser plantada de janeiro a julho (referente aos períodos 1 a 7); a cultura Y, também da família botânica 1, possui um ciclo de 4 meses e pode ser plantada durante todo o ano; por fim a cultura $Z$, de família botânica 2 , é utilizada para adubação verde e, além de poder ser cultivada em qualquer período, possui um ciclo de 2 meses. O pousio exigido é de 1 mês (1 período). Uma programação factível para este exemplo pode ser visualizada pela Figura 3.2

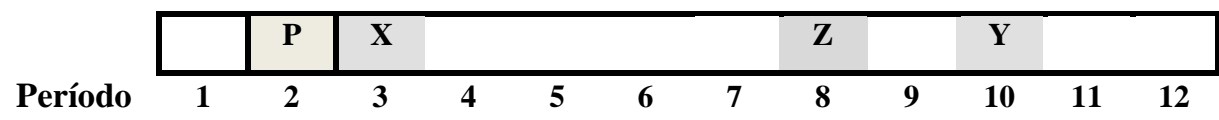

Figura 3.2. Uma programação de rotação de culturas (fonte: Santos L. M., 2009)

Vemos nesta figura que a cultura X é plantada no mês (período) 3, dentro de seu período favorável de plantio, e durando até o mês (período) 7. A cultura Z, de outra família botânica e utilizada para adubação verde, sucede o cultivo, ocupando os meses 8 e 9. A cultura Y começa seu cultivo no mês 10, e é concluído no mês 1 do ano seguinte, havendo então um período de pousio durante o mês 2 . Ao mês 3, a cultura X é plantada novamente e o ciclo se repete. Respeitamos aqui a necessidade de pousio, adubação verde e não temos culturas de mesma família botânica plantadas sucessivamente, como também não há sobreposição de cultivos, isto é, duas culturas não são plantadas simultaneamente neste mesmo lote.

Define-se, então, um modelo matemático para este problema, respeitando os critérios ecológicos e as restrições técnicas listadas acima. Os parâmetros e dados usados são:

\section{Parâmetros e dados:}

$M \quad$ número de períodos de uma rotação;

C conjunto de culturas que podem ser selecionadas para o plantio, excluindo as culturas para adubação verde;

$G \quad$ conjunto de culturas para adubação verde;

$N \quad$ cardinalidade de $C \cup G$, ou seja, o número total de culturas;

$N+1$ cultura fictícia que representa o pousio obrigatório de ciclo pré-definido; 
NF número de famílias botânicas;

$F(p) \quad$ conjunto de culturas da família botânica $p, p=1 . . N F$;

$t_{i} \quad$ ciclo de cultivo da cultura $i$, incluindo os períodos estimados para preparo do solo e colheita: ou seja, o tempo em períodos do plantio até a colheita;

$I_{i} \quad$ conjunto de períodos em que a cultura $i$ pode ser plantada. Para o pousio, adotamos $I_{N+1}=\{1, \ldots, M\}$.

É possível definir um período restrito para o pousio, porém usualmente isso não se mostra necessário. Alternativamente pode-se obrigar o pousio após o cultivo de uma certa cultura, o qual poderia ser implementado como um período a mais para a cultura em questão ou com o uso de restrições adicionais. Nota-se que o modelo pode ser facilmente expandido conforme necessário.

As variáveis de decisão são:

Variáveis:

$x_{i j}= \begin{cases}1, & \text { se aculturaié plantada no período } j \\ 0, & \text { casocontrário }\end{cases}$

$$
\text { para } i=1 . . N+1 \text { e } j \in I_{i}
$$

Utilizando-se destes parâmetros, dados e variáveis de decisão, uma formulação matemática que caracteriza uma rotação factível é dada por:

$$
\begin{aligned}
& \sum_{i=1}^{N+1} \sum_{r=0}^{t_{i}-1} x_{i, j-r} \leq 1, \quad j=1 . . M \\
& \sum_{i \in F_{p}} \sum_{r=0}^{t_{i}} x_{i, j-r} \leq 1, \quad p=1 . . N F, j=1 . . M \\
& \sum_{i \in G} \sum_{j \in I_{i}} x_{i j}=1 \\
& \sum_{j=1}^{M} x_{N+1, j}=1 \\
& x_{i j} \in\{0,1\}, \quad i=1 . . N+1, j \in I_{i}
\end{aligned}
$$

Obs.: nas equações (3.1)-(3.2), $j-r \leq 0$ é substituído por $j-r+M$. 
As restrições em (3.1) nos garantem que apenas uma cultura pode ocupar a terra em um dado período (incluindo o pousio, que é tratado como uma cultura pelo modelo). As restrições (3.2) proíbem o cultivo de culturas de mesma família botânica em seqüência, garantindo então que diferentes famílias sejam plantadas após a colheita de uma dada cultura. As restrições (3.3) e (3.4), por sua vez, nos garantem a ocorrência de um cultivo de uma cultura destinada à adubação verde e um pousio, respectivamente. Por fim, (3.5) definem as variáveis de decisão como binárias. Para as restrições (3.1) e (3.2), apenas as variáveis $x_{i, j-r}$ tal que $j-r \in I_{i}$ são consideradas.

As restrições (3.1) e (3.2) podem ser de difícil visualização. Para melhor compreendê-las, utilizemos como referência primeiramente a figura abaixo, para ilustrar a restrição (3.1):

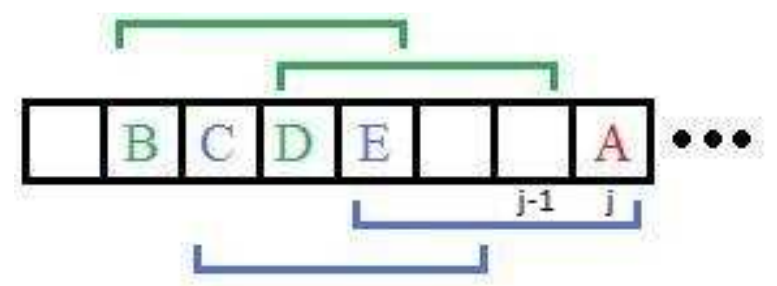

Figura 3.3. Exemplificação do funcionamento das restrições (3.1)

Por simplicidade, todas as culturas do exemplo acima, $A, B, C, D$ e $E$, possuem um ciclo de quatro períodos para sua colheita a partir de sua plantação. Seja $A$ a cultura que desejamos plantar em um período $j$, e queremos verificar quais (e quando) hortaliças podem ser plantadas. Cada cultura terá seu período de plantio verificado conforme sua alocação na figura acima. Com isso, não seria possível plantar a cultura $E$ no período $j$-3, uma vez que sua colheita ocorreria no período $j$, conflitando com o plantio de $A$. A cultura $D$, a ser plantada no período $j-4$, seria colhida no período $j-1$, podendo assim o período $j$ ser utilizado pela cultura $A$. $B$ e $C$ seriam colhidas antes do plantio de $A$, nos períodos $j-3$ e $j-2$ respectivamente. Neste caso, uma entre as culturas $B, C$ e $D$ poderiam ser cultivadas sem conflito com o plantio de $A$ em $j$, enquanto $E$ não seria viável de cultivo.

Portanto, para o cultivo de uma cultura $i$ qualquer em um dado período $j$, é necessário que os $t_{k}-1$ períodos anteriores ao período $j$ não tenham sido ocupados por outra cultura $k$. Evitamos, assim, a sobreposição dos plantios. 
De forma análoga para a restrição (3.2), temos o mesmo conceito. Referenciando a figura abaixo para exemplificar:

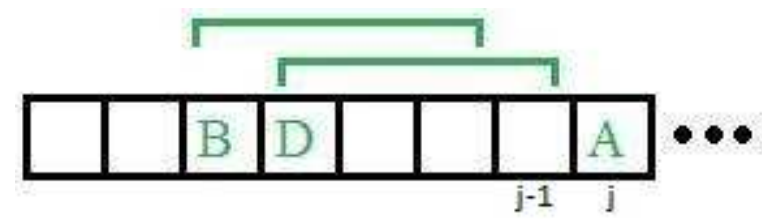

Figura 3.4. Exemplificação do funcionamento das restrições (3.2)

Assumamos que $A, B$ e $D$ pertençam à mesma família botânica, todas com ciclo de 4 períodos. Mesmo que $D$ seja plantada em $j-4$ e, portanto, sua colheita ocorre em $j$ 1 , evitando a sobreposição, $A$ será cultivada no período seguinte $j$, o que não é permitido. Para que não haja cultivos em sequência de culturas de mesma família, o plantio deveria ser feito em um período $j-5$ (ou anterior), como mostrado pela cultura $B$ da figura 3.4, resultando em uma colheita no período $j$-2 (ou anterior).

Portanto, para o cultivo de uma cultura $i$ qualquer em um dado período $j$, é necessário que os $t_{k}$ períodos anteriores a $j$ não tenham sido ocupados por uma dada cultura $k$ de mesma família botânica. Evitamos assim o cultivo sequencial de hortaliças de mesma família.

Vale ressaltar que o número de pousios e de culturas para a adubação verde exigidos na rotação podem assumir valores diferentes de 1 , caso necessário. Neste caso, as restrições (3.3) e (3.4) sofreriam algumas alterações, além da necessidade da inclusão de um par de restrição que garanta um intervalo mínimo entre as ocorrências. Santos (2009) discute estas alterações. Neste trabalho, entretanto, o número de pousio e adubação verde a serem incluídos na rotação não será modificado.

O modelo (3.1)-(3.5), proposto inicialmente por Santos et al. (2007), não impede que em um dado período, nenhuma cultura seja cultivada: isso implica, na prática, em uma ocorrência de pousio, além do que é exigido pela formulação. Porém, isso não implica em infactibilidade.

Note que as restrições (3.2) podem, sem perda de generalidade, ser reescritas como:

$$
\sum_{i \in F(p)} x_{i, j}+x_{i, j-t_{i}} \leq 1, p=1 . . N F, j=1 . . M
$$


Assim como (3.2), as restrições (3.6) evitam o plantio consecutivo de culturas de mesma família botânica, já que a sobreposição já é evitada por (3.1). Para visualizar isto, utilizemos novamente um exemplo simples ilustrado na figura abaixo:

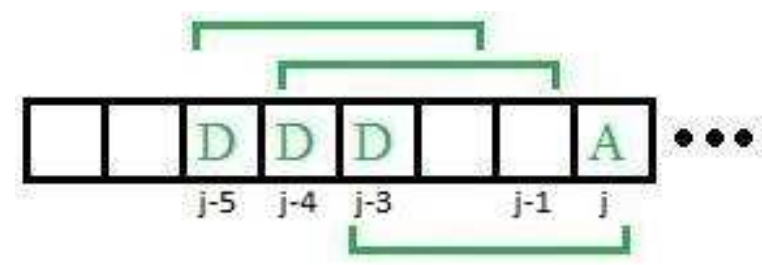

Figura 3.5. Exemplificação do funcionamento das restrições (3.6)

Seja $A$ e $D$ culturas de mesma família, e $D$ com ciclo de 4 períodos. Para $A$ plantada no período $j, D$ irá sobrepô-la se seu cultivo ocorresse em j-3. Esta sobreposição já é evitada pela restrição (3.1). O cultivo em $j$-4 acarretará no cultivo de $A$ ocorrendo logo após a colheita de $D$, o que deve ser evitado. O cultivo em $j-5$, por sua vez, não viola os critérios ecológicos definidos. Com a sobreposição já impedida por (3.1), a restrição (3.2) pode ser simplificada: para o plantio de uma cultura $i$ qualquer em um dado período $j$, é necessário que no período $j-t_{i}$ não tenha sido ocupado pelo plantio de uma cultura qualquer de mesma família botânica.

Com o uso da restrição (3.6), a matriz de coeficientes do problema torna-se mais esparsa, podendo ser mais bem explorada por pacotes de otimização e a resolução do modelo torna-se mais eficiente. Testes computacionais foram realizados para comparar o desempenho obtido utilizando-se cada conjunto de restrição, e estão descritos na seção 5.1.3.

O modelo final adotado neste trabalho que define uma rotação de culturas factível para um lote, respeitando os critérios ecológicos (a)-(c), é portanto:

$$
\begin{aligned}
& \sum_{i=1}^{N+1} \sum_{r=0}^{t_{i}-1} x_{i, j-r} \leq 1, \quad j=1 . . M \\
& \sum_{i \in F(p)} x_{i, j}+x_{i, j-t_{i}} \leq 1, \quad p=1 . . N F, j=1 . . M \\
& \sum_{i \in G} \sum_{j \in I_{i}} x_{i j}=1
\end{aligned}
$$




$$
\begin{aligned}
& \sum_{j=1}^{M} x_{N+1, j}=1 \\
& x_{i j} \in\{0,1\}, \quad i=1 . . N+1, j \in I_{i}
\end{aligned}
$$

Obs.: nas equações (3.7)-(3.8), $j-r \leq 0$ é substituído por $j-r+M$.

A formulação matemática (3.7)-(3.11) é de fundamental importância para o desenvolvimento deste projeto, pois determina as programações de rotações de culturas de um lote a serem utilizadas em um problema de otimização detalhado na seção seguinte. 


\subsection{MODELO DE OTIMIZAÇÃO LINEAR DE ATENDIMENTO DE DEMANDA}

Devido à realidade dos pequenos agricultores, com áreas de plantio disponíveis reduzidas e culturas passíveis de plantio dependentes do solo e clima local, sua produção não é constante e, com isso, não há condições para um comércio ativo de forma independente, que além de exigir um abastecimento contínuo também exige investimentos de limpeza, empacotamento e entrega: ou seja, há custos de produção e logística que um produtor pequeno não consegue suportar. Cresce então o surgimento de cooperativas ou associações, em que pequenos agricultores de uma região (podendo ser ampla) trabalham em conjunto para atender a uma certa demanda, visto que suas diferentes propriedades comumente permitem o cultivo de diferentes culturas devido à variação climática e terrena, podendo assim cumprir a produção necessária conjuntamente, compartilhando os custos de produção e logística. É necessário então decidir quando e quanto será produzido de cada cultura por cada membro da cooperativa.

O modelo para a programação de rotação de culturas com demanda (PRC-D) visa atender uma demanda conhecida ao longo do tempo, considerando áreas de produção heterogêneas (isto é, permitem o cultivo de diferentes hortaliças com diferentes produtividades, conforme as características do solo e do clima de cada região de plantio), mas ainda respeitando os aspectos ecológicos e restrições técnicas discutidos anteriormente, modelado pelas restrições (3.7)-(3.11).

Consideramos um conjunto de áreas $A_{1}, \ldots, A_{L}$ disponíveis para o cultivo de diferentes culturas pertencentes a um conjunto $C$ (além de um conjunto $G$ para as culturas destinadas à adubação verde), culturas estas com suas demandas conhecidas ao longo do tempo (não há demanda para as culturas pertencentes a $G$ ). Como explicado anteriormente, as áreas apresentam diferentes características e com isso as culturas podem ser passíveis ou não de plantio em cada uma delas, assim como apresentar diferente produtividade. Deseja-se definir então um plano de plantio de culturas para cada uma das $L$ áreas de forma a atender a demanda, podendo cada área ser dividida em diferentes lotes, cada um seguindo uma programação de rotação independente.

Definimos então os parâmetros e dados usados pelo modelo: 
L número de áreas de cultivo (hortas ou fazendas, independentes entre si);

$C_{k} \quad$ conjunto de culturas que podem ser plantadas na área $k, k=1 . . L$;

$S_{k}$ conjunto das possíveis programações de produção para a área $k$, isto é, todas as soluções do sistema (3.7) - (3.11);

$I_{i} \quad$ conjunto de possíveis períodos de colheita para a cultura $i$;

$d_{i j} \quad$ demanda da cultura $i$ no período $j$ (dependendo da cultura, este dado pode ser unidade, peso ou volume).

Por simplicidade de notação, escrevemos $s \in S_{k}$ para nos referirmos à $s$-ésima programação para a área $k$. Para cada área $k$, as restrições (3.7)-(3.11) devem ser satisfeitas com os dados correspondentes.

As variáveis de decisão são:

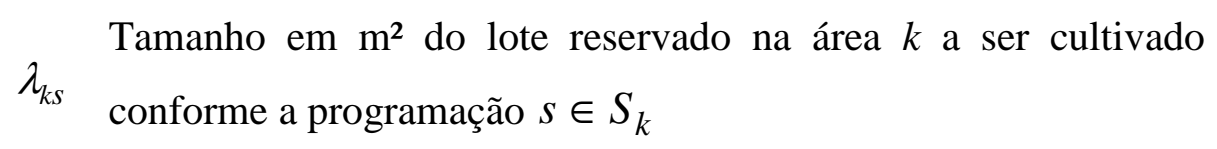

Para cada programação $s \in S_{k}$, seja $a_{i j k}^{s}$ a quantidade colhida por unidade de área da cultura $i \in C_{k}$ no período $j \in I_{i}$, na área de cultivo $k$.

Com estes dados é possível escrever então o modelo do PRC-D como:

$$
\begin{gathered}
z_{P R C-D}=\max \sum_{k=1}^{L} \sum_{s \in S_{k}} c_{k s} \lambda_{k s} \\
\text { s.a. } \quad \sum_{k=1}^{L} \sum_{s \in S_{k}} a_{i j k}^{S} \lambda_{k s} \geq d_{i j}, \quad j \in I_{i}, i \in C_{k} \\
\sum_{s \in S_{k}} \lambda_{k s} \leq A_{K}, \quad k=1 . . L \\
\lambda_{k s} \geq 0, \quad s \in S_{k}, \quad k=1 . . L
\end{gathered}
$$

Sendo o parâmetro $c_{k s}$ o retorno obtido por unidade de área $k$ utilizando-se da programação $s$. Notamos aqui que as restrições de adjacência de cultivo de culturas de mesma família botânica aplicam-se apenas de forma temporal dentro de cada programação de rotação: não há restrições de adjacência física entre os lotes. Restrições 
de adjacência são abordadas nos diversos trabalhos de Santos, conforme descrito na revisão bibliográfica.

A função objetivo (3.12) do modelo busca maximizar o retorno obtido pelas áreas utilizadas de cada programação de produção. As restrições (3.13) nos garantem que, ao somar as produções realizadas por cada programação de todas as áreas, a demanda de cada cultura em cada período é atendida. As restrições (3.14), por sua vez, nos asseguram que não será utilizada uma área total maior que a disponível em cada uma das $k=1, \ldots, L$ áreas, enquanto (3.15) garantem a não-negatividade das variáveis de decisão.

Santos (2009) considera também a ocorrência de colheitas parciais, por ser um aspecto prático de relevância. Para isso, o modelo (3.12)-(3.15) é reformulado, adicionando então os seguintes dados:

$o_{i} \quad$ número de períodos entre o plantio e a primeira colheita da cultura $i \in C$;

$p_{i k r}$ quantidade obtida na $r$-ésima colheita da cultura $i \in C_{k}$ por unidade de área $k$, para $r=1, \ldots, t_{i}-o_{i}-1$

A partir da primeira colheita parcial, todo período subsequente passa a ter uma colheita parcial disponível (indicada por $p_{i k r}$ ), até o último período do ciclo da cultura em questão.

Assim, os dados no modelo (3.12)-(3.15) são alterados. Podemos reescrever o retorno $c_{k s}$ em função do planejamento de rotação correspondente. Seja $\hat{x}_{i j k}^{S}$ a $s$-ésima rotação da área $k$ que satisfaz as restrições (3.7)-(3.11), que equivale a 1 se a cultura $i$ é cultivada no período $j$, e 0 caso contrário. Temos que o retorno obtido por unidade de área de uma dada cultura $i$, no período $j$, desta programação é dado por $\sum_{j \in I_{i}} \sum_{r=1}^{t_{i}-o_{i}-1} p_{i k r} \hat{x}_{i j k}^{S}$.

Assim, se $r_{i}$ é o retorno unitário da cultura $i$, o retorno total por unidade de área $c_{k s}$ da rotação $s$ para a área $k$ é dado por:

$$
c_{k s}=\sum_{i \in C_{k}} r_{i} \sum_{j \in I_{i}} \sum_{r=1}^{t_{i}-o_{i}-1} p_{i k r} \hat{x}_{i j k}^{s}
$$


Com o uso dos dados de produção, podemos também reescrever $a_{i j k}^{s}$, e definir a quantidade obtida pela $r$-ésima colheita por unidade de área da cultura $i \in C_{k}$ no período $j \in I_{i}$, referente à área de cultivo $k$, como:

$$
a_{i j k}^{S}=p_{i k r} \hat{x}_{i, j-o_{i}-r, k}^{S}
$$

Ou seja, a quantidade colhida por unidade de área no período $j$ é definida pela produção da $r$-ésima colheita, cujo plantio ocorreu no período $j$ - $o_{i}-r$.

Desta forma, o modelo (3.12)-(3.15) utilizando-se das reformulações (iii)-(iv) é reescrito como:

$$
\begin{array}{ll} 
& z_{P R C-D}=\max \sum_{k=1}^{L} \sum_{s \in S_{k}} \sum_{i \in C_{k}} r_{i} \sum_{j \in I_{i}} \sum_{r=1}^{t_{i}-o_{i}-1} p_{i k r} \hat{x}_{i j k}^{s} \lambda_{k s} \\
\text { s.a. } & \sum_{k=1}^{L} \sum_{s \in S_{k}} \sum_{r=1}^{t_{i}-o_{i}-1} p_{i k r} \hat{x}_{i, j-o_{i}-r, k}^{S} \lambda_{k s} \geq d_{i j}, \quad j \in I_{i}, i \in C_{k} \\
& \sum_{s \in S_{k}} \lambda_{k s} \leq A_{K}, \quad k=1 . . L \\
& \lambda_{k s} \geq 0, \quad s \in S_{k}, \quad k=1 . . L
\end{array}
$$

A função objetivo (3.16) utiliza a reformulação (iii) para definir o retorno total obtido em uma única unidade (tipicamente monetária), e a restrição (3.17) é reformulada conforme (iv) para definir que toda a produção atenda a demanda definida, utilizando-se das colheitas parciais. 


\subsection{MODELO DE OTIMIZAÇÃO INTEIRA PARA O PROBLEMA DE ATENDIMENTO DE DEMANDA E LOTE MÍNIMO}

O modelo (3.12)-(3.15) e sua re-escrita (3.16)-(3.19) apenas definem que as variáveis $\lambda_{\mathrm{ks}}$ sejam não negativas: uma solução ótima pode incluir valores de $\lambda$ considerados muito pequenos, além de possivelmente possuírem grande diversidade de rotações, ou seja, diferentes lotes. Isto é impraticável em uma situação real, visto que há uma manutenção não contabilizada pelo modelo quanto à divisão dos lotes, e portanto deve ser evitado. Faz-se necessário, então, o tratamento do número e tamanho dos lotes, para evitar que um resultado indesejado ocorra. Santos (2009) propõe um modelo simples para reduzir o número de lotes e algumas heurísticas simples para lidar com esta dificuldade.

Neste trabalho, para lidar com a ocorrência de lotes muito pequenos exigimos um tamanho de lote mínimo. Para isto, faz-se necessário incluir variáveis binárias $y_{k s}$, referentes a cada variável $\lambda_{k s}$. Seja:

$$
y_{k s}= \begin{cases}1, & \text { se a programação sé utilizada na área } k \\ 0, & \text { caso contrário }\end{cases}
$$

Seja $\lambda^{\text {min }}$ o valor que define o tamanho mínimo de um lote. As restrições adicionais são então definidas:

$$
\begin{gathered}
\lambda_{k s} \geq \lambda^{\min } y_{k s} \\
\lambda_{k s} \leq A_{k} y_{k s}
\end{gathered}
$$

O modelo (3.16)-(3.19), acrescido das restrições de lote-mínimo é, portanto:

$$
\begin{array}{r}
z_{P R C-D}=\max \sum_{k=1}^{L} \sum_{s \in S_{k}} \sum_{i \in C_{k}} r_{i} \sum_{j \in I_{i}} \sum_{r=1}^{t_{i}-o_{i}-1} p_{i k r} \hat{x}_{i j k}^{S} \lambda_{k s} \\
\text { s.a. } \sum_{k=1}^{L} \sum_{s \in S_{k}} \sum_{r=1}^{t_{i}-o_{i}-1} p_{i k r} \hat{x}_{i, j-o_{i}-r, k}^{S} \lambda_{k s} \geq d_{i j}, \quad j \in I_{i}, i \in C_{k}
\end{array}
$$




$$
\begin{array}{lr}
\sum_{s \in S_{k}} \lambda_{k s} \leq A_{K}, \quad k=1 . . L & \\
\lambda_{k s} \geq \lambda^{m i n} y_{k s}, & s \in S_{k}, \quad k=1 . . L \\
\lambda_{k s} \leq A_{k} y_{k s}, & s \in S_{k}, \quad k=1 . . L \\
y_{k s} \in\{0,1\}, \quad \lambda_{k s} \geq 0, & s \in S_{k}, \quad k=1 . . L
\end{array}
$$

Além de garantir o tamanho mínimo desejado para um lote, as variáveis binárias permitem trabalhar de forma mais eficaz com o total de lotes usados, como minimizar este total. Porém, o modelo final torna-se bem mais complexo ao incluirmos tais restrições e variáveis para lidar com a ocorrência de lotes muito pequenos, pois as variáveis binárias tornam o problema em inteiro-misto. Métodos híbridos e heurísticas para resolver este problema adaptado são o foco principal deste projeto.

Conforme descrito na seção anterior, o modelo matemático (3.20)-(3.25) será o modelo-chave deste estudo. Devido ao enorme número de rotações factíveis para uma dada área (ou seja, a cardinalidade de $S_{k}$ é muito grande), e apenas uma parte delas deve compor uma solução ótima, um método de geração de colunas mostra-se atrativo. É preciso, entretanto, definir uma ligação entre o modelo (3.20)-(3.25) e as restrições (3.7)-(3.11), que definem uma rotação factível.

Considerando o modelo linear de atendimento demanda PRC-D representado por (3.16)-(3.19) (isto é, sem restrições referentes ao tamanho do lote) como o problema mestre, denotamos as variáveis duais $(\pi, \alpha)$ relativas às restrições (3.17) e (3.18), respectivamente. Para o subproblema, o custo relativo é definido como uma função objetivo a se maximizar, sujeita às restrições (3.7)-(3.11), que caracterizam uma rotação factível.

O custo relativo de uma variável é dado pelo seu custo na função objetivo decrementado do produto de seus coeficientes pelas variáveis duais de cada restrição. Pelo modelo (3.16)-(3.19), temos que o custo de uma variável $\lambda_{k s}$ na função objetivo (3.16) é dado por $\sum_{i \in C_{k}} r_{i} \sum_{j \in I_{i}} \sum_{r=1}^{t_{i}-o_{i}-1} p_{i k r} \widehat{x}_{i j k}^{S}$. Pelas restrições (3.17) temos os coeficientes $p_{i k r} \hat{x}_{i, j-o_{i}-r, k}^{S}$. Para as restrições (3.18), o coeficiente é 1. Sendo $x_{i j k}$ as variáveis de decisão do subproblema referente à área $k$, definido pelas restrições (3.7)(3.11), temos que a função objetivo do subproblema, que é encontrar o maior custo relativo para a área $k$, é escrita como: 


$$
\hat{c}_{k}=\max \sum_{i \in C_{k}} \sum_{j \in I_{i}} \sum_{r=1}^{t_{i}-o_{i}-1}\left(r_{i}-\pi_{i, j-r}\right) p_{i r k} x_{i j k}-\alpha_{k}
$$

A função objetivo (3.26), sujeita às restrições (3.7)-(3.11), retorna o maior lucro relativo para as variáveis duais fornecidas, e a solução $\hat{x}_{i j k}$ determina a respectiva rotação. Com os dados da rotação, podemos calcular os coeficientes da nova variável $\lambda_{k s}$ (ou seja, uma coluna do problema mestre), conforme estabelecido por (i) e (ii) na seção anterior.

Os métodos de resolução propostos consideram o modelo (3.16)-(3.19) na resolução inicial, e o subproblema é definido com a maximização de (3.26) restrito às restrições de rotação (3.7)-(3.11), que gerará colunas ao problema mestre. O modelo (3.20)-(3.25) é utilizado posteriormente. A seção seguinte detalha, além dos métodos de resolução propostos, estas e outras considerações. 


\section{MÉTODOS HEURÍSTICOS DE RESOLUÇÃO}

Esta seção descreve as duas heurísticas de resolução propostas para o problema de atendimento de demanda com restrição de lote mínimo. Estes métodos foram desenvolvidos como alternativas ao branch-and-price. Embora o método branch-andprice pareça ser atrativo para resolver este problema de forma ótima, ele traz consigo dificuldades intrínsecas: a primeira dificuldade diz respeito à resolução da relaxação linear do problema mestre, uma vez que as restrições (3.23)-(3.24) não estão disponíveis de antemão e, portanto, a construção dos custos relativos (que dependem das variáveis duais associadas a estas restrições) não podem ser calculados explicitamente. Uma outra dificuldade é associada à ramificação: como repassar a informação ao subproblema? Uma estratégia típica seria obter uma formulação compacta, em que o modelo (3.20)(3.25) seria uma reformulação. Esta tarefa não é trivial e não traz necessariamente garantia de êxito na aplicação do método branch-and-price. Para contornar estas dificuldades, métodos heurísticos são apresentados.

De forma geral, ambos os métodos propostos partem da resolução linear do modelo sem a utilização das restrições de lotes mínimos, portanto uma relaxação do problema. A partir desta solução, diferentes estratégias para construção de soluções factíveis, respeitando as restrições de lote mínimo, são propostas.

\subsection{HEURÍSTICA GC-BC}

A primeira heurística proposta é denominada GC-BC: Geração de Colunas Branch and Cut.

Utilizamos a solução do modelo linear (3.16)-(3.19), o qual é resolvido por geração de colunas, para adicionar as variáveis binárias e restrições para cada coluna gerada, obtendo o modelo (3.20)-(3.25) restrito (ou seja, com apenas um conjunto de todas as colunas), que é resolvido de forma exata por um branch-and-cut. A heurística GC-BC possui, portanto, duas fases bem definidas: a geração de colunas usando o modelo (3.16)-(3.19), e a resolução do modelo (3.20)-(3.25) restrito às colunas geradas na primeira fase.

Para a geração de colunas do modelo (3.16)-(3.19), entretanto, é necessário que um conjunto inicial de variáveis esteja definido. Uma opção é definir um conjunto 
inicial de rotações factíveis para o problema. Porém, por simplicidade e praticidade, optou-se pelo uso de variáveis artificiais para as restrições (3.17), as quais funcionam como indicadores de demanda não atendida, possuindo um custo elevado e negativo na função objetivo: desta forma, na otimalidade seus valores tendem a zero, caracterizando o atendimento da demanda. Se valores não-nulos para as variáveis artificiais ocorrem na solução ótima, então a demanda original não é possível ser atendida com os dados disponíveis. Esta situação, embora indesejável, pode ser real e aceitável na prática, isto é, um plano de plantios e colheitas que não atende toda a demanda.

O algoritmo que define a heurística é descrito como:

\section{Algoritmo: Heurística GC-BC para o problema PRC-D}

\section{Fase I}

1. Inicie o problema mestre restrito (3.16)-(3.19) (PMR) com variáveis artificiais associadas às restrições (3.17), com custo elevado e negativo.

2. Solucione o PMR e obtenha as variáveis duais $(\pi, \alpha)$ referentes às restrições (3.17) e (3.18), respectivamente.

3. Para cada área $k=1 . . L$, resolva um subproblema $P_{k}$ restrito por (3.7)-(3.11) de modo a maximizar (3.26), e obtenha os lucros relativos $\hat{c}_{k}$ e as colunas $a_{k s}$ correspondente, se $\hat{c}_{k}>0$.

4. Se $\hat{c}_{k} \leq 0$, para todo $k=1 . . L$, finalize a Fase I e vá para o passo 5 (Fase II). Caso contrário, insira no PMR as colunas $a_{k s}$ para os respectivos custos relativos $\hat{c}_{k}>0$, e retorne ao passo 2 .

\section{Fase II}

5. Para cada coluna adicionada na Fase I, inclua no PMR o par de restrições (3.23)-(3.24) correspondente, As variáveis artificiais são mantidas para garantir a factibilidade do novo modelo.

6. Resolva o PMR (3.20)-(3.25) obtido no Passo 5 via branch-and-cut.

As variáveis artificiais são mantidas mesmo durante a Fase II, permitindo que o não-atendimento da demanda ocorra, já que as novas restrições de tamanhos mínimos aos lotes podem acarretar infactibilidade do problema. Porém, devido ao alto custo 
associado às variáveis, a demanda deixará de ser atendida apenas na impossibilidade de cumpri-la com a área máxima permitida com as colunas geradas na Fase I.

A partir do algoritmo e modelo apresentados, diferentes parâmetros foram alterados e analisados: apresentamos a seguir um sumário deles, e descrevemos na seção 5.1 os resultados dos testes realizados a partir deste modelo.

Uma variação da função objetivo permite que a Fase II busque o atendimento da demanda visando reduzir o número de lotes necessários:

$$
\max \sum_{k=1}^{L} \sum_{s \in S_{k}} \sum_{i \in C_{k}} r_{i} \sum_{j \in I_{i}} \sum_{r=1}^{t_{i}-o_{i}-1} p_{i k r} \hat{x}_{i j k}^{s} \lambda_{k s}-z \sum_{k=1}^{L} \sum_{s \in S_{k}} y_{k s}
$$

Incluímos as variáveis binárias $y_{k s}$ na função objetivo com um custo representado pelo coeficiente $z$, que refere-se à penalidade ou custo financeiro associado à utilização/criação de um lote. Poder-se-ia utilizar penalidades diferentes para cada área de cultivo ou mesmo diferentes rotações, porém optou-se por manter o custo constante entre elas, sem perda de generalidade. A somatória é incluída com o sinal negativo, denominando a perda referente. A rigor, temos dois objetivos que compõem (4.1): maximizar o retorno $(f(\lambda))$, na primeira parte, e minimizar o número de lotes que a área é dividida $(g(y))$, segunda parte. Podemos escrever como:

$$
\begin{array}{ll}
\max & f(\lambda) \\
\min & g(y)
\end{array}
$$

Se considerarmos apenas $f(\lambda)$ temos o problema (3.20)-(3.25) descrito pelo algoritmo acima. Ao considerarmos apenas $g(y)$, temos o problema de atendimento de demanda com minimização de lotes. Um balanço entre as duas funções pode ser feito e remete a um dos conjuntos de testes computacionais realizados e descritos na seção 5.1.2 (Gomes e Arenales, 2010). Uma curva de eficiência (curva de Paretto) pode ser gerada, de modo que não se tem uma solução ótima mas um conjunto de soluções eficientes para auxiliar o tomador de decisões, que saberá o quanto deve abrir mão do retorno para diminuir o número de lotes.

Os testes são apresentados na seção subseqüente 5.1.3 foram realizados para comprovar a melhoria obtida pela reescrita do segundo conjunto de restrições definida em (3.6), como mencionado na seção 3.1. 


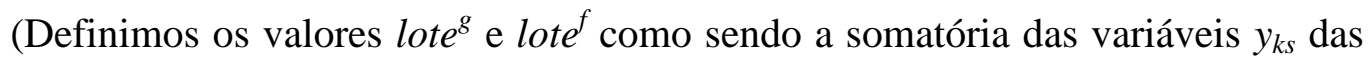
soluções obtidas ao se minimizar $g(y)$ e ao se maximizar $f(\lambda)$, respectivamente. Ou seja, estes valores representam o total de lotes utilizados em cada objetivo. Pode-se definir então uma curva de Paretto ao fixar o número de lotes usados em diferentes valores do intervalo $\left[\right.$ lote $^{g}$, lote $\left.^{f}\right]$ ao se maximizar $f(\lambda)$. Diferente dos testes descritos na seção 5.1.2, que considera um balanço entre o lucro e penalidades associadas ao uso de cada lote, a seção 5.1.4 descreve a geração de uma curva de Paretto com os valores de $f(\lambda)$ obtidos ao variar o valor máximo de lotes usados dentro do intervalo descrito acima.

Visando alternativas para melhorar o desempenho computacional do algoritmo, por tratar-se de geração de colunas, foi avaliado o uso de um valor $c^{\min }>0$, para a verificação da condição de parada da Fase I do algoritmo. O propósito de um valor maior que 0 seria evitar que o algoritmo ficasse, por muitas iterações, gerando colunas com custos relativos muito baixos, aumentando o tempo computacional necessário para uma melhora não significativa no retorno obtido. Os testes computacionais referentes ao uso de custos alternativos são discutidos na seção 5.1.5.

Uma análise de situações de simetria no problema, ocorrência que surgiu durante testes preliminares e estudada em mais detalhes, é feita na seção 5.1.6.

Na seção 5.1.7, avaliamos como a dificuldade de resolução do algoritmo varia conforme mudamos o valor de $\lambda^{\text {min }}$ utilizado, visto que o tamanho mínimo definido a um lote pode variar de acordo com a necessidade ou disponibilidade dos agricultores.

Observe que a Fase II do algoritmo é, por si só, resolvida de forma exata, porém não é a solução exata do problema (3.20)-(3.25) como um todo, já que apenas um pequeno conjunto de todas as colunas possíveis são consideradas. Por isso, o procedimento GC-BC é considerado heurístico.

\subsection{HEURÍSTICA LOTE FIXO}

A segunda heurística proposta utiliza apenas o modelo linear (3.16)-(3.19) e, por meio de avaliações das coordenadas na solução, fixa o valor de algumas variáveis no tamanho mínimo desejado para um lote. Após a fixação, o modelo tem a demanda atualizada, considerando o atendimento cumprido pelas variáveis fixadas, como também a área disponível é atualizada, e um problema residual, análogo ao inicial, é resolvido. O processo é repetido até que algum critério de parada seja satisfeito. 
Devido à atualização do modelo em cada iteração, mais colunas tendem a ser geradas na nova resolução, abrindo mais possibilidades de solução.

Para caracterizar o algoritmo, faremos uso de dois grupos $V$ e $F$ : o grupo $V$ contém as variáveis candidatas a serem fixadas em uma iteração, e o grupo $F$ contém as variáveis que já foram fixadas pelo algoritmo. Sabendo disso, o algoritmo que descreve a heurística Lote Fixo é definida como:

\section{Algoritmo: Heurística Lote Fixo para o problema PRC-D}

1. Resolva (3.16)-(3.19) por geração de colunas. Faça $V=\emptyset$ e $F=\emptyset$.

2. Faça $\mathrm{t}=0$.

3. Se $\lambda_{k s} \geq \lambda^{\min }, \forall \lambda_{k s}>0$, PARE: a solução é ótima para o problema (3.20)(3.25) se $\mathrm{t}=0$, heurística se $\mathrm{t}>0$.

4. Caso contrário, seja $V=\left\{(k, s) \mid \lambda_{k s}<\lambda^{\min } e(k, s) \notin F\right\}$ o conjunto das variáveis cujo valor viola a restrição de lote mínimo. Avalie as condições de parada.

5. Determine $(k, s) \in V$ segundo um critério de seleção pré-definido.

6. Para todo $(k, s)$ selecionado, faça $\lambda_{k s}=\lambda^{\text {min }} \mathrm{e}$ atualize as informações referentes (faça $F \leftarrow F \cup\{(k, s)\}$ e atualize o total de fixações de $(k, s)$ ).

7. Atualize as demandas $d_{i j}=d_{i j}-a_{i j k}^{S} \lambda_{k s}$, para todo $i$ e $j$, conforme as variáveis $\lambda_{k s}$ selecionadas no passo 6 .

a. Se $d_{i j}<0$, faça $d_{i j}=0$.

8. Atualize a área restante disponível $A_{k}=A_{k}-\lambda^{\text {min }}$, para cada $\lambda_{k s}$ selecionado.

9. Resolva (3.16)-(3.19) (agora com $d_{i j} e A_{k}$ atualizados) por geração de colunas.

10. Faça $\mathrm{t}=\mathrm{t}+1$, e retorne para 3 .

As condições de parada podem diversificar, e por questões de simplicidade de leitura, não foram incluídas no algoritmo acima. O algoritmo implementado utilizou as seguintes condições de parada: 


\section{Condições de parada para a Heurística Lote Fixo para o problema PRC-D}

1. Se, $\forall k=1, \ldots, L$, a área total disponível $A_{k}<n * \lambda^{\min }$, PARE. (utilizou-se $n=$ $1,5)$.

2. Se, para todo $k^{\prime}=1, \ldots, \mathrm{L}, \sum_{k s \in V \mid k=k^{\prime}} \lambda_{k s}<\lambda^{\text {min }}$, PARE.

3. Calcule as perdas associadas: seja $\lambda^{\prime}$ a solução obtida ao se considerar $\lambda_{k s}=0$ para todo $(k, s) \in V$ :

a. Calcule: $\mathrm{f}\left(\lambda^{\prime}\right)=\mathrm{f}(\lambda)-\sum_{k s \in V} c_{k s} \lambda_{k s}$

b. Calcule demanda não atendida:

$$
\mathrm{d}_{\mathrm{ij}}{ }^{\prime}=\sum_{k=1}^{L} \sum_{s \in S_{k}} a_{i j k}^{S} \lambda_{k s}-\sum_{k s \in V} a_{i j k}^{S} \lambda_{k s}
$$

c. Se $d_{i j}{ }^{\prime} \geq d_{i j}$, faça $d_{i j}{ }^{\prime}=0$ (a demanda é atendida); caso contrário, faça $d_{i j}$ ' $=\mathrm{d}_{\mathrm{ij}}-\mathrm{d}_{\mathrm{ij}}$ '.

d. Se $f\left(\lambda^{\prime}\right) \leq t o l \_f$ e $d_{i j}{ }^{\prime} \leq t o l \_d$ para todo $i, j$, PARE.

A primeira condição de parada proposta assume que, se a área restante de todas as hortas tratadas em uma dada iteração é menor ou igual a um certo múltiplo do tamanho mínimo de lote definido, não há área restante suficiente que compense um replanejamento. Esta verificação é mais bem aplicada no passo 8 do algoritmo, antes da resolução do modelo.

Uma idéia similar é utilizada na segunda condição, que considera que se todos os lotes pequenos forem somados e ainda não formarem uma área maior ou igual a um lote mínimo, são de pouca contribuição para a solução e poderiam ser desprezados sem perdas significativas.

A terceira condição, por sua vez, avalia se a perda (na função objetivo e nãoatendimento de demanda) associada à desconsideração dos lotes pequenos é menor que uma tolerância pré-determinada. Esta perda pode ser avaliada em valores brutos (conforme descrito nas condições acima) ou proporcionalmente aos valores originais. A perda proporcional foi escolhida para ser verificada no algoritmo implementado.

A consideração feita por se anular valores menores que um valor estipulado (neste caso, $\lambda^{\mathrm{min}}$ ), é inspirada pela heurística $\alpha$-lote apresentada em Santos (2009): neste trabalho, a autora desconsiderou lotes menores que um dado valor $\alpha$. Calculou-se a perda percentual desta consideração, e avaliações foram feitas sobre sua eficácia. A autora usou $\alpha=1$ para seus testes, um valor que julgamos ser muito baixo perante os 
resultados obtidos: assumimos então uma abordagem mais ousada, adaptando um dos critérios de parada para uma análise similar à $\alpha$-heurística com $\alpha=\lambda^{\text {min }}$.

Para o passo 5, o critério de seleção de variáveis a ser fixada também é sujeito a mudanças. Este critério é crucial e suas variações serão o foco do desenvolvimento da heurística. O primeiro critério escolhido para a fixação das variáveis foi:

\section{Critério 1 de seleção de variável a ser fixada para a Heurística Lote Fixo}

1. Seja $V=\left\{(k, s) \mid \lambda_{k s}<\lambda^{\min } e(k, s) \notin F\right\}$.

2. Determine $(k, s) \in V$ tal que $\bar{\lambda}_{k s}=\operatorname{Max}\left\{\lambda_{k s} \mid(k, s) \in V\right\}$.

Outros padrões de escolha de variáveis a serem fixadas em cada iteração são propostos. Mais detalhes são fornecidos juntamente dos testes computacionais correspondentes, descritos nas seções 5.2.2, 5.2.3 e 5.2.4. Uma mistura dos conceitos das Heurísticas Lote Fixo com GC-BC é apresentada, discutida e testada para cada diferente critério de escolha em sua respectiva seção. Por fim, a seção 5.2 .5 compara o desempenho computacional entre os critérios. 


\section{TESTES COMPUTACIONAIS}

Todos os testes computacionais foram realizados em uma máquina Pentium Dual CPU com 2.16/2.17 GHz e 2.0 GB de memória RAM, sob o sistema operacional Windows Vista. Os modelos são iniciados com variáveis artificiais, as quais são mantidas no modelo como representantes de demanda não-atendida.

Os dados de culturas utilizados foram os mesmos de Santos (2009), obtidos em uma horta da cidade de Barbacena - MG, que consistem de 23 culturas divididas em 9 famílias botânicas. O Apêndice A contém todos os detalhes referentes às 23 culturas utilizadas. Em alguns testes, grupos menores de culturas foram usados, como 12 culturas divididas em 6 famílias botânicas, 16 culturas em 7 famílias, e 20 culturas em 8 famílias. Nos grupos menores, pequenas alterações nos períodos favoráveis de plantio das adubações verdes foram feitas para garantir que não ocorresse falta de atendimento de demanda em razão à impossibilidade de plantio, já que as adubações verdes são obrigatórias nas rotações: estas alterações são meras extensões dos períodos factíveis de plantio e foram feitas unicamente devido à redução da amostra, pois uma situação prática não seria tão limitada, e com isso garantindo a factibilidade das instâncias.

A menos que explicitado o contrário, todos os testes utilizam a re-escrita (3.6) de restrições e assumem lote mínimo $\lambda^{\text {min }}=100$, além da disponibilidade de $20.000 \mathrm{~m}^{2}$ de área total para cultivo dividida em $\mathrm{k}=1, \mathrm{k}=3 \mathrm{e} \mathrm{k}=5$ hortas distintas. Nos casos de múltiplas hortas, a produtividade das hortaliças foi variada entre elas, além da inclusão de algumas proibições de plantio e totais de área para cada horta variando em um intervalo $A_{k} \in[3000,7500]$, porém a somatória de todas as áreas mantém o total estipulado de $20.000 \mathrm{~m}^{2}$.

O tempo de execução foi limitado em 3600 segundos (1 hora) para todo o processo de geração de colunas, e também em 3600 segundos para a resolução do problema inteiro-misto.

Os códigos foram implementados na linguagem $\mathrm{C}++$ utilizando o software Microsoft Visual C++ 2008 Express Edition, e o solver IBM CPLEX 12.1 foi usado como ferramenta de solução dos modelos matemáticos. 


\subsection{TESTES HEURÍSTICA GC-BC}

Os testes referentes à Heurística GC-BC são apresentados a seguir. Inicialmente, avaliamos os testes preliminares, baseados no algoritmo descrito na seção 4.1 e, a seguir tratamos algumas análises de parâmetros como discutidos anteriormente.

Os testes usualmente consistem de 12 classes de problemas (referente às combinações do número de culturas e hortas consideradas), para as quais foram utilizados os dados de 5 diferentes cenários de demanda). As áreas disponíveis para plantio são variadas, assim como a produtividade de cada cultura, além de algumas proibições relativas a cada área de plantio, como mencionado anteriormente. A menos que expresso o contrário, o valor de lote mínimo utilizado foi $\lambda^{\min }=100$, e a área máxima disponível, considerando todas as regiões de cultivo, é sempre igual a $20.000 \mathrm{~m}^{2}$.

\subsubsection{TESTES PRELIMINARES}

O primeiro conjunto de testes realizados consiste em resolver o modelo (3.16)(3.19) (caracterizado pela maximização do retorno financeiro sem restrições de tamanho de lote), obtendo um valor para a função objetivo e o número de lotes usados (Fase I do algoritmo). Após adaptar o modelo para (3.20)-(3.25) (caracterizado pela maximização do lucro com restrições de lote mínimo), o modelo inteiro-misto é resolvido e um novo valor de função objetivo e total de lotes usados é obtido (Fase II do algoritmo, usando $f(\lambda)$ como objetivo, isto é, maximizando o lucro). Por fim, as instâncias foram rodadas novamente, com a Fase II adaptada para que a função objetivo seja composta apenas de $g(y)$, isto é, minimizando o número de lotes. Desta forma, comparamos o valor do lucro obtido (ou seja, $f(\lambda)$ ) e o total de lotes usados nas três situações: sem restrição de lote mínimo, com restrição de lote mínimo, e com restrição de lote mínimo visando minimizar o total de lotes usados.

As tabelas abaixo apresentam os resultados obtidos para cinco cenários de demanda, cada cenário aplicado a 12 classes de problema relativas ao número de culturas e hortas. A colunas $f_{l}(\lambda)$ e $y_{l}$ apresentam respectivamente o valor de função objetivo e número de lotes obtidos na Fase I do algoritmo. Para melhor visualização e compreensão, as colunas seguintes são exibidas em valores percentuais em relação às 
anteriores: as colunas $f_{2}(\lambda)$ e $y_{2}$ fornecem a redução dos resultados obtidos pela Fase II do algoritmo em relação à Fase $\mathrm{I}$, e de forma análoga as colunas $f_{\min }(\lambda)$ e $y_{\min }$ referem-se aos valores obtidos na Fase II ao minimizarmos $g(y)$.

Tabela 5.1: resultados dos testes preliminares para o cenário de demanda 1

\begin{tabular}{|r|c|ccc|ccc|}
\hline \multicolumn{1}{|c}{ hortas } & \multicolumn{1}{c}{ cult. } & $\boldsymbol{f}_{\mathbf{1}}(\boldsymbol{\lambda})$ & $\boldsymbol{f}_{\mathbf{2}}(\boldsymbol{\lambda})$ & $\boldsymbol{f}_{\min }(\boldsymbol{\lambda})$ & $\boldsymbol{y}_{\mathbf{1}}$ & $\boldsymbol{y}_{\mathbf{2}}$ & $\boldsymbol{y}_{\min }$ \\
\hline & $\mathbf{1 2}$ & 2676582,78 & $-0,97 \%$ & $-90,80 \%$ & 39 & $-10,26 \%$ & $-51,28 \%$ \\
& $\mathbf{1 6}$ & 2575102,28 & $-1,35 \%$ & $-75,17 \%$ & 53 & $-18,87 \%$ & $-52,83 \%$ \\
& $\mathbf{2 0}$ & 2016602,28 & $-1,51 \%$ & $-78,15 \%$ & 76 & $-10,53 \%$ & $-56,58 \%$ \\
& $\mathbf{2 3}$ & 1366246,73 & $-3,96 \%$ & $-65,63 \%$ & 83 & $-20,48 \%$ & $-50,60 \%$ \\
\hline \multirow{5}{*}{$\mathbf{3}$} & $\mathbf{1 2}$ & 2302470,56 & $-0,91 \%$ & $-90,48 \%$ & 43 & $-23,26 \%$ & $-55,81 \%$ \\
& $\mathbf{1 6}$ & 2389692,38 & $-1,07 \%$ & $-81,23 \%$ & 53 & $-16,98 \%$ & $-52,83 \%$ \\
& $\mathbf{2 0}$ & 2155522,00 & $-1,18 \%$ & $-80,39 \%$ & 80 & $-22,50 \%$ & $-58,75 \%$ \\
& $\mathbf{2 3}$ & 1271723,57 & $-4,43 \%$ & $-69,82 \%$ & 104 & $-14,42 \%$ & $-61,54 \%$ \\
\hline \multirow{5}{*}{$\mathbf{5}$} & $\mathbf{1 2}$ & 2986404,85 & $-0,17 \%$ & $-93,71 \%$ & 41 & $-17,07 \%$ & $-53,66 \%$ \\
& $\mathbf{1 6}$ & 2978234,81 & $-1,46 \%$ & $-89,92 \%$ & 59 & $-20,34 \%$ & $-57,63 \%$ \\
& $\mathbf{2 0}$ & 2692998,10 & $-1,43 \%$ & $-71,77 \%$ & 80 & $-12,50 \%$ & $-60,00 \%$ \\
& $\mathbf{2 3}$ & 2100988,03 & $-2,21 \%$ & $-79,61 \%$ & 94 & $-10,64 \%$ & $-60,64 \%$ \\
\hline
\end{tabular}

Tabela 5.2: resultados dos testes preliminares para o cenário de demanda 2

\begin{tabular}{|c|c|c|c|c|c|c|c|}
\hline hortas & cult. & $f_{1}(\lambda)$ & $f_{2}(\lambda)$ & $f_{\min }(\lambda)$ & $y_{1}$ & $y_{2}$ & $y_{\min }$ \\
\hline \multirow{4}{*}{1} & 12 & 3620969,21 & $-3,90 \%$ & $-96,27 \%$ & 56 & $-44,64 \%$ & $-53,57 \%$ \\
\hline & 16 & 3806712,14 & $-4,18 \%$ & $-10,55 \%$ & 65 & $-43,08 \%$ & $-53,85 \%$ \\
\hline & 20 & 3258701,03 & $-5,64 \%$ & $-84,49 \%$ & 77 & $-40,26 \%$ & $-54,55 \%$ \\
\hline & 23 & 3031934,37 & $-5,92 \%$ & $-81,18 \%$ & 86 & $-33,72 \%$ & $-54,65 \%$ \\
\hline \multirow{4}{*}{3} & 12 & 2928602,19 & $-2,90 \%$ & $-83,91 \%$ & 53 & $-41,51 \%$ & $-50,94 \%$ \\
\hline & 16 & 3034318,92 & $-3,67 \%$ & $-87,38 \%$ & 68 & $-36,76 \%$ & $-54,41 \%$ \\
\hline & 20 & 2800574,81 & $-3,13 \%$ & $-60,58 \%$ & 78 & $-33,33 \%$ & $-55,13 \%$ \\
\hline & 23 & 2502294,27 & $-3,36 \%$ & $-80,14 \%$ & 100 & $-35,00 \%$ & $-60,00 \%$ \\
\hline \multirow{4}{*}{5} & 12 & 3167395,36 & $-0,93 \%$ & $-69,28 \%$ & 59 & $-44,07 \%$ & $-57,63 \%$ \\
\hline & 16 & 3717112,01 & $-5,65 \%$ & $-88,15 \%$ & 80 & $-45,00 \%$ & $-60,00 \%$ \\
\hline & 20 & 3465639,85 & $-5,49 \%$ & $-93,76 \%$ & 90 & $-42,22 \%$ & $-63,33 \%$ \\
\hline & 23 & 3207488,54 & $-5,75 \%$ & $-91,40 \%$ & 110 & $-43,64 \%$ & $-65,45 \%$ \\
\hline
\end{tabular}


Tabela 5.3: resultados dos testes preliminares para o cenário de demanda 3

\begin{tabular}{|r|c|ccc|ccc|}
\hline \multicolumn{1}{|c}{ hortas } & \multicolumn{1}{c}{ cult. } & $\boldsymbol{f}_{\mathbf{1}}(\boldsymbol{\lambda})$ & $\boldsymbol{f}_{\mathbf{2}}(\boldsymbol{\lambda})$ & $\boldsymbol{f}_{\min }(\boldsymbol{\lambda})$ & $\boldsymbol{y}_{\mathbf{1}}$ & $\boldsymbol{y}_{\mathbf{2}}$ & $\boldsymbol{y}_{\min }$ \\
\hline \multirow{5}{*}{$\mathbf{1}$} & $\mathbf{1 2}$ & 3753049,21 & $-4,11 \%$ & $-7,22 \%$ & 55 & $-47,27 \%$ & $-54,55 \%$ \\
& $\mathbf{1 6}$ & 3943085,22 & $-4,72 \%$ & $-83,78 \%$ & 73 & $-47,95 \%$ & $-57,53 \%$ \\
& $\mathbf{2 0}$ & 3781761,33 & $-5,66 \%$ & $-84,83 \%$ & 86 & $-41,86 \%$ & $-59,30 \%$ \\
& $\mathbf{2 3}$ & 3562613,13 & $-6,81 \%$ & $-90,88 \%$ & 97 & $-46,39 \%$ & $-58,76 \%$ \\
\hline \multirow{5}{*}{$\mathbf{3}$} & $\mathbf{1 2}$ & 2996466,15 & $-3,09 \%$ & $-53,55 \%$ & 56 & $-44,64 \%$ & $-55,36 \%$ \\
& $\mathbf{1 6}$ & 3120223,20 & $-3,81 \%$ & $-86,25 \%$ & 71 & $-47,89 \%$ & $-54,93 \%$ \\
& $\mathbf{2 0}$ & 2924227,10 & $-3,18 \%$ & $-83,45 \%$ & 85 & $-43,53 \%$ & $-58,82 \%$ \\
& $\mathbf{2 3}$ & 2690223,49 & $-3,77 \%$ & $-82,24 \%$ & 120 & $-47,50 \%$ & $-65,00 \%$ \\
\hline \multirow{5}{*}{$\mathbf{5}$} & $\mathbf{1 2}$ & 3162745,25 & $-0,61 \%$ & $-90,79 \%$ & 66 & $-50,00 \%$ & $-60,61 \%$ \\
& $\mathbf{1 6}$ & 3781033,31 & $-5,94 \%$ & $-82,65 \%$ & 93 & $-53,76 \%$ & $-64,52 \%$ \\
& $\mathbf{2 0}$ & 3802939,82 & $-6,23 \%$ & $-89,41 \%$ & 99 & $-48,48 \%$ & $-64,65 \%$ \\
& $\mathbf{2 3}$ & 3504055,11 & $-5,57 \%$ & $-53,77 \%$ & 121 & $-46,28 \%$ & $-64,46 \%$ \\
\hline
\end{tabular}

Tabela 5.4: resultados dos testes preliminares para o cenário de demanda 4

\begin{tabular}{|r|c|ccc|ccc|}
\hline \multicolumn{1}{|c}{ hortas } & \multicolumn{1}{c}{ cult. } & $\boldsymbol{f}_{\mathbf{1}}(\boldsymbol{\lambda})$ & $\boldsymbol{f}_{\mathbf{2}}(\boldsymbol{\lambda})$ & \multicolumn{1}{c|}{$\boldsymbol{f}_{\min }(\boldsymbol{\lambda})$} & $\boldsymbol{y}_{\mathbf{1}}$ & $\boldsymbol{y}_{\mathbf{2}}$ & $\boldsymbol{y}_{\min }$ \\
\hline \multirow{5}{*}{$\mathbf{1}$} & $\mathbf{1 2}$ & 3515827,43 & $-7,02 \%$ & $-92,59 \%$ & 90 & $-56,67 \%$ & $-56,67 \%$ \\
& $\mathbf{1 6}$ & 3691871,00 & $-7,54 \%$ & $-78,41 \%$ & 101 & $-51,49 \%$ & $-58,42 \%$ \\
& $\mathbf{2 0}$ & 3512078,85 & $-8,35 \%$ & $-64,56 \%$ & 113 & $-48,67 \%$ & $-56,64 \%$ \\
& $\mathbf{2 3}$ & 3360192,06 & $-9,93 \%$ & $-85,82 \%$ & 148 & $-53,38 \%$ & $-62,84 \%$ \\
\hline \multirow{5}{*}{$\mathbf{3}$} & $\mathbf{1 2}$ & 2971776,10 & $-4,17 \%$ & $-82,21 \%$ & 96 & $-57,29 \%$ & $-60,42 \%$ \\
& $\mathbf{1 6}$ & 2792967,07 & $-8,04 \%$ & $-88,63 \%$ & 107 & $-54,21 \%$ & $-60,75 \%$ \\
& $\mathbf{2 0}$ & 2767989,41 & $-4,18 \%$ & $-83,20 \%$ & 122 & $-49,18 \%$ & $-57,38 \%$ \\
& $\mathbf{2 3}$ & 2550466,96 & $-8,73 \%$ & $-79,48 \%$ & 174 & $-50,57 \%$ & $-67,82 \%$ \\
\hline \multirow{5}{*}{$\mathbf{5}$} & $\mathbf{1 2}$ & 3141466,78 & $-1,79 \%$ & $-62,94 \%$ & 90 & $-50,00 \%$ & $-58,89 \%$ \\
& $\mathbf{1 6}$ & 3717125,05 & $-9,98 \%$ & $-79,84 \%$ & 111 & $-52,25 \%$ & $-59,46 \%$ \\
& $\mathbf{2 0}$ & 3752085,15 & $-9,61 \%$ & $-89,06 \%$ & 127 & $-53,54 \%$ & $-62,20 \%$ \\
& $\mathbf{2 3}$ & 3422370,78 & $-8,41 \%$ & $-82,24 \%$ & 163 & $-49,69 \%$ & $-65,64 \%$ \\
\hline
\end{tabular}


Tabela 5.5: resultados dos testes preliminares para o cenário de demanda 5

\begin{tabular}{|r|c|cccc|ccc|}
\hline \multicolumn{1}{|c}{ hortas } & \multicolumn{1}{c}{ cult. } & $\boldsymbol{f}_{\mathbf{1}}(\boldsymbol{\lambda})$ & $\boldsymbol{f}_{\mathbf{2}}(\boldsymbol{\lambda})$ & $\boldsymbol{f}_{\min }(\boldsymbol{\lambda})$ & $\boldsymbol{y}_{\mathbf{1}}$ & $\boldsymbol{y}_{\mathbf{2}}$ & $\boldsymbol{y}_{\min }$ \\
\hline \multirow{5}{*}{$\mathbf{1}$} & $\mathbf{1 2}$ & 3620818,17 & $-5,63 \%$ & $-93,89 \%$ & 51 & $-41,18 \%$ & $-43,14 \%$ \\
& $\mathbf{1 6}$ & 3828331,51 & $-5,37 \%$ & $-65,16 \%$ & 54 & $-40,74 \%$ & $-42,59 \%$ \\
& $\mathbf{2 0}$ & 3735951,29 & $-5,67 \%$ & $-64,46 \%$ & 73 & $-45,21 \%$ & $-54,79 \%$ \\
& $\mathbf{2 3}$ & 3619333,91 & $-6,03 \%$ & $-82,84 \%$ & 79 & $-46,84 \%$ & $-54,43 \%$ \\
\hline \multirow{5}{*}{$\mathbf{3}$} & $\mathbf{1 2}$ & 2978193,64 & $-3,26 \%$ & $-35,53 \%$ & 54 & $-40,74 \%$ & $-46,30 \%$ \\
& $\mathbf{1 6}$ & 2951827,95 & $-4,27 \%$ & $-75,75 \%$ & 58 & $-41,38 \%$ & $-48,28 \%$ \\
& $\mathbf{2 0}$ & 2903786,52 & $-4,42 \%$ & $-54,20 \%$ & 75 & $-36,00 \%$ & $-53,33 \%$ \\
& $\mathbf{2 3}$ & 2690167,63 & $-2,69 \%$ & $-85,09 \%$ & 91 & $-47,25 \%$ & $-60,44 \%$ \\
\hline \multirow{5}{*}{$\mathbf{5}$} & $\mathbf{1 2}$ & 3171795,08 & $-1,37 \%$ & $-91,69 \%$ & 51 & $-31,37 \%$ & $-45,10 \%$ \\
& $\mathbf{1 6}$ & 3772279,13 & $-6,65 \%$ & $-66,61 \%$ & 75 & $-49,33 \%$ & $-60,00 \%$ \\
& $\mathbf{2 0}$ & 3879189,84 & $-5,90 \%$ & $-86,94 \%$ & 84 & $-50,00 \%$ & $-61,90 \%$ \\
& $\mathbf{2 3}$ & 3544769,74 & $-2,80 \%$ & $-86,38 \%$ & 85 & $-48,24 \%$ & $-60,00 \%$ \\
\hline
\end{tabular}

Observamos nas tabelas que para os 5 cenários o número de lotes usados na solução fornecida pela Fase II é significativamente menor que a solução linear da Fase I. Apenas esta redução é capaz de simplificar consideravelmente a administração física dos lotes: em alguns casos obtemos mais de 50\% de redução, uma ocorrência freqüente no cenário 4. Há, entretanto, reduções menores e de pouco impacto, como notamos nos testes referentes ao cenário de demanda 1.

Ao focarmos os esforços em minimizar os lotes, o valor obtido nem sempre se mostrou muito menor que o número de lotes gerado pela Fase II convencional, mas há ocorrências de reduções grandes, algo que podemos observar mais facilmente nos resultados do cenário 1 . Por sua vez, este é o cenário que obteve a menor redução de lotes usados ao maximizar o lucro, indicando que a redução do número de lotes impacta bastante o lucro.

É possível que parte desta alta redução no lucro se deva ao fato de que o modelo é resolvido em função das variáveis $y_{k s}$, e como as respectivas variáveis $\lambda_{k s}$ satisfazem a demanda final, não há utilização da área restante para produção extra e, com isso, aumento do lucro. Porém, veremos adiante nos testes da seção 5.1.4 que estes baixos valores não estão distantes da realidade da solução ótima referente ao problema com o mínimo de lotes necessários para garantir o cumprimento da demanda.

Observamos agora o tempo computacional necessário para a resolução dos problemas, agrupados por fase: Fase I (geração de colunas), Fase II (branch-and-cut 
com as restrições de lote mínimo) e Minimização de lotes (Fase II com função objetivo de minimizar lotes usados).

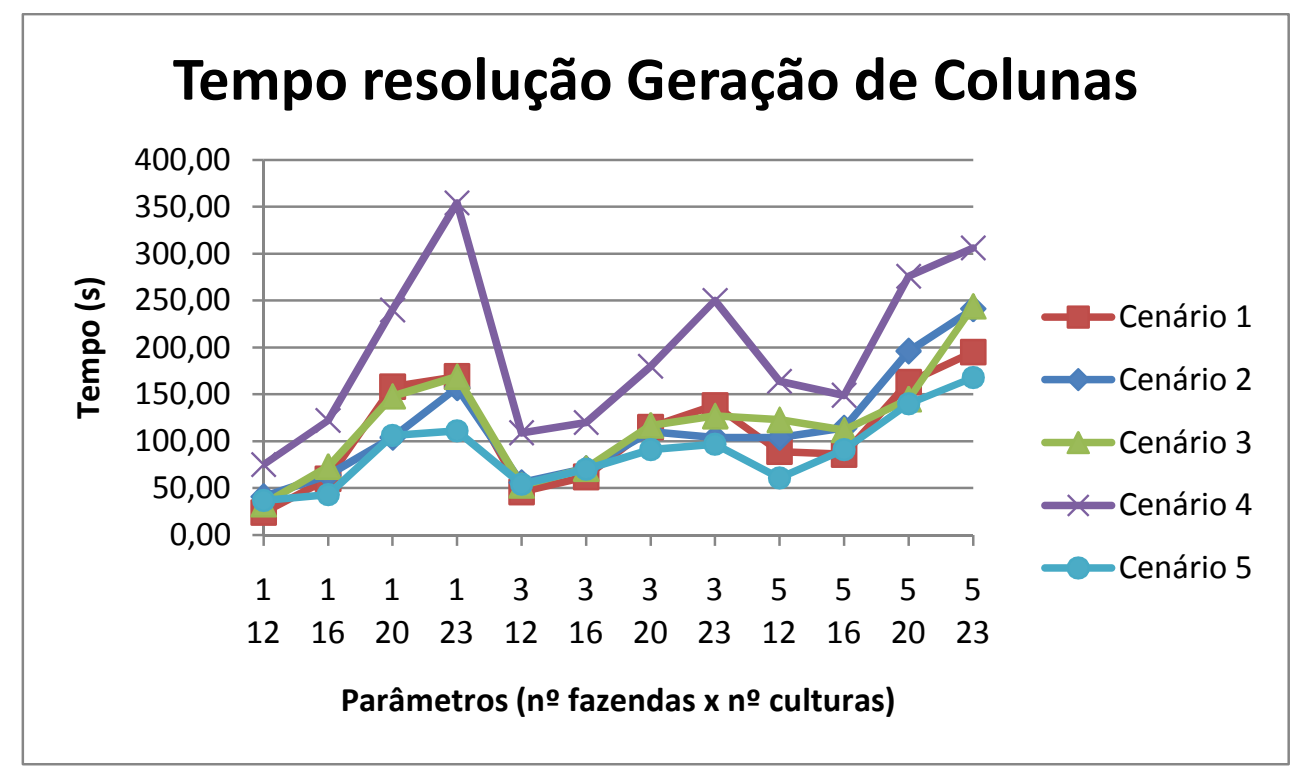

Figura 5.1: Tempo computacional da geração de colunas para 5 cenários de demanda

Observamos na Figura 5.1 que o tempo necessário para a geração de colunas (referente à Fase I do algoritmo) cresce de forma significativa conforme cresce o número de culturas do problema. O número de áreas utilizadas tem pouco impacto no tempo de resolução; embora a tendência seja haver um pequeno aumento, notamos que isso nem sempre ocorre: vemos no cenário 4 que o problema com 1 área e 23 culturas requereu mais tempo que os problemas com 3 e 5 áreas para o mesmo número de culturas.

O aumento do tempo computacional observado nos problemas com mais culturas é natural, uma vez que o número de culturas define em grande parte o número de restrições do modelo: as restrições de demanda (3.17) são da ordem de O(M.N), sendo $\mathrm{M}$ o número de períodos e $\mathrm{N}$ o número de culturas. Cada área a mais, por sua vez, acrescenta uma única restrição ao conjunto de restrições (3.18), que é da ordem de $\mathrm{O}(\mathrm{L})$, sendo L o número de áreas consideradas. 


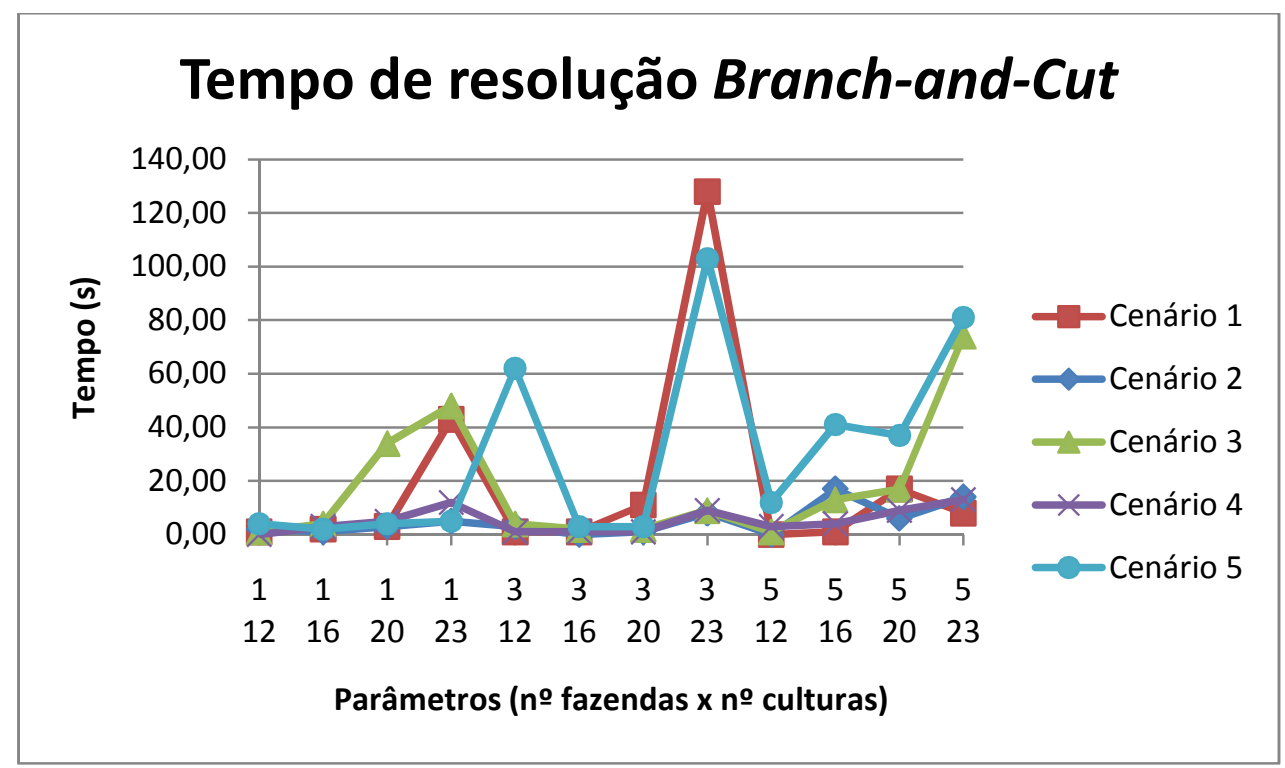

Figura 5.2: Tempo computacional do branch-and-cut para 5 cenários de demanda

Para a Fase II do algoritmo, que consiste da solução do problema inteiro-misto com restrições de lote mínimo via branch-and-cut, o tempo computacional foi bem abaixo do esperado, como observado na Figura 5.2: poucas instâncias passaram da marca de 2 minutos em sua resolução. O pacote de otimização mostrou-se eficiente em resolver um problema inteiro-misto que possui apenas variáveis binárias e que não possuem simetria em sua semântica.

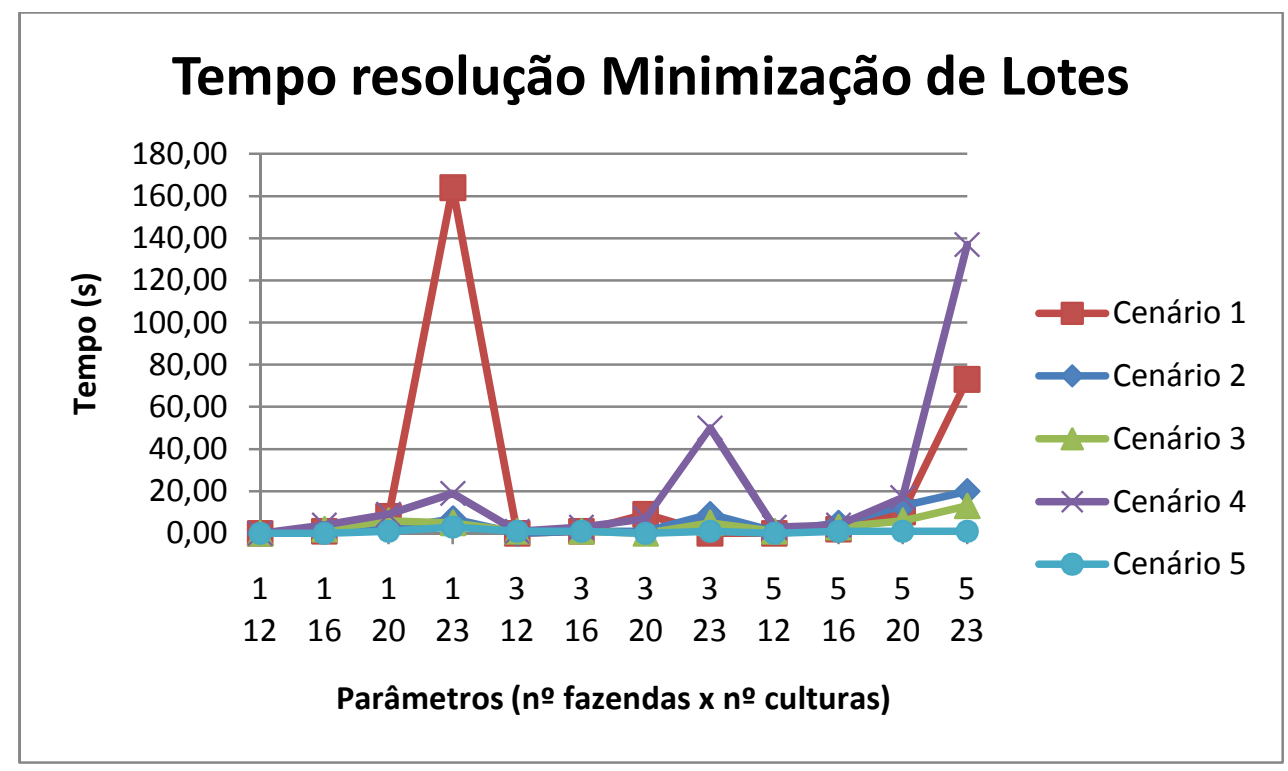

Figura 5.3: Tempo computacional da minimização de lotes para 5 cenários de demanda 
Se a Fase II é alterada de forma que o objetivo é obter a solução com o menor número de lotes possível, o tempo computacional necessário também se mostrou baixo: a Figura 5.3 mostra que a grande maioria dos problemas foi resolvida em menos de 20 segundos. Mesmo em instâncias mais demoradas, não mais que 3 minutos foram necessários para a comprovação da otimalidade do problema.

Uma única exceção foi observada e não incluída no gráfico acima: o problema com 3 hortas e 23 culturas, para o cenário de demanda 1, não foi capaz de provar a otimalidade dentro do tempo limite de 3600 segundos. Devido a este alto valor, a solução não foi inclusa no gráfico para evitar que o gráfico ficasse desconfigurado, com todos os valores concentrados e impossibilitando qualquer distinção entre eles. Curiosamente tal dificuldade não ocorreu no problema de 5 áreas e 23 culturas, que esperava-se ser computacionalmente mais difícil de resolver, o que sugere que a classe de problemas com 3 áreas pode apresentar simetria em sua divisão.

Notamos nos três gráficos que o tempo computacional necessário para a solução do problema proposto é baixo, independente do objetivo final (maximizar lucro ou minimizar lotes). Não é possível comparar este tempo com os resultados de Santos, visto que os problemas abordados são distintos. A perda de lucro comparando-se com o resultado obtido na Fase I é baixa na média, enquanto o número total de lotes usados decresce consideravelmente: a facilidade de administração deste número reduzido de lotes deve ser capaz de compensar o investimento que é perdido considerando-se a solução que desconsidera um tamanho mínimo para os lotes.

\subsubsection{TESTES PONDERAÇÃO- $\alpha$}

As funções objetivos descritas na seção 4.2, que são maximizar o lucro obtido e minimizar o total de lotes utilizados enquanto cumpre-se o atendimento de demanda, são conflitantes. Minimizar o número de lotes necessários enquanto garante-se o atendimento da demanda tende a reduzir drasticamente o lucro das rotações. Por outro lado, o lucro máximo pode requerer uma vasta distribuição de lotes, o que torna a administração inaceitável na prática. É fácil ver, portanto, que um balanço entre os objetivos pode trazer resultados mais satisfatórios na prática. 
Em Gomes e Arenales (2010), esta consideração foi tratada e avaliada. Descreveremos aqui os pontos mais importantes e resultados obtidos de forma resumida.

Uma das técnicas mais clássicas para obter soluções de problemas multiobjetivos é fornecer pesos a cada um dos deles e uni-los em uma única função mono-objetivo. Desta forma, objetivos conflitantes são trabalhados simultaneamente e o problema pode ser abordado de diferentes maneiras conforme os pesos utilizados. Não existe, então, uma solução ótima para o problema, apenas uma solução ótima para um determinado conjunto de coeficientes de peso. Um conjunto de soluções pode ser obtido utilizando diferentes coeficientes, os quais são variados conforme os interesses do usuário. Porém, não é uma tarefa trivial determinar quais coeficientes são adequados (Cohon, 1978).

Para balancear os dois objetivos desejados conforme descritos em (4.2), eles foram unidos em uma função mono-objetivo, sendo que cada objetivo foi então multiplicado por um fator. Podemos escrevê-los, sem perda de generalidade, da seguinte forma:

$$
\max \quad \alpha \cdot f(\lambda)-(1-\alpha) \cdot g(y)
$$

Utilizando valores para $\alpha, 0 \leq \alpha \leq 1$, dá-se menor ou maior peso a um ou outro objetivo. É fácil observar que, para $\alpha=1$, temos apenas a maximização de $f(\lambda)$, enquanto para $\alpha=0$ nosso objetivo se resume a minimizar $g(y)$. Qualquer valor intermediário busca soluções de compromisso entre um objetivo e outro.

Vale ressaltar que o valor retornado por (5.1) considera os lucros e a penalidade pelo número de lotes ao mesmo tempo, portanto uma análise individual de $f(\lambda)$ e $g(y)$ deve ser considerada.

O método de resolução é a Heurística GC-BC, conforme descrito no algoritmo presente na seção 4.1. A única diferença, entretanto, é que a função objetivo é definida conforme (5.1), com a penalização $z$ de $g(y)$ fixada em 1000 e 3000.

Os testes realizados consistiram em utilizar valores de $\alpha=0,0.1, \ldots, 1$, testados em 3 diferentes classes de problemas, para um mesmo cenário de demanda.

As tabelas abaixo apresentam os resultados obtidos na Fase II do algoritmo GCBC (e, portanto, satisfaz as condições de lote mínimo) para um cenário de demanda com 23 culturas em três instâncias: com 1, 3 e 5 áreas de cultivo diferentes. Cada coluna é 
identificada pelo valor de $\alpha$. As informações "\%Redução_Lucro" e "\%Redução_Lote" comparam os valores da $f(\lambda)$ e total de lotes usados na solução obtida (listados acima na tabela) pela Fase II com a Fase I do algoritmo.

Tabela 5.6: resultados computacionais para a Fase II com $k=1$ área

\begin{tabular}{|c|c|c|c|c|c|c|}
\hline Valores de a & $\mathbf{0 . 0}$ & 0.1 & 0.2 & 0.3 & 0.4 & 0.5 \\
\hline $\operatorname{Lucro}(f(\lambda))$ & 364140,00 & 774333,33 & 834416,67 & 850743,33 & 852743,33 & 852743,67 \\
\hline$N^{o}$ de lotes & 42 & 61 & 71 & 77 & 78 & 78 \\
\hline \%Redução_lucro & 59,25 & 13,35 & 6,63 & 4,80 & 4,58 & 4,58 \\
\hline \%Redução_lote & 56,25 & 36,46 & 26,04 & 19,79 & 18,75 & 18,75 \\
\hline Valores de $\alpha$ & 0.6 & 0.7 & 0.8 & 0.9 & 1.0 & Média \\
\hline $\operatorname{Lucro}(f(\lambda))$ & 853543,33 & 853543,33 & 853543,33 & 854260,00 & 854260,00 & 795298,48 \\
\hline$N^{o}$ de lotes & 79 & 79 & 79 & 83 & 83 & 72,09 \\
\hline \%Redução_lucro & 4,49 & 4,49 & 4,49 & 4,41 & 4,41 & 10,50 \\
\hline \%Redução_lote & 17,71 & 17,71 & 17,71 & 13,54 & 13,54 & 23,30 \\
\hline
\end{tabular}

A Fase I do algoritmo forneceu $f(\lambda)=893636,59$ com 96 lotes na primeira instância, reduzindo para pelo menos 83 lotes quando maximizamos o lucro na Fase II. Para valores de $\alpha$ de 0,3 a 0,8, o número de lotes usados pouco variou, como observamos na Tabela 5.6. Para $\alpha=0$, vemos uma redução significativa no lucro obtido, mostrando claramente como os objetivos são conflitantes. O tempo médio da geração de colunas (Fase I) foi de 395 segundos, com a Fase II requerendo uma média de 76 segundos, com menção especial ao caso de $\alpha=0$, que necessitou de 394 segundos, provavelmente devido às múltiplas soluções ótimas do problema quando o foco é apenas a minimização dos lotes.

Tabela 5.7: resultados computacionais para a Fase II com $k=3$ áreas

\begin{tabular}{|c|c|c|c|c|c|c|}
\hline Valores de $\alpha$ & 0.0 & 0.1 & 0.2 & 0.3 & 0.4 & 0.5 \\
\hline Lucro $(f(\lambda))$ & 360045,56 & 786765,95 & 932660,83 & 1059655,83 & 1078824,17 & 1093736,67 \\
\hline № de lotes & 39 & 45 & 53 & 66 & 69 & 73 \\
\hline \%Redução_lucro & 68,48 & 31,12 & 18,34 & 7,22 & 5,55 & 4,24 \\
\hline \%Redução_lote & 60,61 & 54,55 & 46,46 & 33,33 & 30,30 & 26,26 \\
\hline Valores de $\alpha$ & 0.6 & 0.7 & 0.8 & 0.9 & 1.0 & Média \\
\hline Lucro $(f(\lambda))$ & 1096228,33 & 1096228,33 & 1096228,33 & 1096228,33 & 1096634,52 & 981203,35 \\
\hline № de lotes & 74 & 74 & 74 & 74 & 79 & 65,45 \\
\hline \%Redução_lucro & 4,02 & 4,02 & 4,02 & 4,02 & 3,99 & 14,09 \\
\hline \%Redução_lote & 25,25 & 25,25 & 25,25 & 25,25 & 20,20 & 33,88 \\
\hline
\end{tabular}


Para 3 áreas de plantio diferentes, foi obtido $f(\lambda)=1142178,05$ com o uso de 99 lotes na Fase I. A Tabela 5.7 mostra que o comportamento foi similar à primeira instância quanto ao número de lotes: valores intermediários de $\alpha$ pouco variaram a redução de lotes usados. Mesmo no extremo de maximização de lucro, os lotes necessários foram reduzidos para pelo menos 79 , representando quase $20 \%$ de redução. Porém, a Fase II apresentou dificuldades, com tempo médio de execução de 2329 segundos e não-prova da otimalidade para valores baixos de $\alpha(0.1$ a 0.5$)$, ou seja o algoritmo foi interrompido por limite de tempo.

Tabela 5.8: resultados computacionais para a Fase II com cinco áreas

\begin{tabular}{|c|c|c|c|c|c|c|}
\hline Valores de $\alpha$ & 0.0 & 0.1 & 0.2 & 0.3 & 0.4 & 0.5 \\
\hline Lucro $(f(\lambda))$ & 447661,19 & 1491990,67 & 1548892,50 & 1680122,44 & 1684605,56 & 1710453,64 \\
\hline № de lotes & 39 & 47 & 50 & 64 & 65 & 72 \\
\hline \%Redução_lucro & 74,98 & 16,60 & 13,42 & 6,08 & 5,83 & 4,39 \\
\hline \%Redução_lote & 61,00 & 53,00 & 50,00 & 36,00 & 35,00 & 28,00 \\
\hline Valores de $\alpha$ & 0.6 & 0.7 & 0.8 & 0.9 & 1.0 & Média \\
\hline Lucro $(f(\lambda))$ & 1717604,92 & 1719167,44 & 1719967,44 & 1722121,33 & 1722301,33 & 1560444,41 \\
\hline № de lotes & 75 & 76 & 77 & 81 & 83 & 66,27 \\
\hline \%Redução_lucro & 3,99 & 3,90 & 3,85 & 3,73 & 3,72 & 12,77 \\
\hline \%Redução_lote & 25,00 & 24,00 & 23,00 & 19,00 & 17,00 & 33,73 \\
\hline
\end{tabular}

A terceira instância forneceu com 100 lotes na Fase I um valor de $f(\lambda)=$ 1788897,15. A Fase II não conseguiu provar a otimalidade na maioria dos valores de $\alpha$, embora o valor do gap fosse usualmente menor que $1 \%$. Na Tabela 5.8 vemos que o número de lotes reduzidos, por sua vez, não se mostrou constante para valores intermediários de $\alpha$ como nas outras instâncias, e sim um comportamento de mudança mais contínua.

Em todos os casos, é fácil observar como a redução de lotes é significativa quando ela é o único objetivo considerado, e como esta redução traz um impacto grande no lucro obtido. Estes resultados indicam que uma aproximação de uma curva de Paretto (curva de eficiência) com os diferentes valores de lotes pode ser uma ferramenta de grande auxílio na tomada de decisão. Testes dedicados à geração desta curva foram realizados e são descritos na seção 5.1.4.

Os tempos computacionais altos na resolução do problema nas instâncias com 3 e 5 áreas indicam simetria no problema. Testes foram realizados para avaliar o impacto que a simetria do problema pode trazer ao modelo e são apresentados na seção 5.1.6. 


\subsubsection{TESTES CONJUNTO DE RESTRIÇÕES (3.6)}

Conforme discutido na seção 3.1, as restrições que descrevem o subproblema que determina uma rotação factível poderiam ser simplificadas sem perda de generalidade, substituindo o conjunto de restrições (3.2) por (3.6). Esta substituição torna a matriz de coeficientes mais esparsa, potencialmente facilitando sua resolução por pacotes de otimização que exploram esta característica. Nesta seção descreveremos os testes computacionais realizados que verificam o desempenho obtido com esta mudança:

Os testes realizados consistiram em executar o algoritmo GC-BC utilizando o conjunto de restrições (3.1)-(3.5), e na sequência analisar as mesmas instâncias utilizando o conjunto de restrições (3.7)-(3.11). Foram resolvidas 60 instâncias, seguindo o mesmo padrão de 5 cenários de demanda para 12 classes de problema dos testes anteriores.

Os gráficos abaixo mostram o tempo computacional necessário para a resolução da Fase I do algoritmo, que consiste na geração de colunas. As linhas contínuas representam o tempo necessário utilizando-se as restrições (3.1)-(3.5), enquanto as linhas com marcadores indicam o tempo computacional referente à resolução pelas restrições (3.7)-(3.11). Para melhor visualização dividimos os gráficos de forma que cada um apresenta os resultados referentes a um cenário de demanda. Cada ponto do eixo horizontal representa uma classe de problema, definidas pela combinação do número de hortas e culturas utilizadas, mantendo o padrão já utilizado em gráficos anteriores.

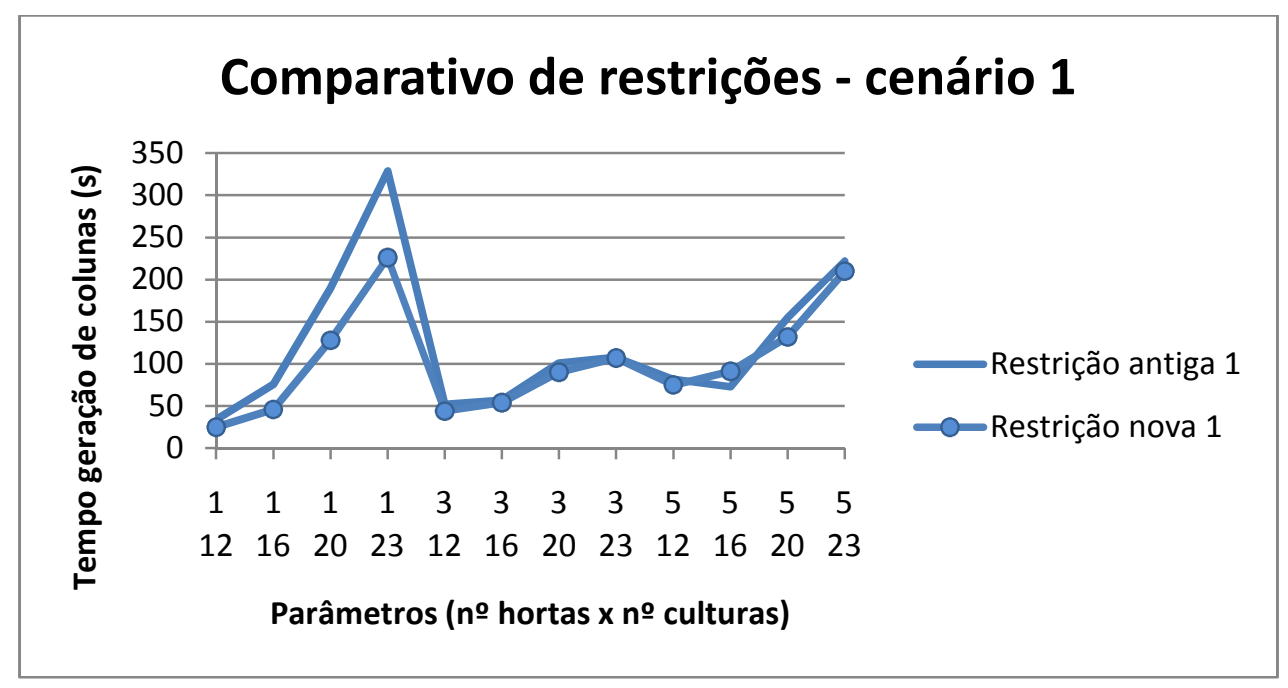

Figura 5.4: Comparativo de tempo para a geração de colunas para cenário de demanda 1 


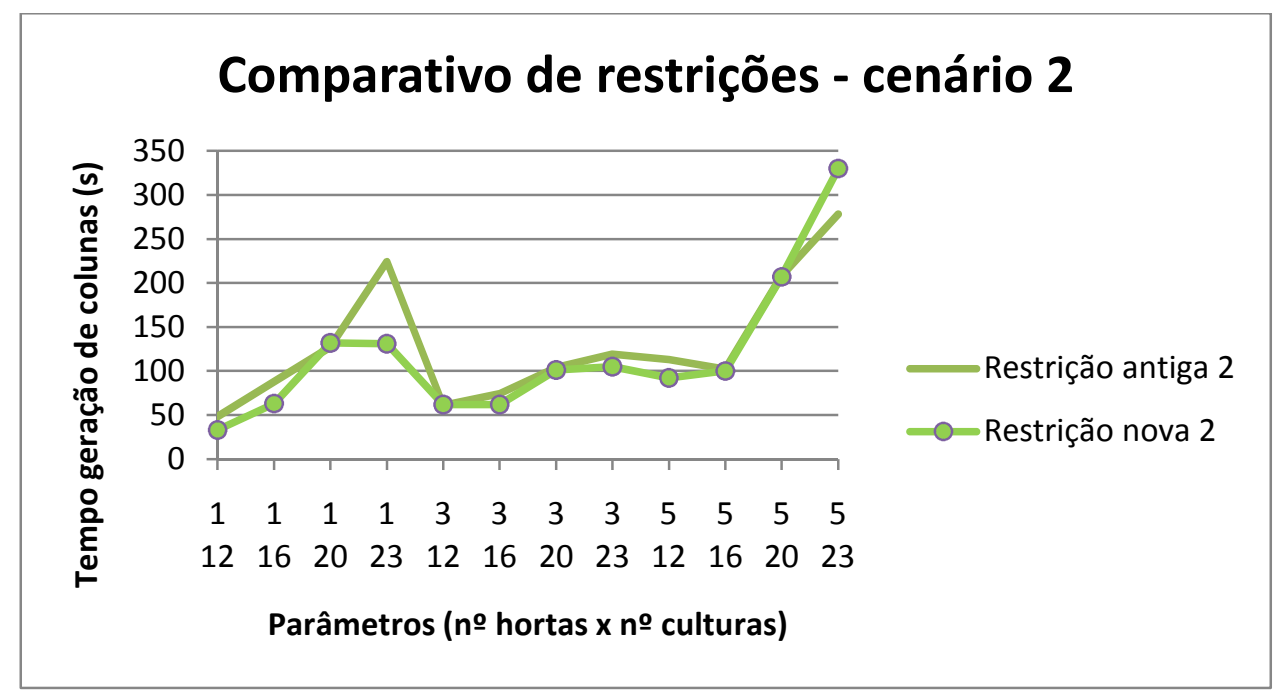

Figura 5.5: Comparativo de tempo para a geração de colunas para cenário de demanda 2

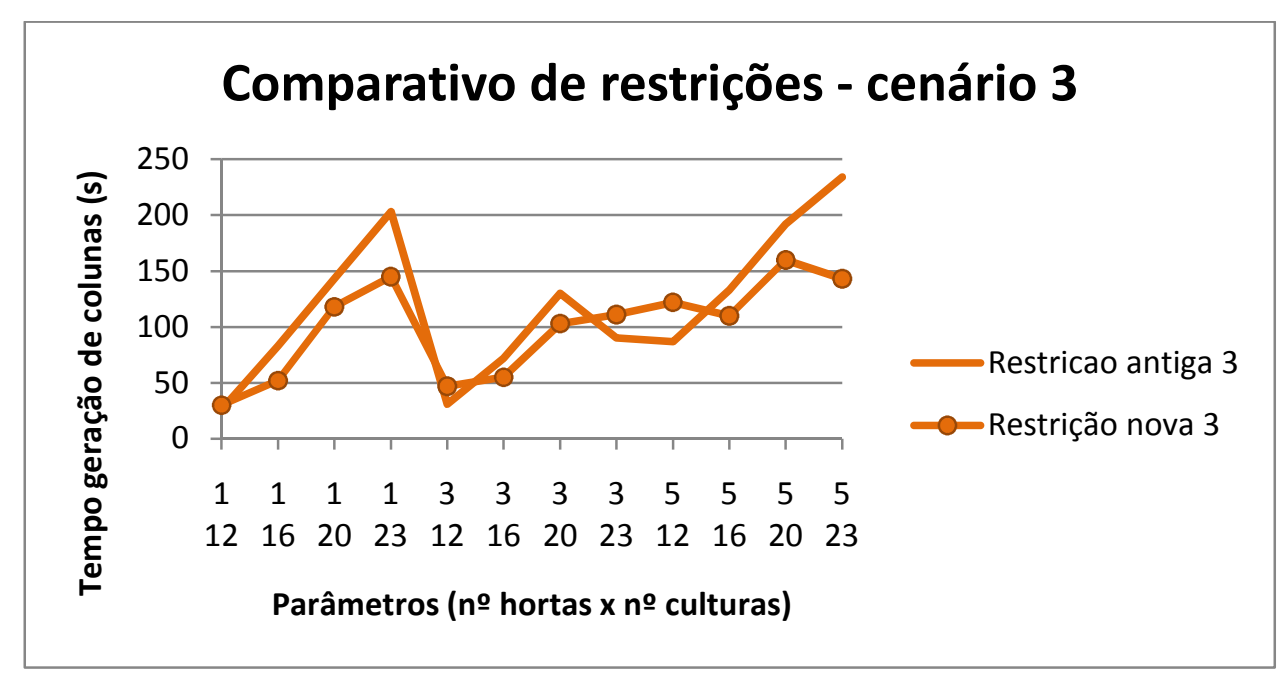

Figura 5.6: Comparativo de tempo para a geração de colunas para cenário de demanda 3

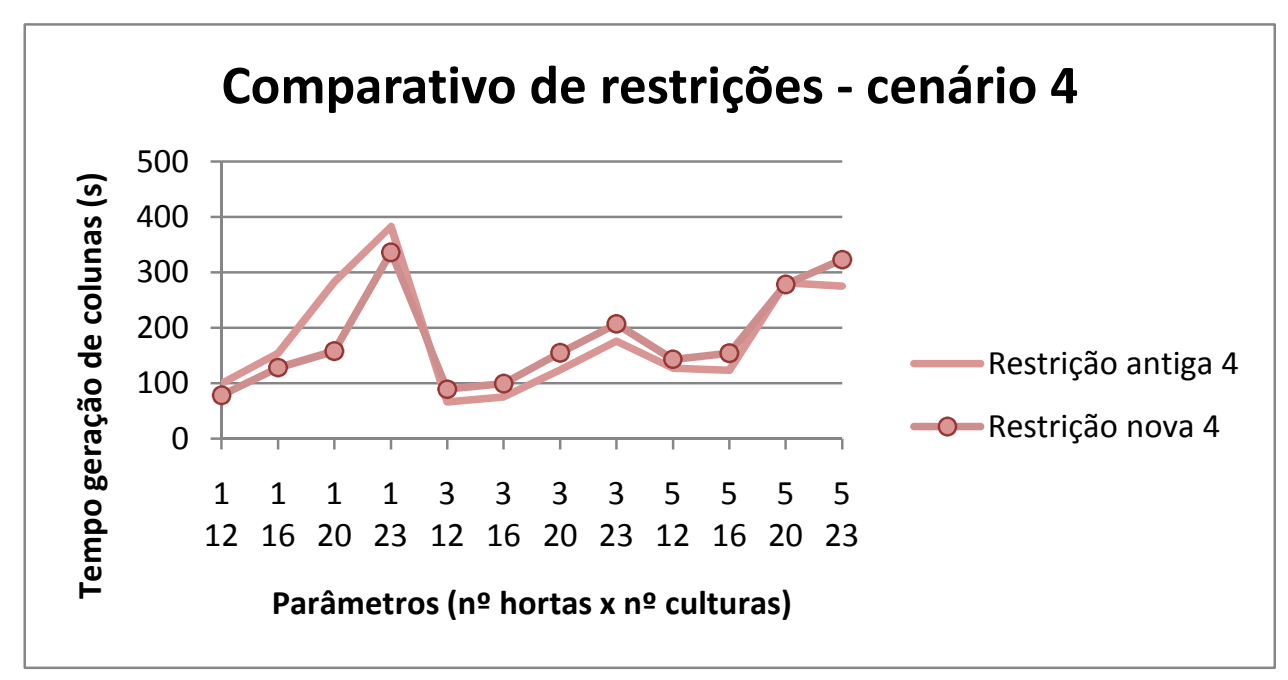

Figura 5.7: Comparativo de tempo para a geração de colunas para cenário de demanda 4 


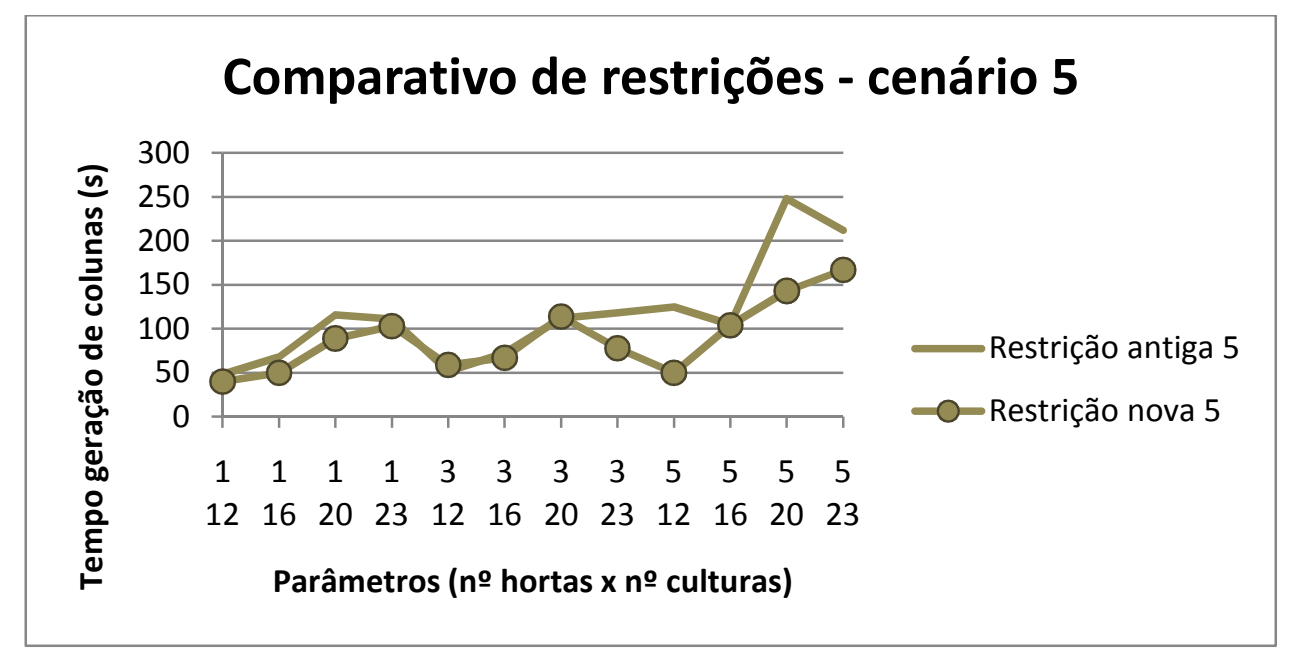

Figura 5.8: Comparativo de tempo para a geração de colunas para cenário de demanda 5

Observamos que, de forma geral, a redução no tempo é presente e, embora não tão significativo, pode chegar a representar até $60 \%$ de redução em uma das instâncias. As variações tendem a ser mais notáveis nas instâncias com mais culturas e que, por sua vez, requereram um tempo computacional total maior: em instâncias com baixo tempo de execução, a redução não aparenta ser tão significativa.

Houve, entretanto, ocorrências em que o segundo conjunto de restrições requereu mais tempo que o primeiro. Essas ocorrências não representam a maioria e, em geral, o tempo extra utilizado não foi de grande impacto. $\mathrm{O}$ quarto cenário de demanda, por sua vez, obteve ganhos e perdas de formas equilibradas (nenhum conjunto de restrição prevaleceu sobre o outro).

Vale ressaltar que em todas as instâncias o valor obtido para a função objetivo na Fase I não se alterava perante a mudança do modelo utilizado, o que comprova que ambos de fato representam o mesmo problema e, portanto, possuem a mesma solução ótima para o problema linear.

Vemos que, em geral, o conjunto de restrições (3.6) substituindo as restrições (3.2) manteve a generalidade do problema e permitiu uma resolução mais rápida do modelo, comprovando que a matriz de coeficientes mais esparsa pôde ser mais bem trabalhada pelo pacote de otimização, mantendo a garantia de otimalidade da geração de colunas. Embora o ganho seja relativamente pequeno nos testes realizados, para instâncias ainda maiores e difíceis, ou métodos que exijam ainda mais iterações, esse ganho pode atingir proporções de grande valia.

Perante o resultado satisfatório obtido, o conjunto de restrições (3.7)-(3.11) foi adotado para todos os testes realizados neste trabalho. 


\subsubsection{TESTES CURVA DE EFICIÊNCIA}

Os resultados descritos na seção 5.1 .2 permitem observar o conflito dos objetivos: para obter mais lucro, é necessária a criação de mais lotes, o que por sua vez torna a administração muito mais complexa. Conforme diferentes pesos eram atribuídos a cada objetivo, o número de lotes variava gradativamente. Mostra-se interessante, como instrumento de apoio à tomada de decisão, a curva de Paretto, a que relaciona o lucro e o número de lotes.

Os testes computacionais realizados para definir uma aproximação da curva de Paretto consistiram em inicialmente resolver uma instância utilizando-se, na Fase II do algoritmo GC-BC, apenas um dos dois objetivos: denotamos lote $e^{f}$ o número de lotes obtidos com a maximização de $f(\lambda)$, e lote ${ }^{g}$ o número de lotes obtidos com a minimização de $g(y)$. Com os dois extremos em mãos, escolhemos o parâmetro lote $e^{\max } \in\left[\operatorname{lote}^{g}\right.$, lote $\left.^{f}\right]$, e assim podemos obter soluções não-dominadas pela resolução do modelo (3.20)-(3.25) com a inclusão da restrição:

$$
\sum_{k=1}^{L} \sum_{s \in S_{k}} y_{k s} \leq \text { lote }^{\max }
$$

Com o objetivo de maximizar $f(\lambda)$ na Fase II do algoritmo, a adição da restrição (5.2) ao modelo (3.20)-(3.25) nos fornecerá o maior lucro possível para o número de lote $^{\max }$ estipulado. As soluções de uma instância com lote ${ }^{\max }$ no intervalo estipulado anteriormente, definem uma curva de Paretto para o problema com os resultados obtidos para cada valor de lote ${ }^{\max }$. A curva será entretanto aproximada, pois as soluções não são necessariamente ótimas, visto que nem todas as colunas são utilizadas.

Devido ao grande número de resoluções necessárias (para cada valor de lote ${ }^{\max }$ no intervalo definido), utilizou-se apenas o cenário de demanda 1 para as diferentes combinações de áreas e culturas, resultando em 12 curvas de Paretto. Os gráficos abaixo representam o valor obtido para a função objetivo para cada valor de lote $^{\max }$ utilizado. Para os intervalos maiores, o valor de $l o t e^{\max }$ foi variado em duas unidades entre um teste e outro. Devido à proximidade dos resultados e para simplicidade de apresentação, os gráficos que exibem as curvas foram divididos conforme o número de culturas de cada instância. O eixo horizontal representa o valor atribuído a lote ${ }^{\max }$, enquanto o eixo 
vertical fornece o valor da função objetivo obtido ao resolver o modelo utilizando o respectivo valor de lote ${ }^{\max }$ na restrição adicional (5.2).

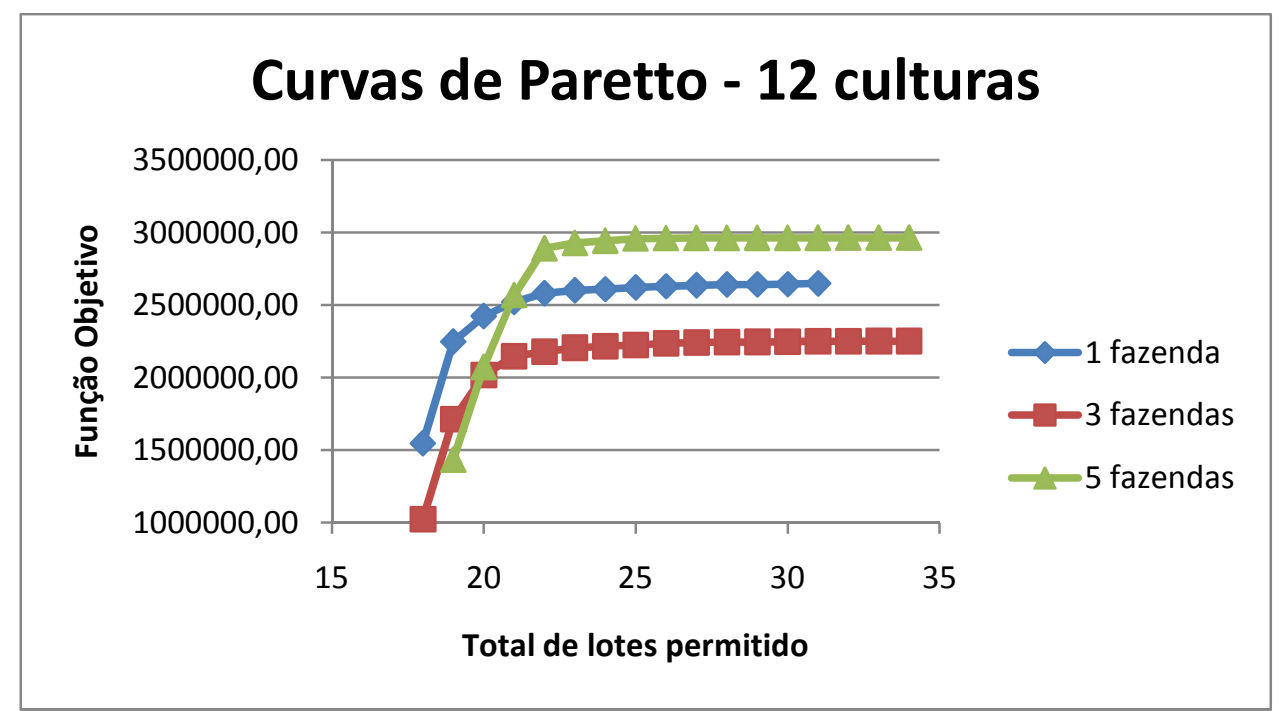

Figura 5.9: Curva de Paretto aproximada para classes de problemas com 12 culturas

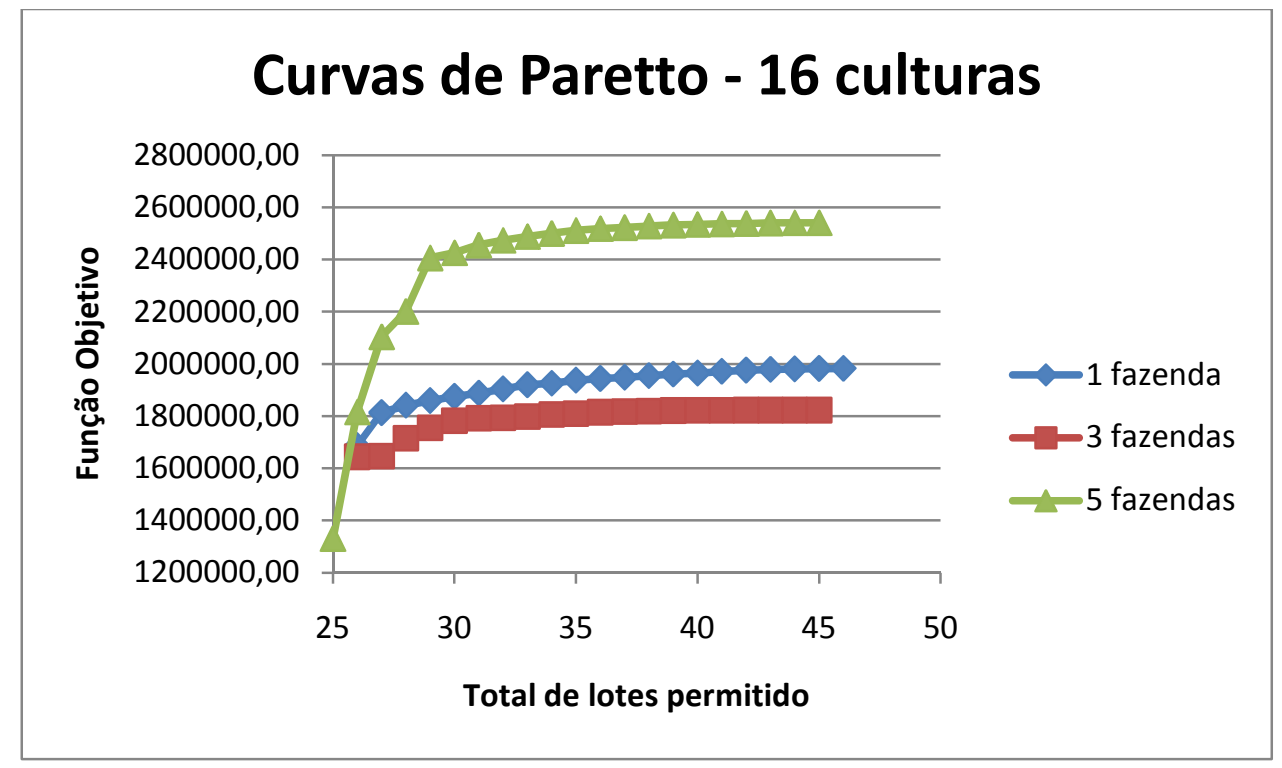

Figura 5.10: Curva de Paretto aproximada para classes de problemas com 16 culturas 


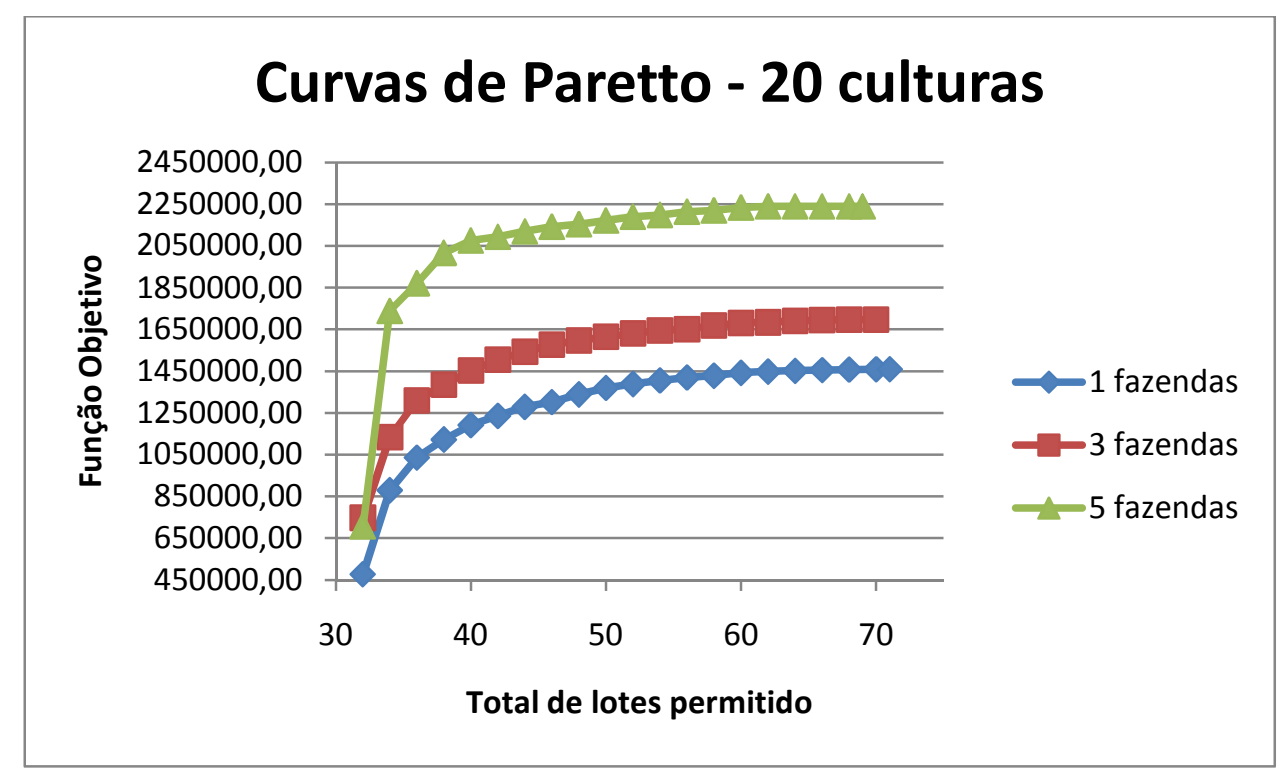

Figura 5.11: Curva de Paretto aproximada para classes de problemas com 20 culturas

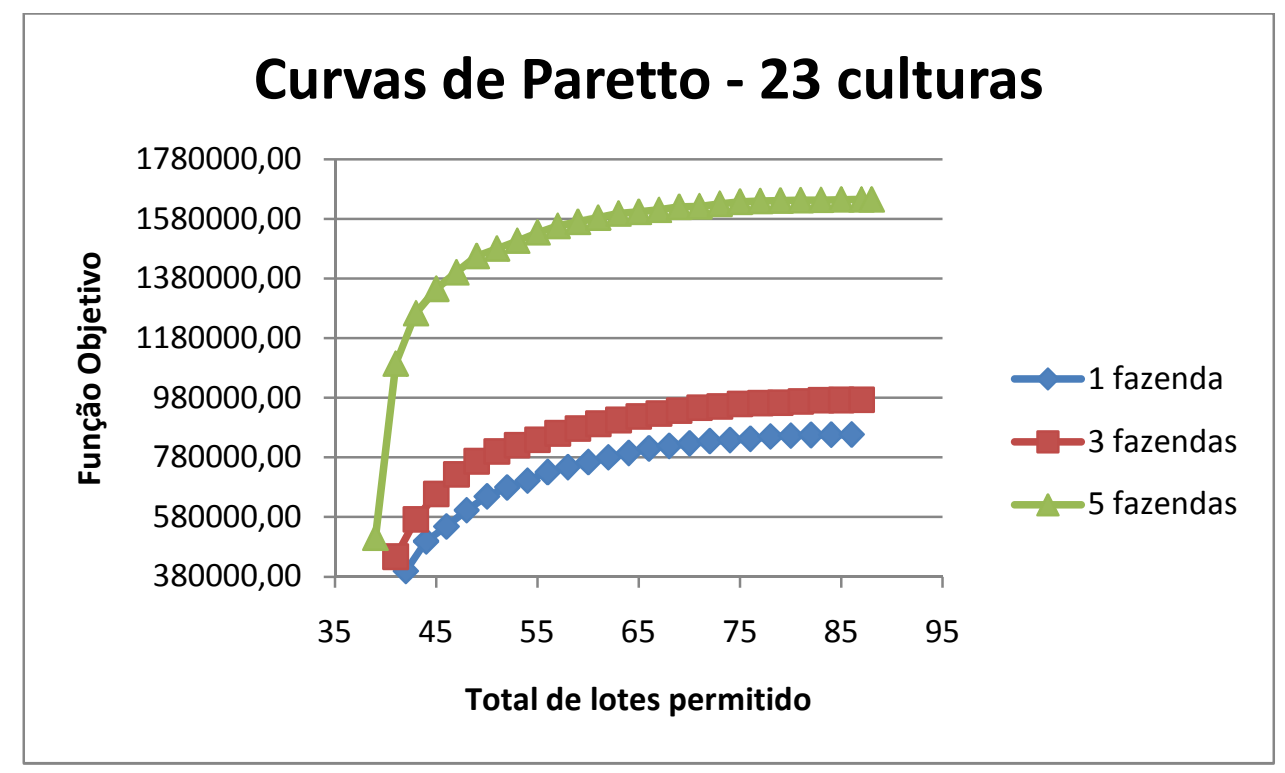

Figura 5.12: Curva de Paretto aproximada para classes de problemas com 23 culturas

Em todos os casos representados pelas Figuras 5.9-5.12, reparamos que valores próximos do mínimo necessário para o cumprimento de demanda resultam em valores muito baixos de lucro: essa discrepância tende a ser mais acentuada conforme o número de áreas de cultivo aumenta. Ainda assim, a queda significativa na função objetivo tende a ocorrer só para valores de lote próximos do mínimo possível, indicando que é possível reduzir ainda mais o número de lotes obtidos pela Fase II do algoritmo convencional (que não busca a reduão do número de lotes) e ainda manter o lucro obtido em bons níveis. 
O tempo computacional de resolução, entretanto, mostrou-se irregular: em geral, o tempo necessário para os valores extremos (próximos do mínimo e máximo) de lote foi baixo, enquanto valores intermediários comumente não conseguiam comprovar a otimalidade dentro do limite estipulado de 3600 segundos. Embora tal limite foi atingido com frequência principalmente nas classes com 20 e 23 culturas, observou-se variações bruscas e intermitentes no tempo computacional.

Concluímos que as curvas de Paretto podem ser de grande auxílio na tomada de decisão, pois é possível reduzir o total de lotes sem grandes perdas no lucro, resultando em uma administração mais fácil e barata. Porém, o intervalo de possíveis soluções pode ser extenso e o custo computacional intermitente em sua resolução pode requerer um tempo muito maior de que se está disposto a investir. Uma alternativa seria definir números de lotes estratégicos para a geração da curva de Paretto, diminuindo o custo computacional total.

\subsubsection{TESTES CRITÉRIO DE PARADA RELAXADO}

Como uma alternativa para agilizar o processo de resolução do algoritmo sem perdas significativas no retorno, usamos uma tolerância $c^{\text {min }}>0$ como critério de parada para a geração de colunas (Fase I da heurística GC-BC): ou seja, o algoritmo para quando os custos relativos $c_{k} \leq c^{\text {min }}$, para todo $k=1, \ldots, L$.

Esta abordagem é feita para avaliar se, em uma ocorrência frequente de valores baixos de $c_{k}$ ao final do algoritmo, obtém-se pouco retorno para a função objetivo. Para evitar que o algoritmo perca muito tempo gerando colunas de baixo retorno, paramos precocemente o processo.

Esta ideia foi aplicada inicialmente por Gilmore e Gomory (1963): no problema de cortes, os autores observaram que em um conjunto de instâncias gerava-se muitos padrões com pouco ganho após um certo tempo. O critério de parada utilizado, entretanto, não foi o custo relativo bruto, e sim a ocorrência consecutiva de 10 gerações que não reduziam o desperdício dos cortes em pelo menos $0,1 \%$. Os resultados obtidos pelos autores foram satisfatórios para o conjunto de instâncias resolvido.

Os testes descritos abaixo foram realizados utilizando-se 3 classes de problemas: para 1, 3 e 5 áreas de plantio, todas com 23 culturas disponíveis. Para cada classe de 
problema aplicou-se 5 cenários de demanda. Em cada teste, o valor de $c^{\text {min }}$ foi variado em 0 (que caracteriza a otimalidade), 1,10 e 50.

As comparações foram feitas em relação ao tempo e valor de função objetivo $f(\lambda)$ obtido pela Fase I do algoritmo para $c^{\min }=0$. Desta forma podemos avaliar o ganho de tempo e quanto isso impacta o lucro.

As tabelas abaixo são compostas pelas colunas Tempo $(s), f_{1}(\lambda)$ e $f_{2}(\lambda)$, que indicam respectivamente o tempo computacional necessário para a conclusão da geração de colunas (Fase I), o valor de função objetivo obtido na Fase I e o valor de função objetivo obtido na Fase II. As linhas que representam $c^{\min }=0$ correspondem à otimalidade. Por facilidade de visualização, as linhas subseqüentes que representam outros valores de $c^{\text {min }}$ possuem os valores representados porcentualmente em relação à linha de $c^{\text {min }}=0$ correspondente.

Tabela 5.9: resultados computacionais para diferentes $c^{\text {min }}$ para o cenário de demanda 1

\begin{tabular}{|c|c|c|c|c|}
\hline hortas & $c^{\min }$ & Tempo(s) & $f_{1}(\lambda)$ & $f_{2}(\lambda)$ \\
\hline \multirow{4}{*}{1} & 0 & 292,00 & 1156875,67 & 1120579,75 \\
\hline & 1 & $-23,63 \%$ & $0,00 \%$ & $0,00 \%$ \\
\hline & 10 & $-27,40 \%$ & $-0,41 \%$ & $-1,91 \%$ \\
\hline & 50 & $-39,38 \%$ & $-3,40 \%$ & $-13,45 \%$ \\
\hline \multirow{4}{*}{3} & 0 & 147,00 & 1047989,23 & 977276,44 \\
\hline & 1 & $-19,73 \%$ & $0,00 \%$ & $0,00 \%$ \\
\hline & 10 & $-28,57 \%$ & $-0,29 \%$ & $-0,80 \%$ \\
\hline & 50 & $-47,62 \%$ & $-4,87 \%$ & $-7,65 \%$ \\
\hline \multirow{4}{*}{5} & 0 & 213,00 & 1932003,46 & 1883068,76 \\
\hline & 1 & $-6,10 \%$ & $-0,08 \%$ & $-0,15 \%$ \\
\hline & 10 & $-33,80 \%$ & $-0,50 \%$ & $-1,23 \%$ \\
\hline & 50 & $-49,30 \%$ & $-3,30 \%$ & $-5,23 \%$ \\
\hline
\end{tabular}

Tabela 5.10: resultados computacionais para diferentes $c^{\text {min }}$ para o cenário de demanda 2

\begin{tabular}{|c|c|ccc|}
\hline \multicolumn{1}{|c}{ hortas } & $c^{\min }$ & Tempo(s) & $\boldsymbol{f}_{1}(\boldsymbol{\lambda})$ & $\boldsymbol{f}_{2}(\boldsymbol{\lambda})$ \\
\hline \multirow{4}{*}{1} & 0 & 134,00 & 2904871,77 & 2710312,33 \\
& 1 & $-1,49 \%$ & $0,00 \%$ & $0,00 \%$ \\
& 10 & $-19,40 \%$ & $-0,13 \%$ & $-0,11 \%$ \\
& 50 & $-27,61 \%$ & $-0,28 \%$ & $-1,15 \%$ \\
\hline \multirow{4}{*}{3} & 0 & 106,00 & 2444687,87 & 2361846,42 \\
& 1 & $-3,77 \%$ & $0,00 \%$ & $-0,22 \%$ \\
& 10 & $-20,75 \%$ & $-0,44 \%$ & $-0,73 \%$ \\
& 50 & $-55,66 \%$ & $-4,18 \%$ & $-4,82 \%$ \\
\hline
\end{tabular}




\begin{tabular}{|c|c|ccc|}
\hline \multirow{5}{*}{5} & 0 & 252,00 & 3077396,00 & 2865280,42 \\
& 1 & $-15,87 \%$ & $-0,01 \%$ & $-0,09 \%$ \\
& 10 & $-48,81 \%$ & $-0,12 \%$ & $-0,24 \%$ \\
& 50 & $-66,67 \%$ & $-2,23 \%$ & $-2,98 \%$ \\
\hline
\end{tabular}

Tabela 5.11: resultados computacionais para diferentes $c^{\text {min }}$ para o cenário de demanda 3

\begin{tabular}{|c|c|c|c|c|}
\hline hortas & $c^{\min }$ & Tempo(s) & $f_{1}(\lambda)$ & $f_{2}(\lambda)$ \\
\hline \multirow{4}{*}{1} & 0 & 170,00 & 3410402,34 & 3203864,68 \\
\hline & 1 & $-4,12 \%$ & $0,00 \%$ & $0,00 \%$ \\
\hline & 10 & $-17,06 \%$ & $-0,07 \%$ & $-0,26 \%$ \\
\hline & 50 & $-23,53 \%$ & $-0,24 \%$ & $-0,96 \%$ \\
\hline \multirow{4}{*}{3} & 0 & 112,00 & 2616609,67 & 2518966,17 \\
\hline & 1 & $-10,71 \%$ & $0,00 \%$ & $0,00 \%$ \\
\hline & 10 & $-24,11 \%$ & $-0,74 \%$ & $-0,64 \%$ \\
\hline & 50 & $-65,18 \%$ & $-2,31 \%$ & $-2,53 \%$ \\
\hline \multirow{4}{*}{5} & 0 & 155,00 & 3398311,09 & 3217143,29 \\
\hline & 1 & $-25,16 \%$ & $0,00 \%$ & $0,00 \%$ \\
\hline & 10 & $-31,61 \%$ & $-0,10 \%$ & $-0,39 \%$ \\
\hline & 50 & $-70,32 \%$ & $-0,98 \%$ & $-2,81 \%$ \\
\hline
\end{tabular}

Tabela 5.12: resultados computacionais para diferentes $c^{\text {min }}$ para o cenário de demanda 4

\begin{tabular}{|c|c|c|c|c|}
\hline hortas & $c^{\min }$ & Tempo(s) & $f_{1}(\lambda)$ & $f_{2}(\lambda)$ \\
\hline \multirow{4}{*}{1} & 0 & 349,00 & 3273730,05 & 2921705,53 \\
\hline & 1 & $-0,57 \%$ & $0,00 \%$ & $0,00 \%$ \\
\hline & 10 & $-17,48 \%$ & $-0,04 \%$ & $-0,63 \%$ \\
\hline & 50 & $-41,26 \%$ & $-0,24 \%$ & $-1,27 \%$ \\
\hline \multirow{4}{*}{3} & 0 & 208,00 & 2504727,03 & 2272860,89 \\
\hline & 1 & $-3,37 \%$ & $0,00 \%$ & $0,00 \%$ \\
\hline & 10 & $-28,37 \%$ & $-0,71 \%$ & $-1,11 \%$ \\
\hline & 50 & $-65,87 \%$ & $-1,87 \%$ & $-3,53 \%$ \\
\hline \multirow{4}{*}{5} & 0 & 302,00 & 3383372,66 & 3062461,18 \\
\hline & 1 & $-4,64 \%$ & $0,00 \%$ & $0,16 \%$ \\
\hline & 10 & $-46,03 \%$ & $-0,12 \%$ & $-0,59 \%$ \\
\hline & 50 & $-64,90 \%$ & $-0,74 \%$ & $-2,25 \%$ \\
\hline
\end{tabular}


Tabela 5.13: resultados computacionais para diferentes $c^{\text {min }}$ para o cenário de demanda 5

\begin{tabular}{|c|c|c|c|c|}
\hline hortas & $c^{\min }$ & Tempo(s) & $f_{1}(\lambda)$ & $f_{2}(\lambda)$ \\
\hline \multirow{4}{*}{1} & 0 & 84,00 & 3561636,11 & 3363829,00 \\
\hline & 1 & $-13,10 \%$ & $0,00 \%$ & $0,00 \%$ \\
\hline & 10 & $-8,33 \%$ & $-0,01 \%$ & $-0,01 \%$ \\
\hline & 50 & $-34,52 \%$ & $-0,11 \%$ & $-0,48 \%$ \\
\hline \multirow{4}{*}{3} & 0 & 73,00 & 2673615,83 & 2605837,23 \\
\hline & 1 & $-13,70 \%$ & $0,00 \%$ & $0,00 \%$ \\
\hline & 10 & $-34,25 \%$ & $-0,48 \%$ & $-0,56 \%$ \\
\hline & 50 & $-60,27 \%$ & $-3,28 \%$ & $-3,46 \%$ \\
\hline \multirow{4}{*}{5} & 0 & 142,00 & 3520000,31 & 3369548,30 \\
\hline & 1 & $-17,61 \%$ & $0,00 \%$ & $0,03 \%$ \\
\hline & 10 & $-46,48 \%$ & $-0,04 \%$ & $-0,09 \%$ \\
\hline & 50 & $-52,82 \%$ & $-0,85 \%$ & $-1,74 \%$ \\
\hline
\end{tabular}

Não avaliamos aqui o tempo necessário para a resolução da Fase II, pois a redução obtida é sempre proporcional à redução referente à Fase I, além de o tempo computacional necessário ser, em sua maioria, muito baixo, de forma que a redução não é significativa. Em nenhuma instância houve não-atendimento de demanda devido ao término precoce da geração de colunas.

Em todos os testes, a redução do lucro na Fase II é sempre maior que na Fase I. Podemos observar que para valores de $c^{\text {min }}=1$, há uma pequena redução no tempo, porém o lucro obtido manteve-se o mesmo na maior parte das instâncias testadas. Isso indica que raramente colunas geradas com custos menores que 1 são utilizadas na solução final. $\mathrm{O}$ mesmo pode ser dito para os testes de $c^{\text {min }}=10$, havendo uma redução mais significativa no tempo de execução da geração de colunas, mas com reduções de lucro usualmente menores que $1 \%$ mesmo para a Fase II.

Nos testes referentes a $c^{\text {min }}=50$, a redução de tempo foi grande, chegando até a $70 \%$ em uma das instâncias. Porém, este valor mais alto de $c^{\text {min }}$ acarretou em uma redução mais acentuada nos lucros, principalmente na Fase II. Embora a redução fique em torno dos $3 \%$, os valores altos de função objetivo são significativos em valores absolutos.

Embora a redução porcentual de tempo perante redução de lucro seja atrativa, vale lembrar que mesmo sem estas considerações o tempo computacional é baixo em todas as instâncias, tratando-se de um planejamento anual. A análise necessária para avaliar se a redução obtida é compensada provavelmente não justificaria tal 
simplificação. Entretanto, se tais proporções forem mantidas em instâncias muito maiores e de difícil resolução, a redução de tempo pode ser útil, especialmente se forem necessárias múltiplas resoluções.

\subsubsection{TESTES SIMETRIA}

Durante os testes da seção 5.1.2, observou-se a ocorrência de simetria nas instâncias verificadas, o que ocasionava em aumento do tempo computacional de resolução do modelo. Para melhor avaliar este impacto, propomos um conjunto de testes que abordasse este ponto, comparando instâncias normais com suas versões com simetria imposta.

Os testes realizados consistiram em rodar um conjunto de 5 cenários de demanda, dividido em 8 classes de problema: combinações de 3 ou 5 áreas de plantio com os diferentes produtividades para as culturas usados nos testes anteriores (as classes de problema que consideram uma única horta não possuem simetria). Na sequência repetem-se os testes, de forma que todas as áreas possuam a mesma produtividade da primeira para todas as culturas, além de remover qualquer proibição de plantio: desta forma, todas as áreas de plantio da instância testada possuem as mesmas características, impondo simetria ao problema.

Os gráficos abaixo mostram o tempo computacional necessário para cada cenário de demanda, tanto para a geração de colunas referente à Fase I (Tempo GC) como para a resolução do problema inteiro-misto referente à Fase II (Tempo BC). As curvas acrescidas de "Sim." referem-se às respectivas fases com simetria forçada.

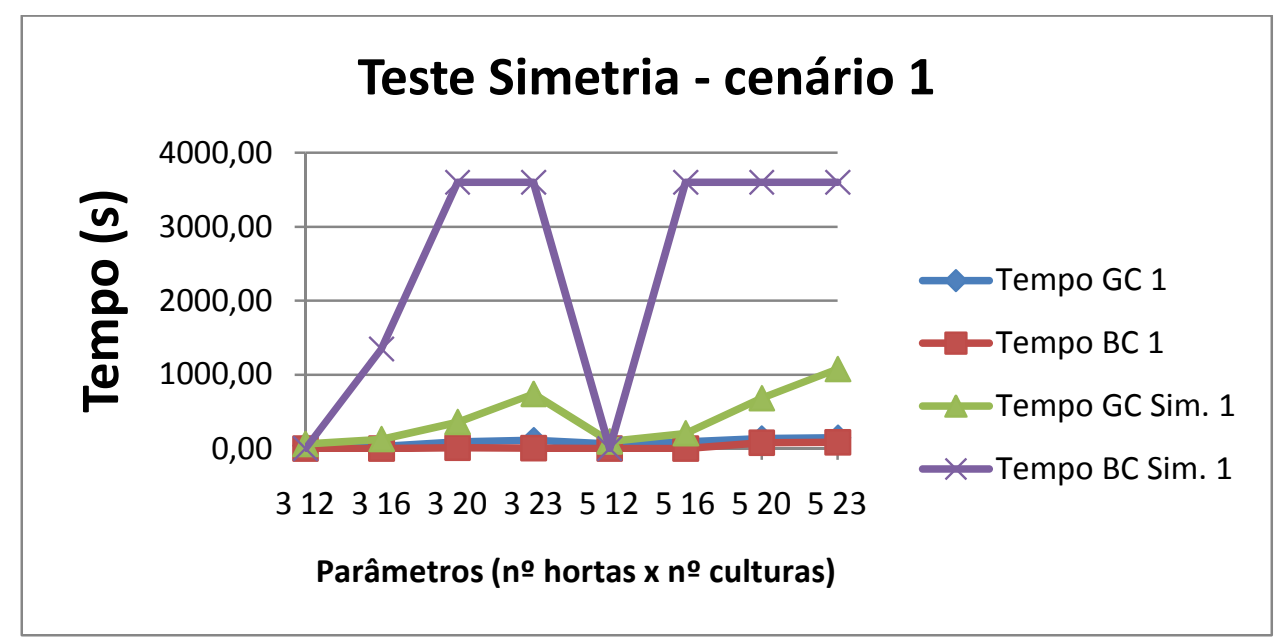

Figura 5.13: Tempo computacional com simetria imposta para cenário de demanda 1 


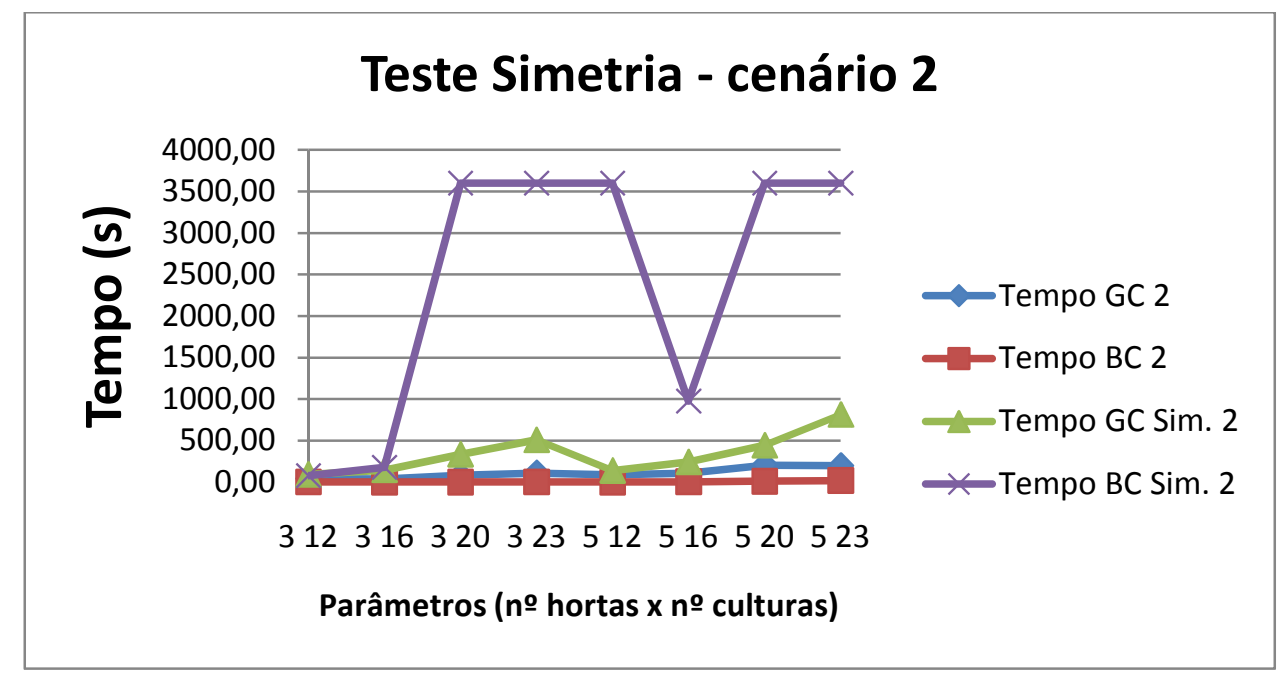

Figura 5.14: Tempo computacional com simetria imposta para cenário de demanda 2

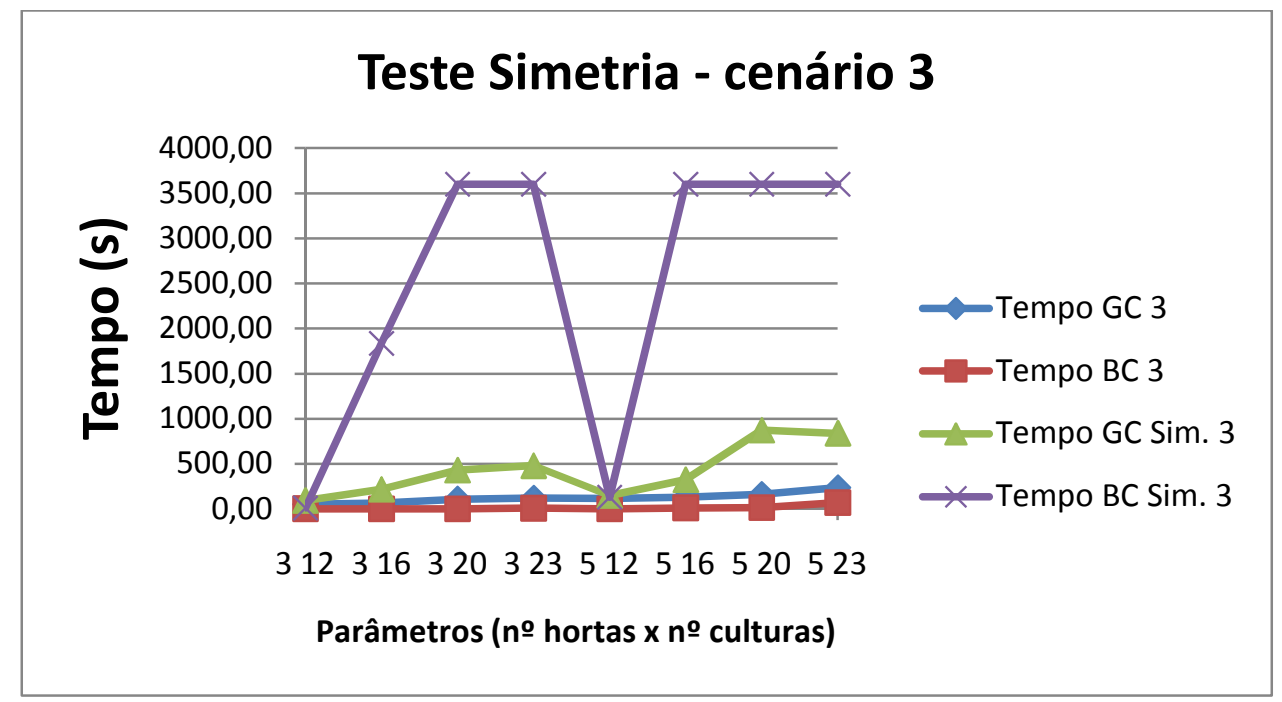

Figura 5.15: Tempo computacional com simetria imposta para cenário de demanda 3

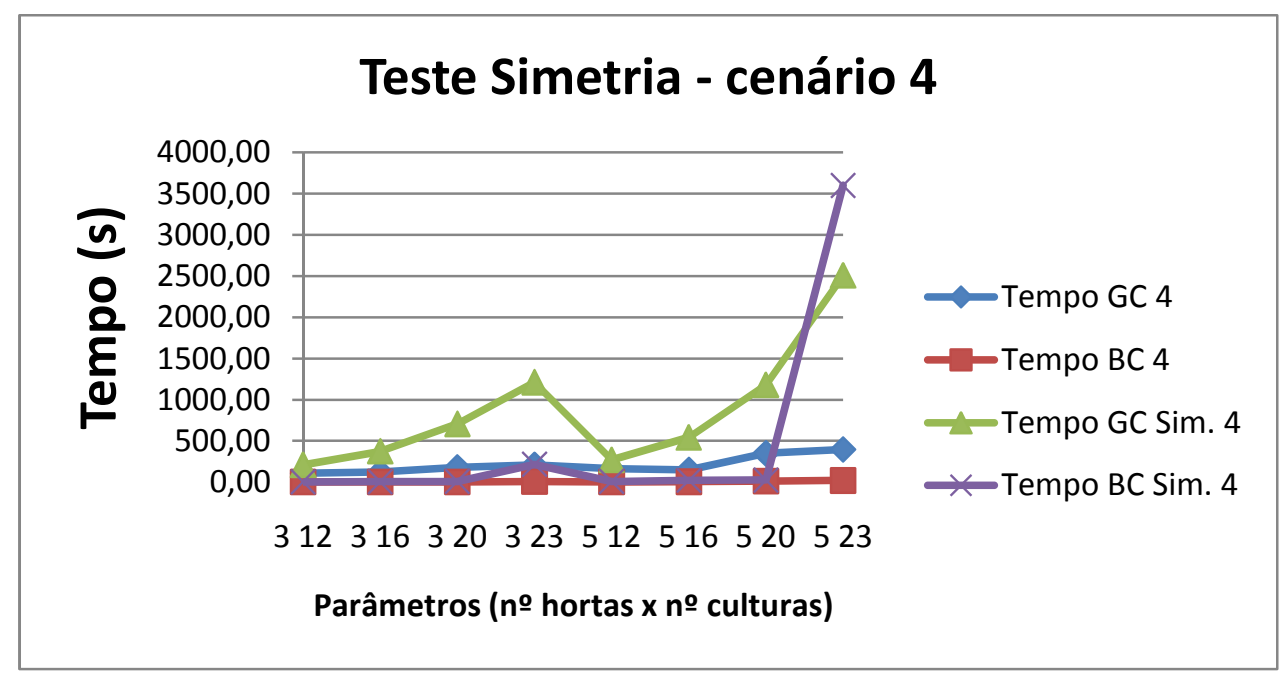

Figura 5.16: Tempo computacional com simetria imposta para cenário de demanda 4 


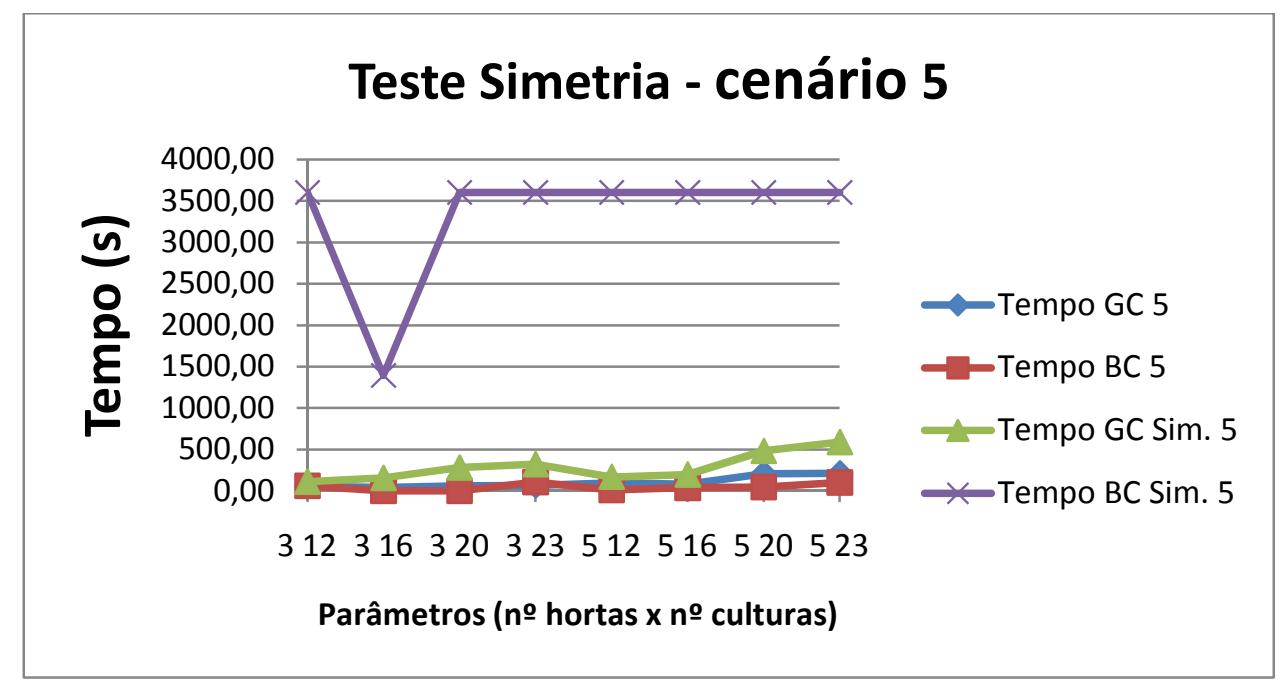

Figura 5.17: Tempo computacional com simetria imposta para cenário de demanda 5

Notamos em todos os gráficos que o aumento do número de culturas leva o tempo computacional de execução do branch-and-cut ao limite de 3600 segundos facilmente. O cenário de demanda 5 representado pela Figura 5.17, por sua vez, possui uma única combinação de dados que não chegou neste limite. O cenário 4, entretanto, apresentou dificuldades apenas na última classe, como observado na Figura 5.16. Nos casos em que o limite não era atingido, a resolução foi rápida, com poucos casos de tempo médio de execução (entre 1000 e 1500 segundos). Nos cenários 1, 2 e 3 o limite sempre foi alcançado nas classes de problemas com mais de 20 culturas, eventualmente atingindo este limite também nas classes de 12 e 16 culturas.

Em contrapartida, o cenário 4 mostrou mais explicitamente o aumento do tempo computacional necessário para a geração de colunas: houve classes de problemas para as quais o tempo foi até 5 vezes maior. Embora a visualização não seja tão clara, podemos observar que o aumento de tempo na geração de colunas ocorre em todos os testes e tende a ser proporcional ao número de áreas de cultivo consideradas.

De forma geral, o problema inteiro misto para as instâncias com simetria forçada ainda é resolvido rapidamente nas instâncias menores, mas sua dificuldade aumenta exponencialmente nas instâncias médias e grandes, atingindo facilmente o limite de 3600 segundos para a sua execução na Fase II do algoritmo.

A simetria também pôde ser observada pelo número de colunas geradas, que em todos os casos o total de colunas era sempre maior que o total obtido pelas respectivas instâncias para uma única área de cultivo, seguindo novamente a proporção do número de hortas do problema. Isso é reflexo de os subproblemas obterem as mesmas 
informações para cada fazenda durante o processo de geração de colunas em cada iteração, resultando em colunas idênticas.

É importante ressaltar que os valores obtidos na geração de colunas para a função objetivo das instâncias com simetria forçada foram sempre iguais aos valores obtidos ao se rodar as respectivas instâncias com uma única área de plantio: ou seja, o valor de $f(\lambda)$ para um cenário de demanda aplicado a uma classe de problema com 1 área de cultivo e 20 culturas e aplicado a uma classe com 3 áreas de cultivo e 20 culturas eram iguais. Tal resultado era esperado, visto que as áreas de cultivo são idênticas e a área total é a mesma, o que também comprova que é possível tratar áreas com as mesmas características como uma única região, evitando a simetria e toda a dificuldade computacional envolvida, agilizando de forma significativa o processo de resolução e adquirindo o mesmo resultado.

\subsubsection{TESTES LOTE MÍNIMO}

Um parâmetro de importância no modelo utilizado, que refletirá diretamente nos resultados práticos obtidos, é o tamanho mínimo que um lote deverá assumir na solução final, representado por $\lambda^{\min }$. Este valor traduz diretamente a mão-de-obra envolvida com a separação da área de cultivo de cada horta e, portanto, deve ser avaliado com cautela antes de ser definido.

No modelo utilizado neste trabalho, o valor de $\lambda^{\text {min }}$ é o mesmo para todas as áreas de plantio. Pode-se definir diferentes valores para cada área, respeitando as condições de cada agricultor, porém manteremos um valor igual para todas as áreas nos testes realizados nesta seção.

Os testes realizados previamente consideram $\lambda^{\text {min }}=100$. Para analisar os impactos causados pela mudança deste valor, verificamos 3 classes de problemas, que variam em número de áreas de cultivo (1, 3 e 5 áreas), todas com 23 culturas disponíveis para plantio, para cada qual verificamos os valores $\lambda^{\text {min }}=50,100,150 \mathrm{e}$ 200. Para estas 12 classes de problemas, aplicamos 5 cenários de demanda diferentes.

O gráfico abaixo representa a redução porcentual de lucro que ocorre na Fase II do algoritmo GC-BC em relação à Fase I, a qual não possui restrições de lote mínimo. O eixo horizontal representa as 12 classes de problemas resolvidos, e cada curva representa um cenário de demanda diferente. 


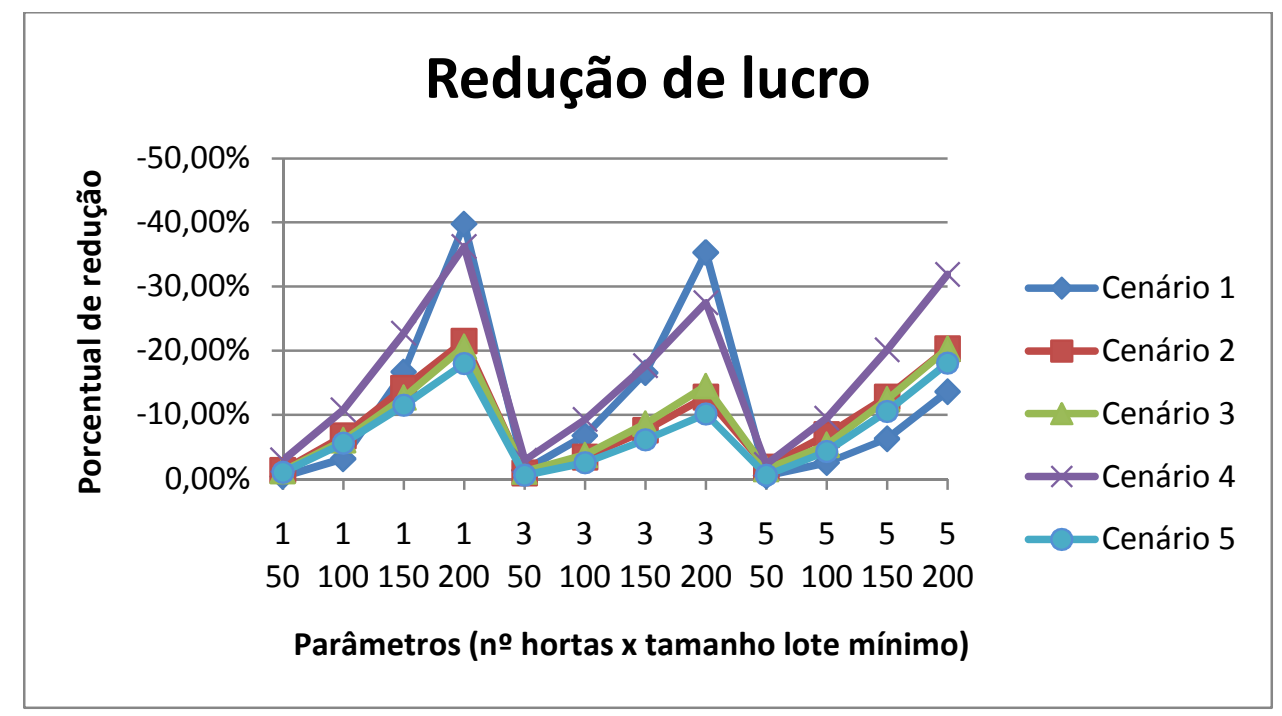

Figura 5.18: Redução de lucro para diferentes valores de lote mínimo

Observamos que, independente do cenário de demanda, o comportamento é o mesmo e notamos que é dependente apenas do valor de $\lambda^{\text {min }}$, e o número de áreas de cultivo não trouxe nenhuma mudança significativa nos valores obtidos. A perda de lucro para $\lambda^{\text {min }}=50$ não é muito menor que o perda que ocorre no valor padrão $\lambda^{\text {min }}=100$ que foi utilizado previamente. Para $\lambda^{\text {min }}=150$, entretanto, essa porcentagem é claramente maior, representando mais que o dobro na maioria dos casos. Com o valor ainda maior de $\lambda^{\text {min }}=200$, a perda atinge grandes escalas, entre $30 \%$ e $40 \%$. Nenhuma classe verificada, por sua vez, tornou-se infactível com o aumento de $\lambda^{\min }$, o que caracteriza que a área de cultivo disponível era suficiente para um valor alto de lote mínimo.

O gráfico abaixo representa o tempo computacional referente à Fase II do algoritmo GC-BC para as instâncias verificadas.

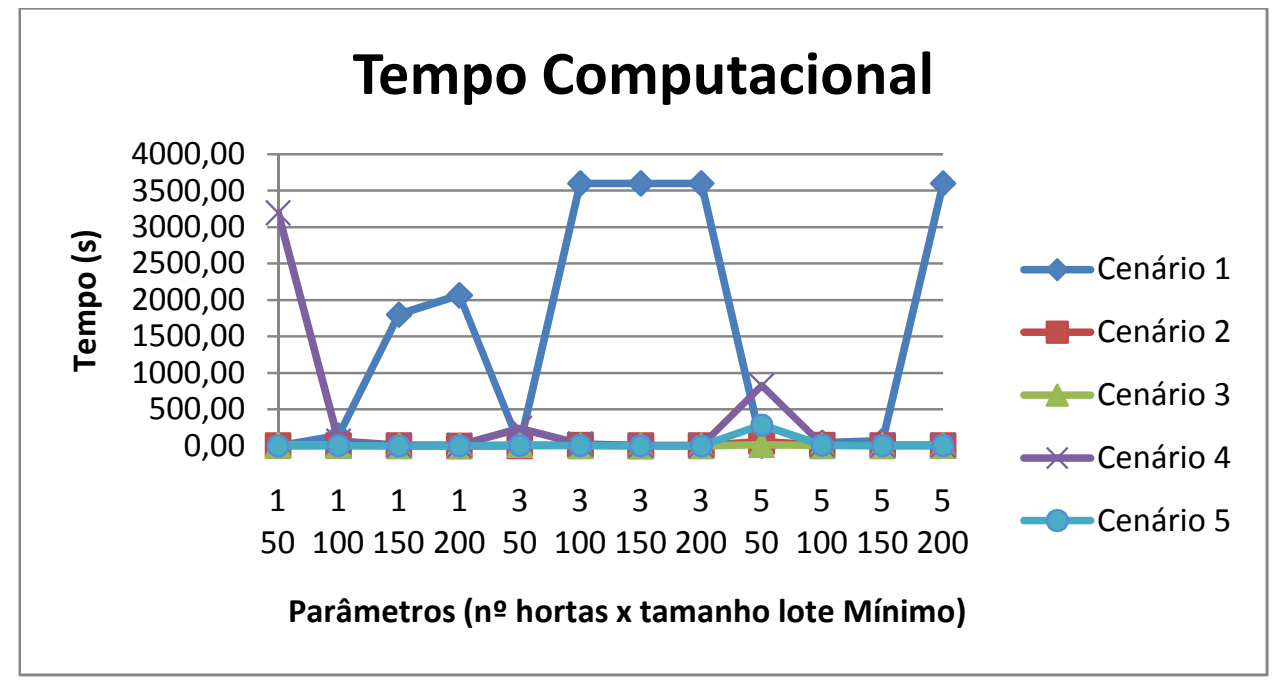

Figura 5.19: tempo computacional para diferentes valores de lote mínimo 
O tempo computacional foi baixo na grande maioria dos casos verificados. Apenas o cenário de demanda 1 teve uma dificuldade constante, excedendo o limite de execução de 3600 segundos em quatro instâncias, cujos gaps foram 0,93\%, 2,64\%, $11,91 \%$ e $1,11 \%$.

Com exceção do primeiro cenário de demanda, as classes de problemas com $\lambda^{\min }$ $=50$ foram as que apresentaram um pequeno aumento no tempo computacional de resolução. Embora esse aumento só se mostrou significativo no cenário de demanda 4, é possível observá-lo nos demais cenários.

Concluimos que o aumento de $\lambda^{\min }$ só resulta em dificuldades significativas se a área total de cultivo disponível não oferecer uma "folga" suficiente para trabalhar com esta mudança. $\mathrm{O}$ valor padrão de 100 usado em todos os testes mostra-se adequado para aplicações práticas, visto que as hortas pertencem a pequenos agricultores, com área de cultivo limitada. Os resultados indicam que valores diferentes de $\lambda^{\text {min }}$ para cada horta provavelmente podem ser utilizados sem perda de generalidade nem comprometer a capacidade de resolução geral do modelo. 


\subsection{TESTES HEURÍSTICA LOTE FIXO}

Os testes referentes à Heurística Lote Fixo são apresentados a seguir. A princípio descrevemos os resultados obtidos para o algoritmo com o critério 1 de seleção de variável apresentados na Seção 4.2 e na sequência discutimos e avaliamos mudanças neste critério de escolha aplicado em cada iteração.

Nos testes realizados, são consideradas tolerâncias relativas aos valores proporcionais de perda (conforme discutido na Seção 4.2). Ambas as tolerâncias na função objetivo e não-atendimento de demanda foram fixadas em $0,1 \%$.

Ratificando, o algoritmo consiste em selecionar variáveis que assumirão um valor igual a $\lambda^{\text {min }}$ e a demanda atendida por esta seleção é atualizada. O modelo é resolvido novamente com a demanda e área residuais. $\mathrm{O}$ critério de escolha de variável a ser fixada a cada iteração é um fator decisivo e os testes realizados avaliam diferentes critérios.

Para posterior comparação entre os processos de fixação de variáveis, todos os testes realizados utilizam 12 classes de problemas com os mesmos 5 cenários de demanda. Desta forma podemos comparar os resultados obtidos para cada método.

Os diferentes processos de seleção de fixação das variáveis são detalhados em cada seção.

\subsubsection{TESTES FIXA LOTE PEQUENO}

Os primeiros testes realizados para a Heurística Lote Fixo consideram o critério 1 de seleção de variável a ser fixada. Por facilidade de leitura, repetimos este critério:

\section{Critério 1 de seleção de variável a ser fixada para a Heurística Lote Fixo}

1. Seja $V=\left\{(k, s) \mid \lambda_{k s}<\lambda^{\min } e(k, s) \notin F\right\}$.

2. Determine $(k, s) \in V$ tal que $\bar{\lambda}_{k s}=\operatorname{Max}\left\{\lambda_{k s} \mid(k, s) \in V\right\}$.

O conjunto $V$ é o conjunto das variáveis candidatas em cada iteração e $F$ é o conjunto das variáveis que já foram fixadas em alguma iteração prévia do algoritmo. A cada iteração, todas as variáveis menores que $\lambda^{\text {min }}$ e que ainda não foram selecionadas são candidatas. Deste conjunto, aquela que possuir o maior valor (portanto, o valor mais 
próximo de $\lambda^{\min }$ ) será selecionada. A demanda e área disponível são atualizadas conforme esta seleção.

Variáveis que pertencem ao conjunto $F$ não são mais candidatas a serem fixadas em $\lambda^{\text {min }}$, pois estas assumem um valor maior que $\lambda^{\text {min }}$ na solução do problema. Por exemplo, seja $\lambda^{\text {min }}=100$ e uma variável qualquer $\lambda=50$ em uma dada iteração, se $\lambda \in F$ a solução respectiva seria $\lambda=\lambda^{\text {min }}+50=150$. Isso implica que toda variável pertencente ao conjunto $\mathrm{F}$ possuirá um valor maior ou igual a $\lambda^{\text {min }}$, e portanto não é passível de escolha para fixação em uma iteração posterior.

O conceito por trás deste critério de seleção é aproximar para $\lambda^{\min }$ as variáveis mais próximas deste valor, presumindo que esta aproximação não deve acarretar em grandes variações nas áreas das outras rotações e em iterações posteriores possam compensar a produção de outros lotes pequenos, gerando uma solução apenas com lotes maiores, de mais fácil administração e manuseio.

Os testes realizados consistem da execução da Fase I e Fase II do algoritmo GCBC, seguidos da execução do algoritmo Lote Fixo, o qual é iniciado com as colunas geradas previamente e, finalmente, o modelo é resolvido por um branch-and-cut com todas as colunas obtidas até então: desta forma uma comparação completa pode ser feita. Como o algoritmo Lote Fixo atualiza a demanda a ser atendida e a área disponível iterativamente, estes valores são redefinidos em seus valores iniciais quando o modelo é resolvido por branch-and-cut na última etapa. O objetivo é avaliar o comportamento da resolução exata do modelo com as colunas adicionais obtidas pelo algoritmo Lote Fixo, tanto em tempo computacional como valor de função objetivo.

O gráfico abaixo informa o tempo computacional total de execução do modelo (algoritmo GC-BC, algoritmo Lote Fixo com as colunas geradas pelo primeiro, e resolução exata com todas as colunas obtidas por ambos os algoritmos), considerando o primeiro critério de escolha de variável para o algoritmo Lote Fixo. 


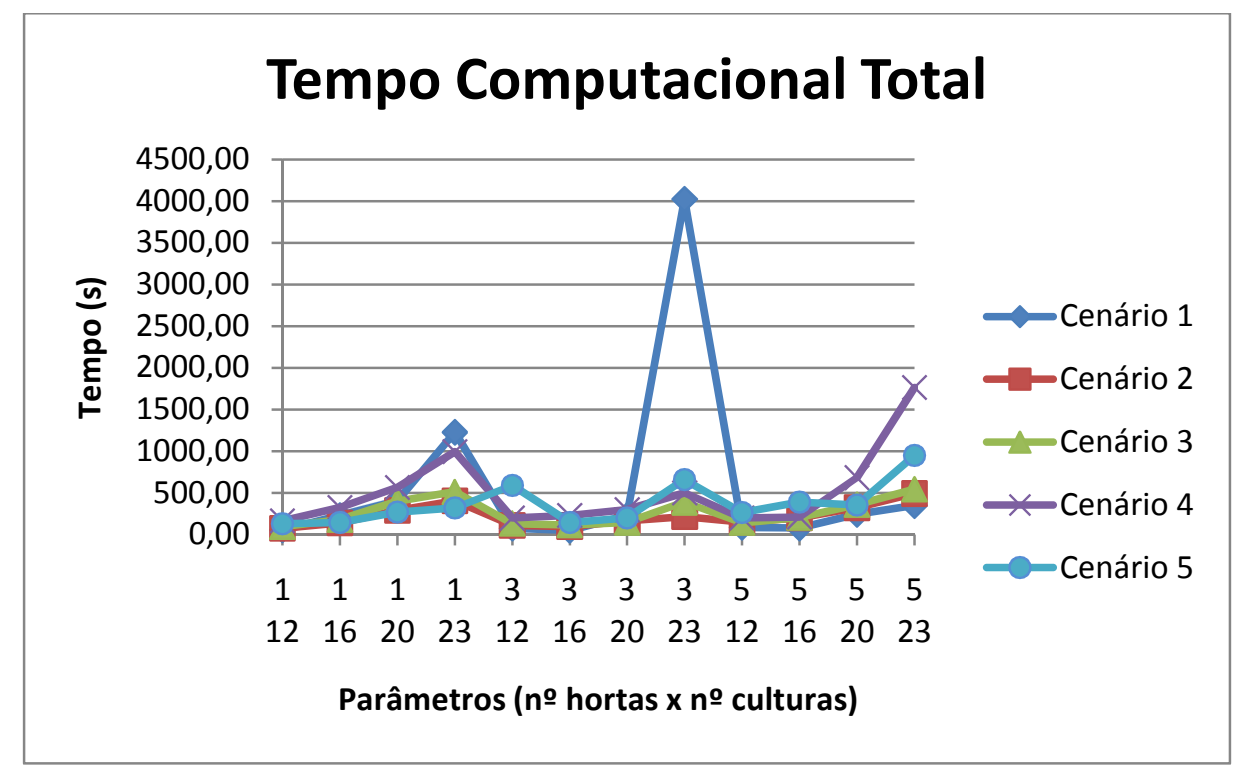

Figura 5.20: tempo computacional total com o critério 1 do algoritmo Lote Fixo

Observamos que o tempo computacional total manteve-se suficientemente baixo, com exceção da classe de problema com 3 áreas de cultivo e 23 culturas para o primeiro cenário de demanda, o qual atingiu o tempo limite de execução de 3600 segundos durante a solução exata após o algoritmo Lote Fixo. Tirando esta ocorrência e o último teste para o cenário de demanda 4 , todos os testes requeriram menos que 1500 segundos ao todo, o que é plenamente viável para um planejamento anual.

Para efeito de comparação, o gráfico abaixo apresenta a redução de lucro obtida na Fase II em relação à solução relaxada da Fase I do algoritmo GC-BC inicial. Este gráfico representa o resultado dos 5 cenários de demanda utilizados para as 12 classes de problemas em todos os testes e servirá de referência para comparações posteriores.

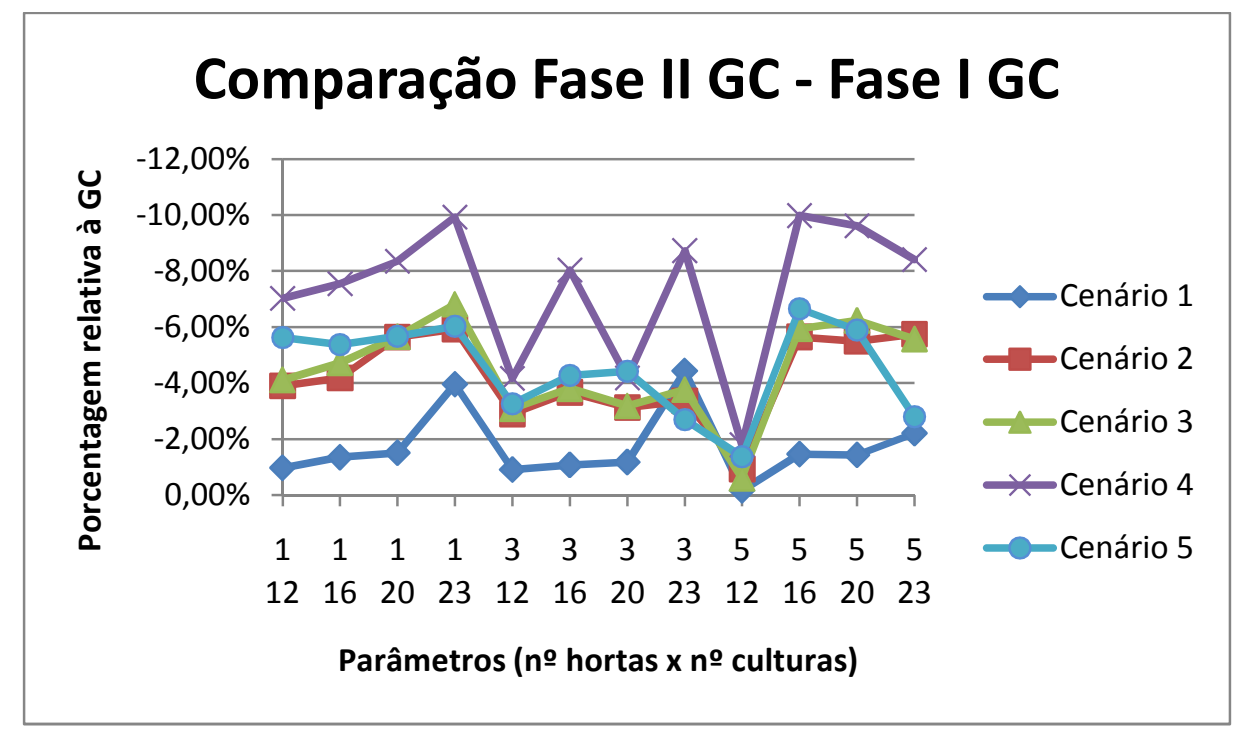

Figura 5.21: Redução de lucro da solução exata obtida na Fase II do algoritmo GC-BC 
O gráfico seguinte mostra o quanto a solução obtida pelo algoritmo Lote Fixo é menor em relação à solução relaxada obtida pela Fase I do algoritmo GC-BC.

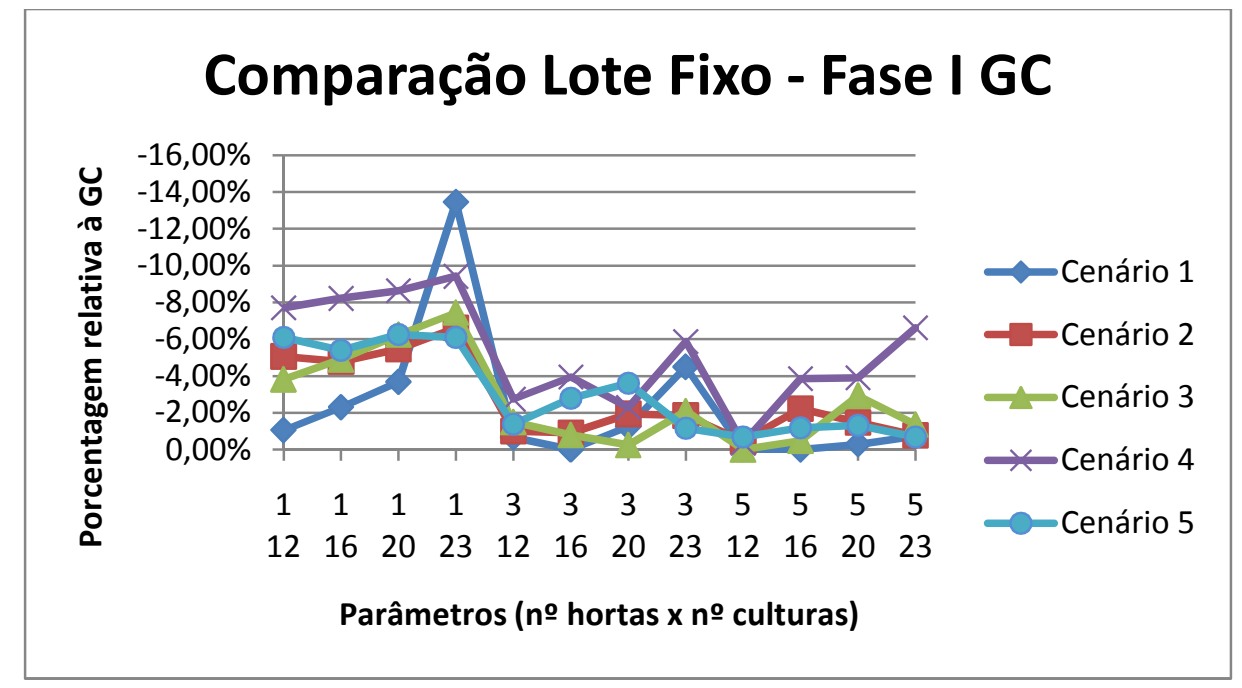

Figura 5.22: Redução de lucro do algoritmo Lote Fixo com o critério 1 de seleção

Os resultados obtidos não são muito distantes da média obtida pelo algoritmo GC-BC tradicional, havendo ocorrências de melhorias e pioras. A porcentagem também não apresenta um comportamento estável, embora a tendência mais comumente observada é da qualidade da solução reduzir conforme o número de culturas utilizadas cresce. O número de áreas de cultivo não mostra influência na qualidade da solução obtida, porém as classes de problemas de uma única área surpreendentemente possuem a maior redução porcentual de lucro, de forma mais acentuada que o algoritmo GC-BC.

A seguir, apresentamos a comparação do resultado obtido pela solução exata do problema mestre restrito às colunas geradas após a execução do algoritmo Lote Fixo com a primeira solução relaxada obtida na Fase I do algoritmo GC-BC.

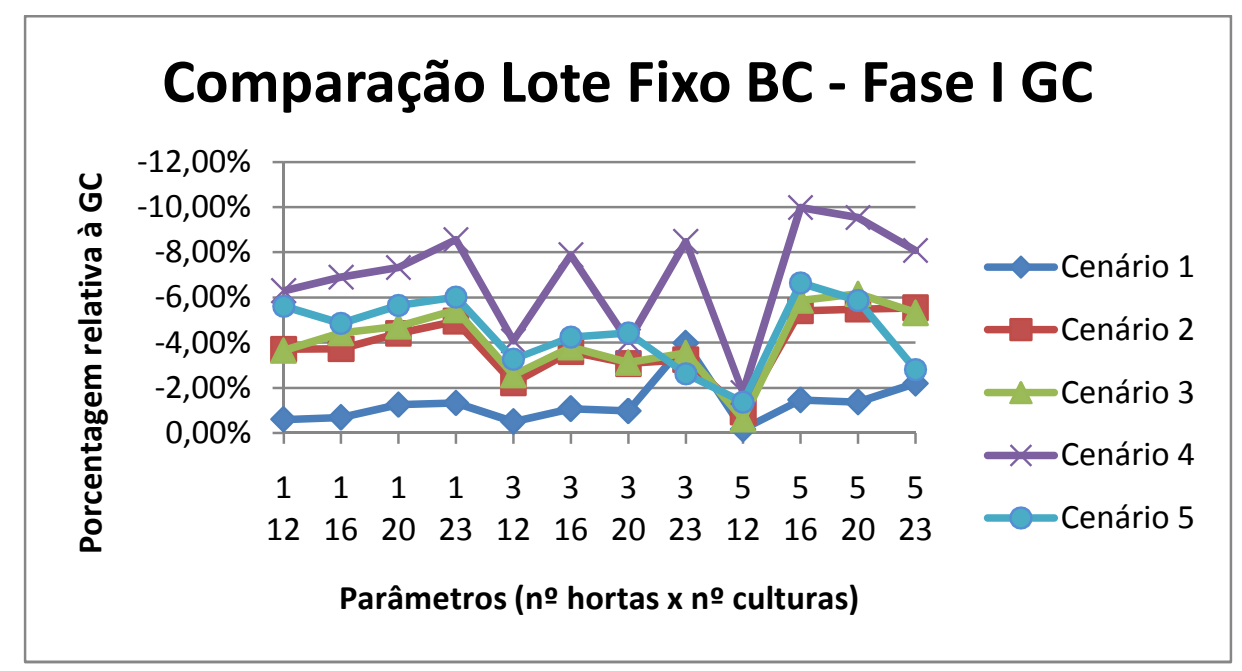

Figura 5.23: Redução de lucro da solução exata após Lote Fixo com o critério 1 de seleção 
Podemos notar que o comportamento das curvas é similar à solução exata do problema mestre restrito obtida pelo algoritmo GC-BC, havendo instâncias de pequenas melhorias na qualidade da solução e outras de ganhos próximos a $2 \%$. Não houve situações de piora, o que era esperado, visto que o modelo possui as novas colunas geradas pelo algoritmo Lote Fixo além das anteriores, logo, em pior caso, a solução ótima obtida é igual à anterior.

Observa-se também que o algoritmo Lote Fixo (figura 5.22) parece gerar soluções de melhor qualidade que as soluções exatas (figuras 5.21 e 5.23), o que não é de todo correto: devido aos diversos critérios de parada possíveis para o algoritmo Lote Fixo, a solução final obtida não necessariamente respeita a condição de lote mínimo para todas as variáveis, com isso sua solução pode gerar valores "melhores" que a solução exata gerada com todas as colunas obtida: esta solução é heurística e potencialmente relaxada.

Concluimos que o algoritmo Lote Fixo com o critério 1 de seleção de variáveis, por si só, não garante soluções de qualidade, porém as colunas extras obtidas podem fornecer melhorias na solução exata do problema, com custo computacional aceitável.

\subsubsection{TESTES FIXA LOTES GRANDES}

Considerando o enfoque do primeiro critério de seleção apenas nas variáveis pequenas, alteramos este critério para focar também nos lotes maiores. O segundo critério de seleção avaliado é descrito como:

\section{Critério 2 de seleção de variável a ser fixada para a Heurística Lote Fixo}

1. Seja $V=\left\{(k, s) \mid \lambda_{k s}<\lambda^{\text {min }} e(k, s) \notin F\right\}$ e $V^{\prime}=\left\{(k, s) \mid \lambda_{k s} \geq \lambda^{\text {min }}\right\}$.

2. Determine um conjunto de pares ordenados $(k, s)$ que satisfaçam $\bar{\lambda}_{k s}=$ $\operatorname{Max}\left\{\lambda_{k s} \mid(k, s) \in V\right\}$ e todos os pares $(k, s) \in V^{\prime}$.

Desta forma, todas as variáveis maiores que $\lambda^{\text {min }}$ e uma variável menor que este valor são fixadas. Este critério é uma extensão do primeiro, pois fixa a mesma variável menor que $\lambda^{\text {min }}$ além de todas as maiores. Com isso, a atualização de demanda atendida é feita de forma mais agressiva. 
O tempo computacional, observado no gráfico abaixo, não é muito diferente do observado para o critério 1 :

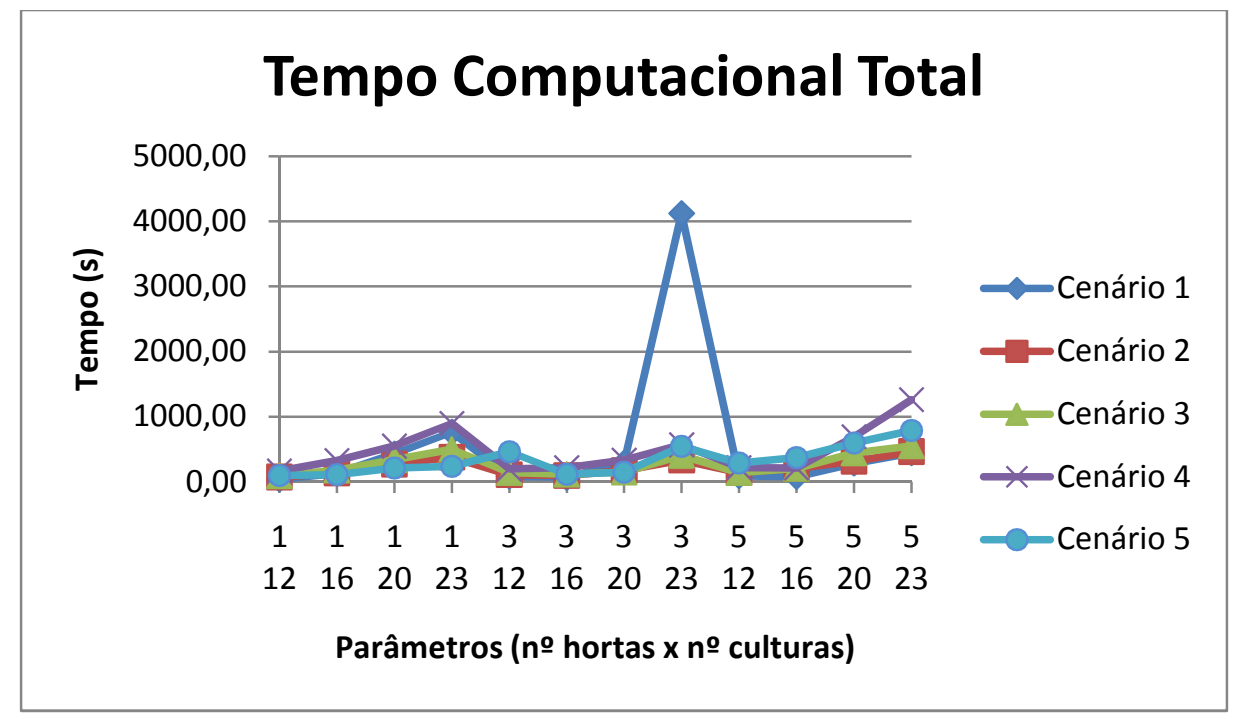

Figura 5.24: tempo computacional total com o critério 2 do algoritmo Lote Fixo

Novamente, apenas a classe de problema com 3 hortas e 23 culturas, aplicado ao primeiro cenário de demanda, excedeu o tempo limite de execução de 3600 na resolução exata via branch-and-cut após a execução do algoritmo Lote Fixo. O critério 2 obteve tempo total de execução um pouco menor que o critério 1 , mas o comportamento é o mesmo. Essa pequena redução ocorre devido à atualização de atendimento de demanda relativo às variáveis de maior valor que são fixadas em cada iteração, acelerando a redução e consequentemente solução do modelo.

Abaixo, avaliamos a qualidade das soluções obtidas pelo algoritmo Lote Fixo com o critério 2 de seleção de variável em relação à solução relaxada obtida na Fase I:

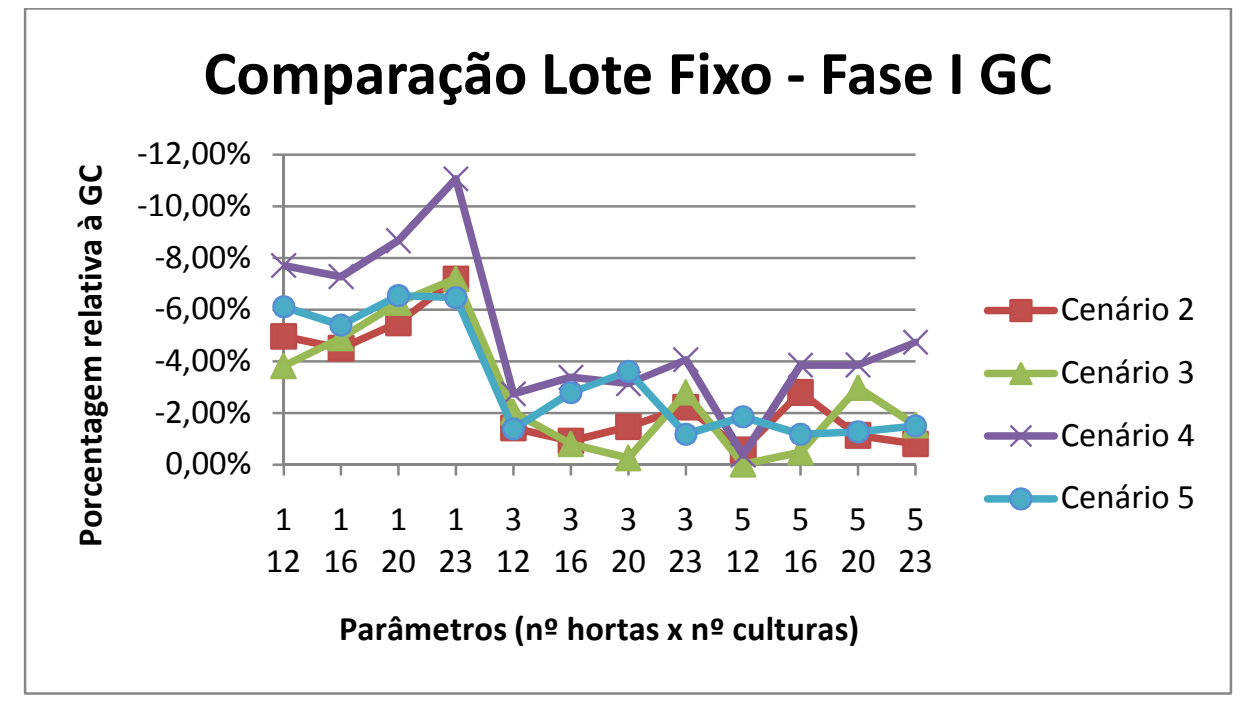

Figura 5.25: Redução de lucro do algoritmo Lote Fixo com o critério 2 de seleção 
O gráfico nos mostra que o critério 2 gera soluções, no geral, levemente melhores que as obtidas pelo critério 1, quando consideramos apenas o resultado retornado pela heurística Lote Fixo. Observamos, entretanto, um comportamento errático nos valores perante a variação de classes de problemas, assim como no primeiro critério. Um detalhe importante é que o resultado heurístico obtido com este critério para as classes de problemas 1-20, 1-23 e 3-23 para o cenário de demanda 1 não foi capaz de atender a demanda imposta: isso resultou no uso das variáveis de nãoatendimento, com custo altamente negativo. Para evitar que estes valores distorcessem o gráfico, o cenário 1 não foi incluído, porém as demais classes com demanda atendida tiveram resultados favoráveis, com redução média de $0,84 \%$.

Porém, novamente esta solução é heurística e não garante que a condição de lote mínimo seja totalmente respeitada na solução final, devido a outras condições de parada como tolerância de redução na função objetivo ao desconsiderar os lotes pequenos. Resolvendo o modelo por branch-and-cut após a geração de novas colunas pelo algoritmo Lote Fixo, obtemos:

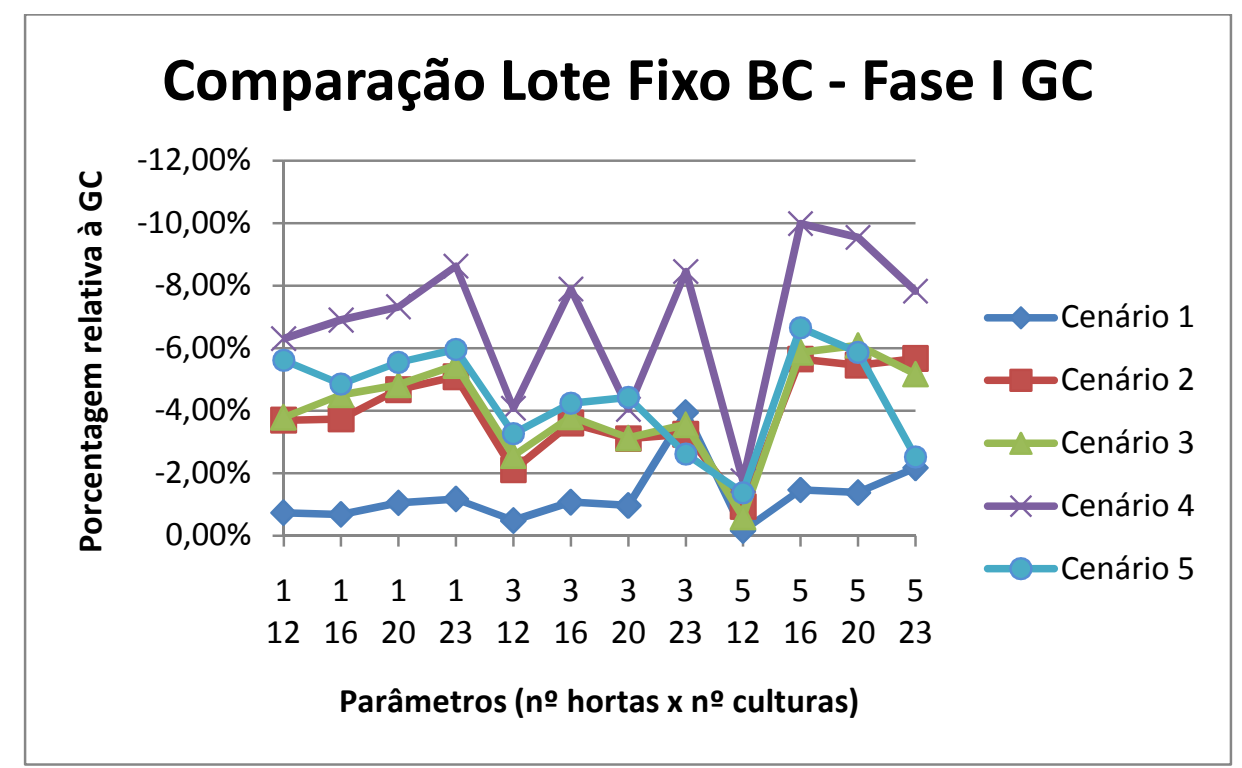

Figura 5.26: Redução de lucro da solução exata após Lote Fixo com o critério 2 de seleção

Ao comparar estes resultados com os demonstrados na Figura 5.21, notamos que as diferenças são mínimas, mantendo o mesmo comportamento e média que o critério 1 de seleção. 
Notamos que o critério 2 de seleção de variáveis não gera soluções melhores para a resolução exata mas a solução heurística e o tempo computacional total são levemente melhores que o primeiro critério.

\subsubsection{TESTES FIXA DOIS LOTES}

Visando mixar as idéias de ambos os critérios anteriores, propomos um terceiro critério de seleção de variáveis, que não foca apenas nas variáveis pequenas nem foca demais nas variáveis grandes. Definimos o terceiro critério como:

\section{Critério 3 de seleção de variável a ser fixada para a Heurística Lote Fixo}

1. Seja $V=\left\{(k, s) \mid \lambda_{k s}<\lambda^{\min } e(k, s) \notin F\right\}$ e $V^{\prime}=\left\{(k, s) \mid \lambda_{k s} \geq \lambda^{\text {min }}\right\}$.

2. Determine dois pares ordenados $(k, s)$ que satisfaçam $\bar{\lambda}_{k s}=\operatorname{Max}\left\{\lambda_{k s} \mid(k, s) \in\right.$ $V\}$ e $\lambda^{\prime}{ }_{k s}=\operatorname{Min}\left\{\lambda_{k s} \mid(k, s) \in V^{\prime}\right\}$.

O critério 3 também pode ser visto como uma extensão do critério 1: além de selecionar a variável mais próxima de $\lambda^{\min }$ do grupo de variáveis menores que este valor, também considera a variável mais próxima deste valor do grupo das maiores que o lote mínimo. Desta forma, duas variáveis são escolhidas por iteração do algoritmo.

Usando este terceiro critério de seleção de variáveis para o algoritmo Lote Fixo, o tempo total de execução obtido é descrito no gráfico abaixo:

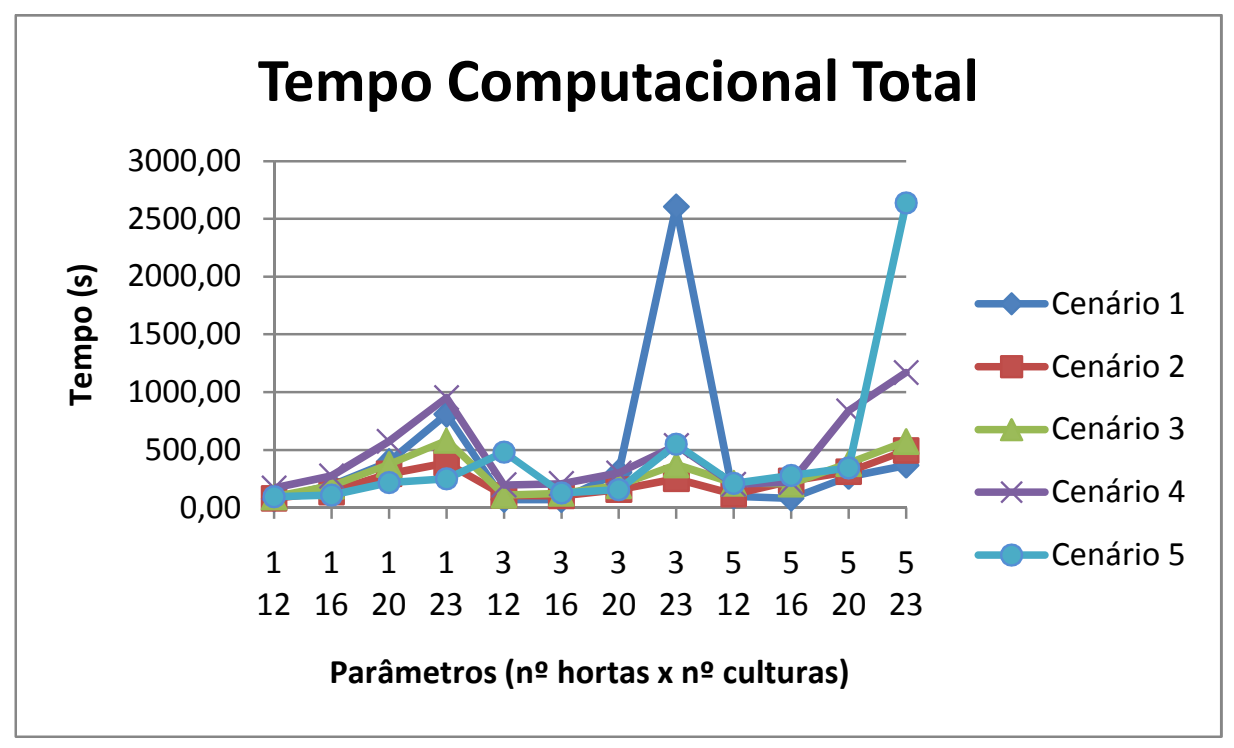

Figura 5.27: tempo computacional total com o critério 3 do algoritmo Lote Fixo 
Notamos que, embora o comportamento geral é bem próximo do obtido pelos critérios anteriores, a classe de problema com 3 áreas de cultivo e 23 culturas não excedeu o tempo de execução de 3600 segundos como previamente. Houve entretanto um aumento significativo no tempo na última classe de problema para o cenário de demanda 5 .

Os resultados computacionais referentes à função objetivo obtida pela heurística Lote Fixo quando comparada à obtida pela geração de colunas inicial seguem:

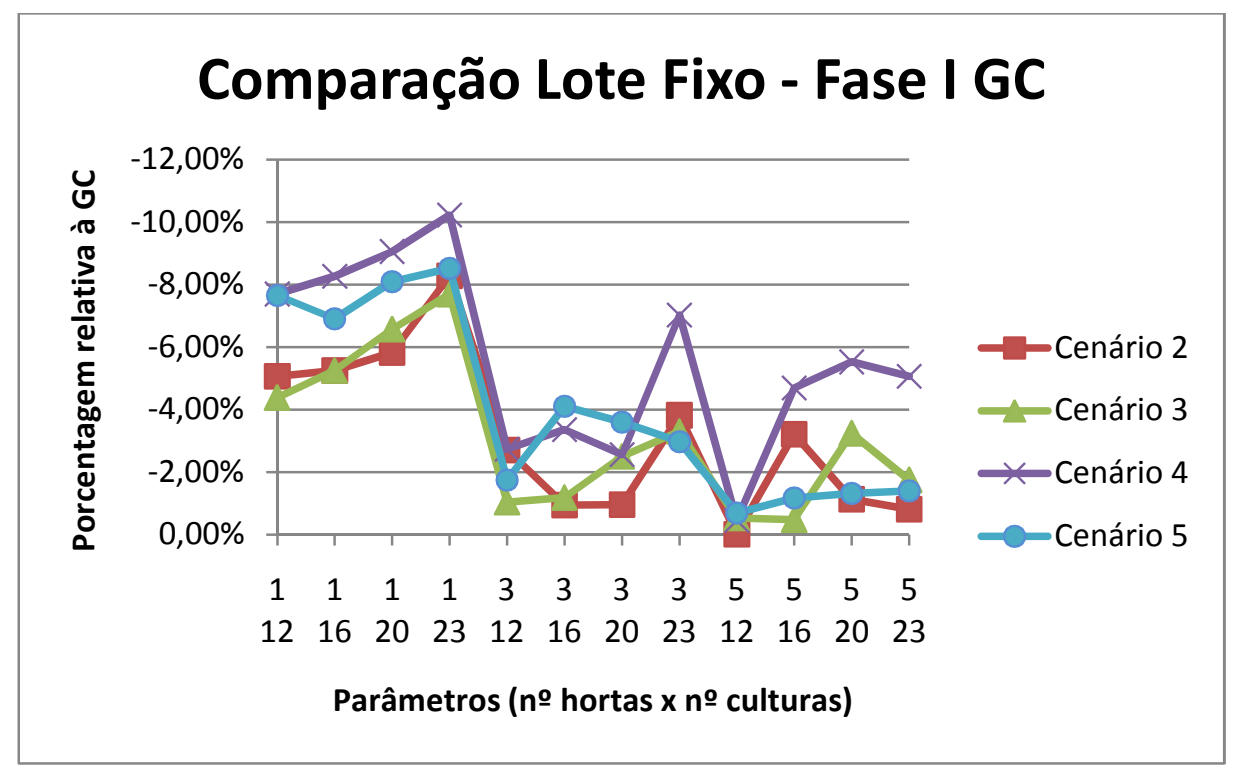

Figura 5.28: Redução de lucro do algoritmo Lote Fixo com o critério 3 de seleção

Podemos observar que a solução heurística tende a ter qualidade levemente pior quando comparada aos critérios anteriores. Além disso, o cenário de demanda 1 para a classe 1-23 terminou sua execução com demanda-não atendida, resultando em valores negativo para a função objetivo, portanto sua curva não foi considerada no gráfico acima: a redução média das demais classes ficou em 2,5\%. Novamente, não há garantia de que a solução fornecida pela heurística respeite todas as restrições de lote mínimo.

$\mathrm{O}$ interesse maior encontra-se na solução exata obtida com as colunas extras geradas pela heurística Lote Fixo. Ao utilizar o critério 3 de seleção, os resultados obtidos foram: 


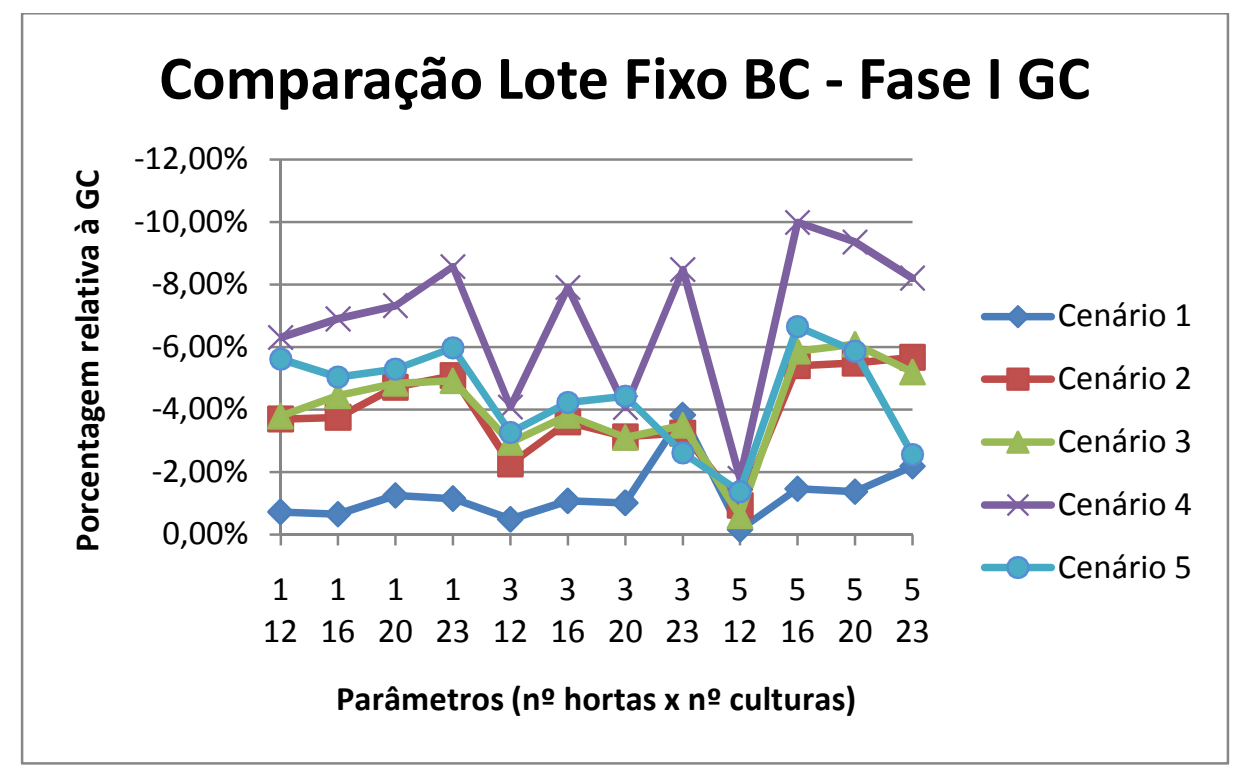

Figura 5.29: Redução de lucro da solução exata após Lote Fixo com o critério 3 de seleção

Os resultados obtidos variaram minimamente quando comparados com os demais critérios. Isso indica que a fixação de uma ou múltiplas variáveis maiores que o valor definido de lote mínimo não afeta o desempenho do algoritmo durante a geração de colunas extras após a atualização da demanda atendida.

O terceiro critério de seleção mostrou-se de qualidade igual ao segundo, com soluções quase idênticas e com o tempo computacional médio próximo.

\subsubsection{TESTES FIXA MAIOR DEMANDA}

Com o intuito de gerar uma abordagem diferente das anteriores, criamos um critério que, ao invés de focar as atenções nos valores das variáveis, foca nas demandas ainda não atendidas.

Várias formulações foram testadas: após definir qual a maior demanda ainda não atendida, é preciso selecionar qual variável capaz de atender tal demanda será selecionada para ser fixada em $\lambda^{\text {min }}$. Após diferentes combinações, o critério final utilizado foi: 


\section{Critério 4 de seleção de variável a ser fixada para a Heurística Lote Fixo}

1. Seja $(i, j)$ tal que $\bar{d}_{i j}=\operatorname{Max}\left\{d_{i j} \mid i=1 . . N, j=1 . . M\right\}$. Em caso de mais de um candidato, o desempate é feito baseado na ordem lexicográfica das demandas.

2. Dentre as variáveis $\lambda_{k s}$, selecione todas as $(k, s)$ tal que seu respectivo coeficiente $a_{i j k}^{S}=\operatorname{Max}\left\{a_{i j k}^{S}|k=1 . . L, s=1 ..| S_{k} \mid\right\}$ para $i$ e $j$ definidos no Passo 1.

3. Caso mais de uma variável seja selecionada, selecione todas as $(k, s)$ que tenham sido fixadas previamente o menor número de vezes.

4. Em caso de um novo empate, escolha $(k, s)$ tal que $\left|\lambda_{k s}-\lambda^{\min }\right|=\operatorname{Min}\left\{\mid \lambda_{k s}-\right.$ $\left.\lambda^{\text {min }} \mid\right\}$ para todas as variáveis selecionadas no Passo 3.

5. Na ocorrência de mais um empate, escolha $(k, s)$ seguindo uma ordem lexicográfica.

De forma resumida, dentre as variáveis capazes de atender a maior demanda ainda pendente, aquela que possuir o maior rendimento (caracterizado pelo maior coeficiente) e foi fixada menos vezes e estiver mais próxima do valor de $\lambda^{\text {min }}$, será selecionada. Para o Passo 4, uma faixa de tolerância de 30 foi utilizada, permitindo que variáveis dentro da menor diferença obtida, acrescida ou subtraída desta tolerância, fossem candidatas. Os diversos critérios de desempate são necessários para tentar evitar vícios e ciclos no processo de escolha. Desta forma, atendemos parte da maior demanda ainda não-atendida usando a rotação de maior produção e que tenha sido menos utilizada, aumentando a variedade da solução.

O tempo computacional descrito abaixo, assim como nos critérios anteriores, envolvem todo o processo, desde a primeira geração de colunas até a resolução exata do problema inteiro após a heurística Lote Fixo. 


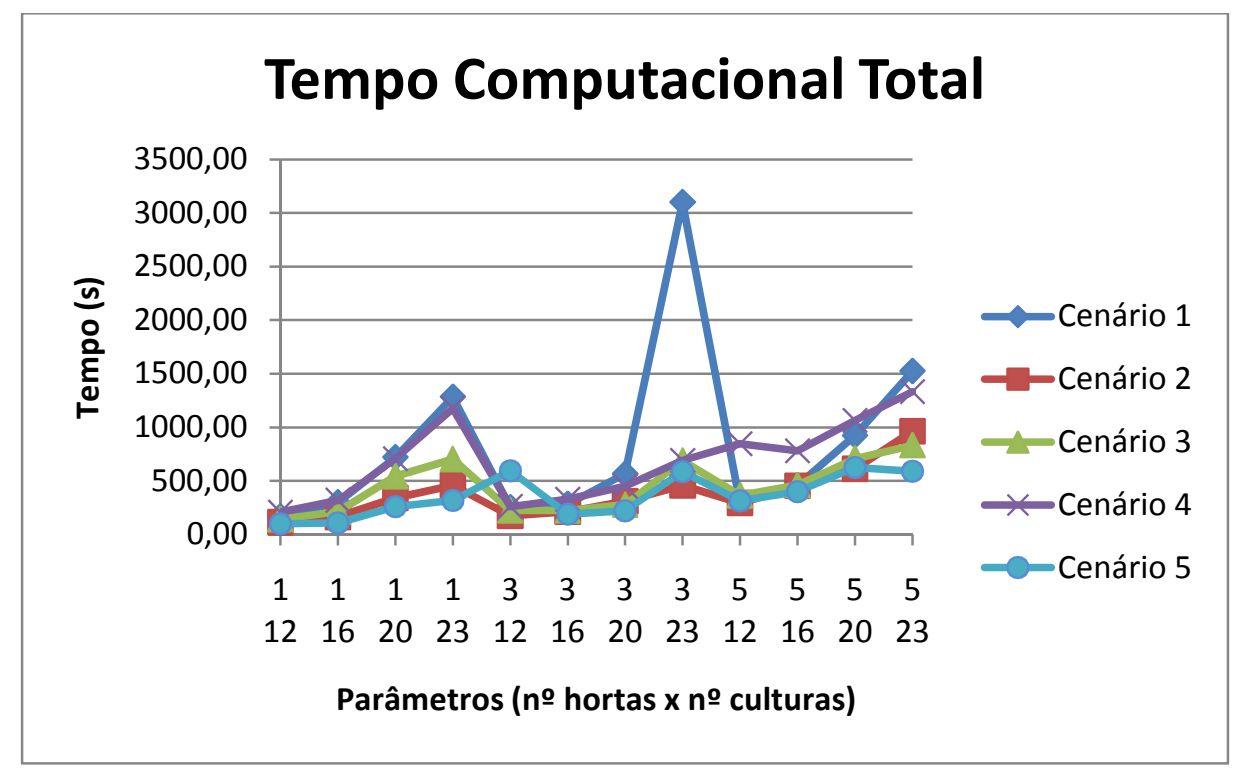

Figura 5.30: tempo computacional total com o critério 4 do algoritmo Lote Fixo

Notamos que o tempo médio de execução é levemente maior que os outros critérios, porém a instância particular da classe de problemas 3-23 para o cenário de demanda 1 não estourou o tempo de resolução do problema inteiro final como nos dois primeiros critérios. Isso sugere que as colunas extras geradas pela heurística Lote Fixo com o critério de seleção baseado em demanda foram de melhor qualidade.

A seguir, analisamos a qualidade da solução retornada pela heurística:

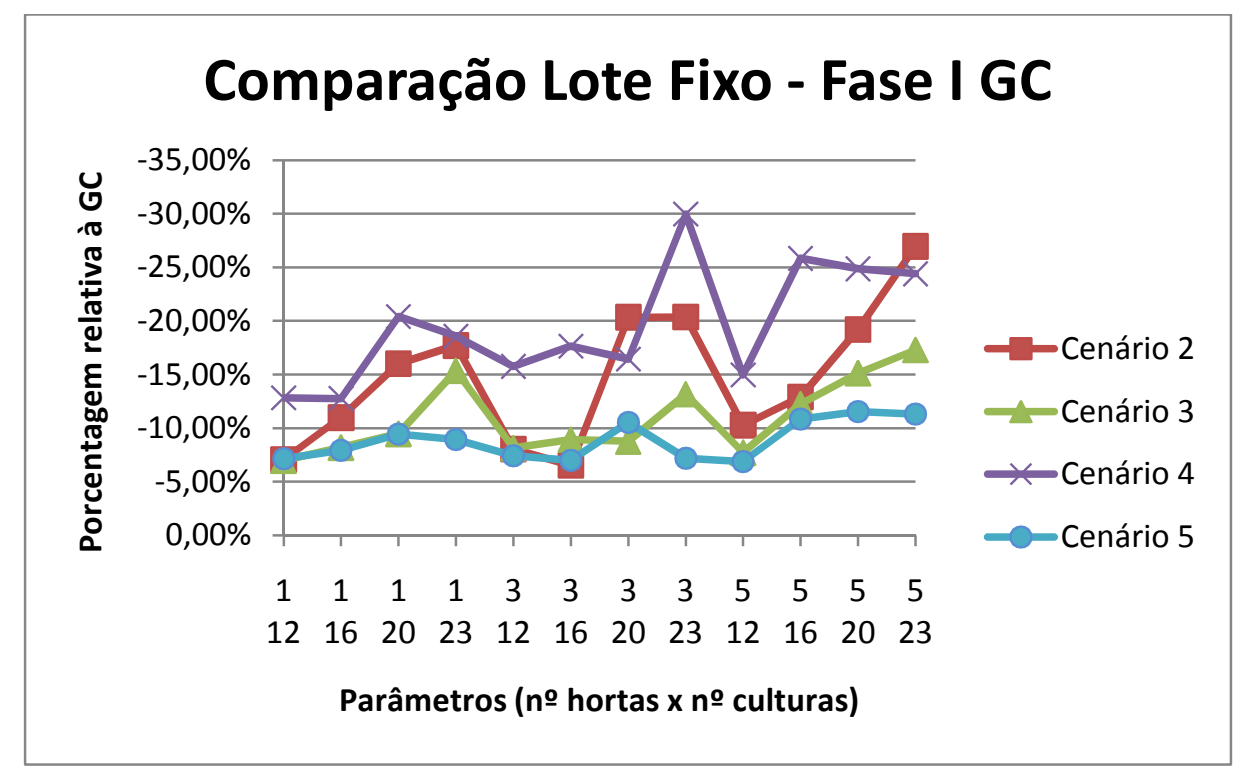

Figura 5.31: Redução de lucro do algoritmo Lote Fixo com o critério 4 de seleção 
Notamos que a heurística por si só gerou soluções de má qualidade: além de duas ocorrências de não-atendimento de demanda observados no cenário 1 para as classes 1-23 e 3-23 (cuja curva foi novamente excluída do gráfico, com redução média de $27,65 \%$ para as classes resolvidas), o resultado obtido chega a ser pior em até $40 \%$. Com uma perda em torno de $20 \%$ entre todas as instâncias, este critério deixou a desejar comparado com os demais, caso limite-se à solução heurística.

Por outro lado, ao usar-se as colunas extras obtidas na resolução exata do modelo inicial, o quadro se inverte, como podemos observar no gráfico abaixo:

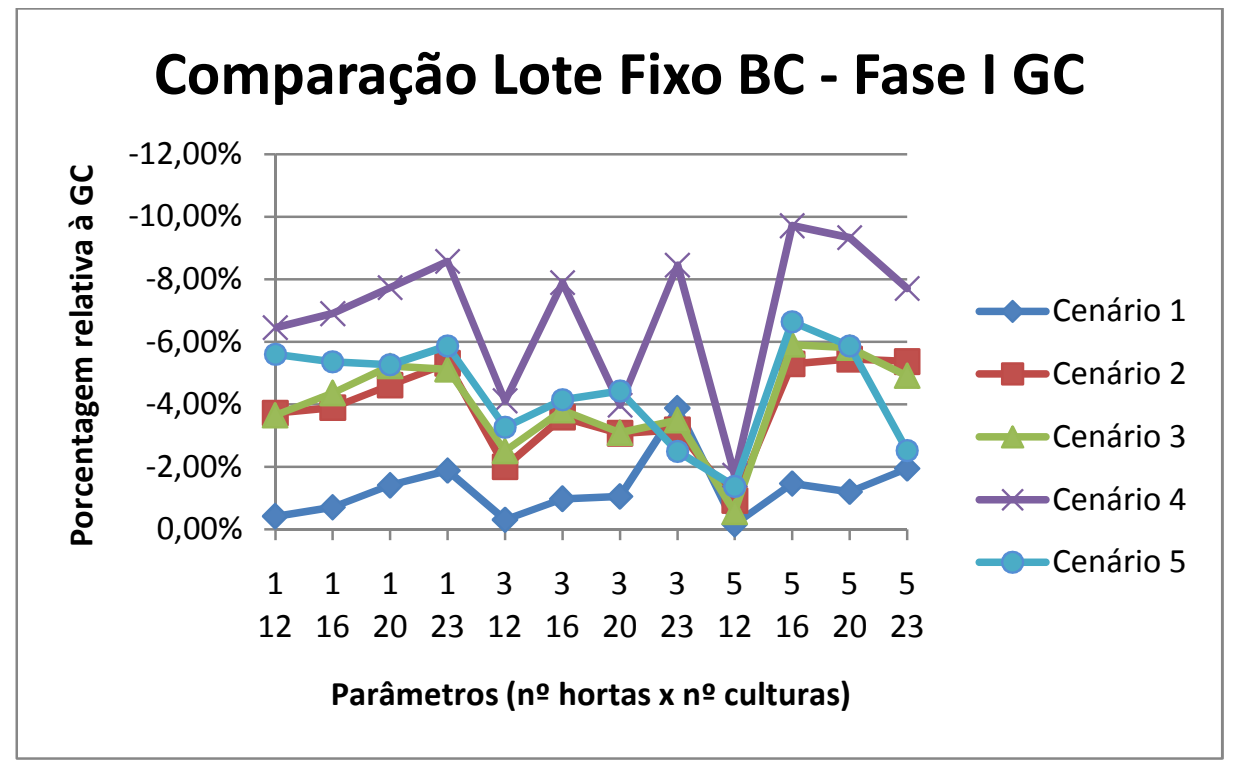

Figura 5.32: Redução de lucro da solução exata após Lote Fixo com o critério 4 de seleção

A solução exata foi de melhor qualidade que os critérios anteriores em boa parte dos casos, havendo poucas situações piores. Embora o comportamento ainda seja similar, há leves oscilações favoráveis em relação aos anteriores.

O critério de seleção baseado em demanda, apesar de gerar soluções heurísticas de má qualidade mesmo com diversos critérios de desempate impostos, permitiu uma abordagem diferenciada ao gerar novas colunas, que pôde trazer melhorias na solução final obtida por um método exato. 


\subsubsection{COMPARATIVO FINAL}

A heurística Lote Fixo proposta, embora gere soluções usualmente piores que a solução exata obtida apenas com as colunas iniciais do algoritmo GC-BC, possui um bom tempo de execução. Todavia, em instâncias mais difíceis, nem sempre foi capaz de gerar soluções que atendessem completamente a demanda, mesmo havendo condições plenas para tal.

Notamos que a principal contribuição da heurística Lote Fixo está justamente na criação de novas colunas para o problema mestre, permitindo refinar ainda mais a solução final, ainda dentro de um tempo computacional aceitável. Para melhor visualizar esta contribuição, juntamos para cada cenário de demanda os resultados da solução exata obtida para o primeiro conjunto de rotações obtido pelo algoritmo GCBC, além da solução exata obtida após a criação de novas colunas para cada critério de seleção da heurística Lote Fixo.

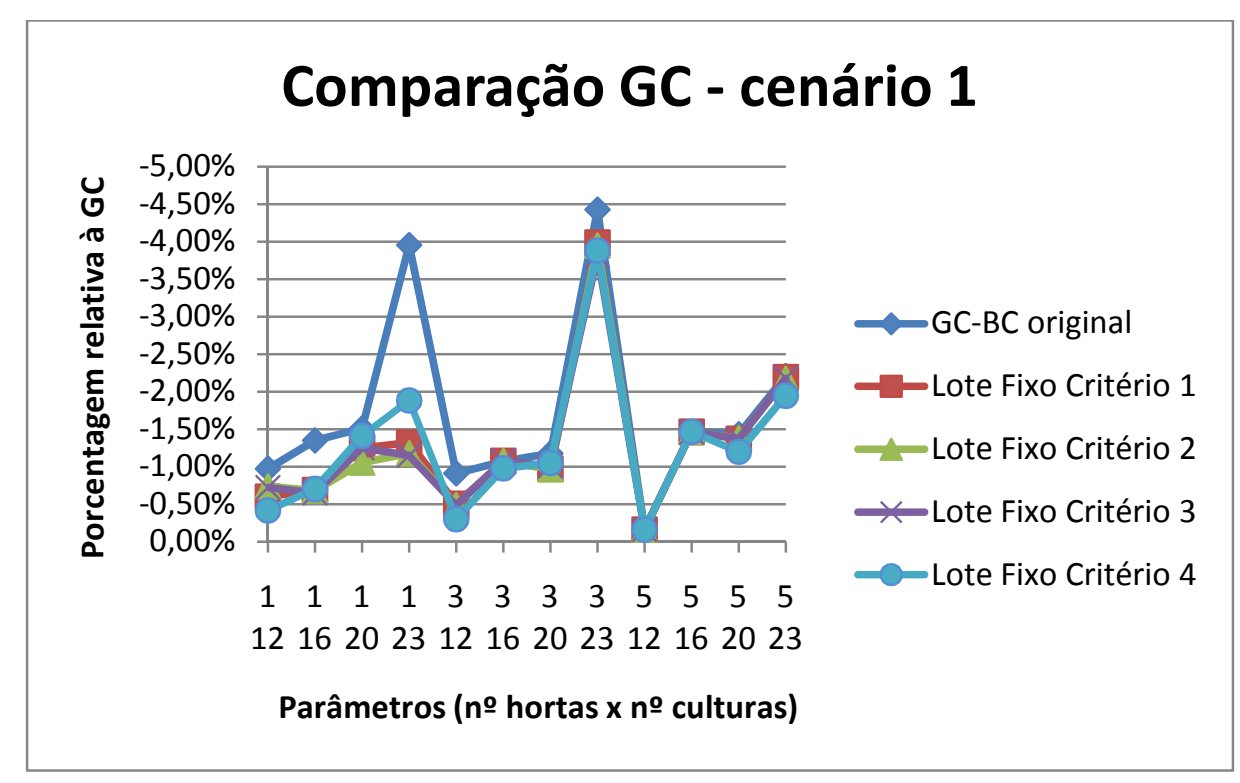

Figura 5.33: Redução de lucro da solução exata aplicado ao cenário de demanda 1 


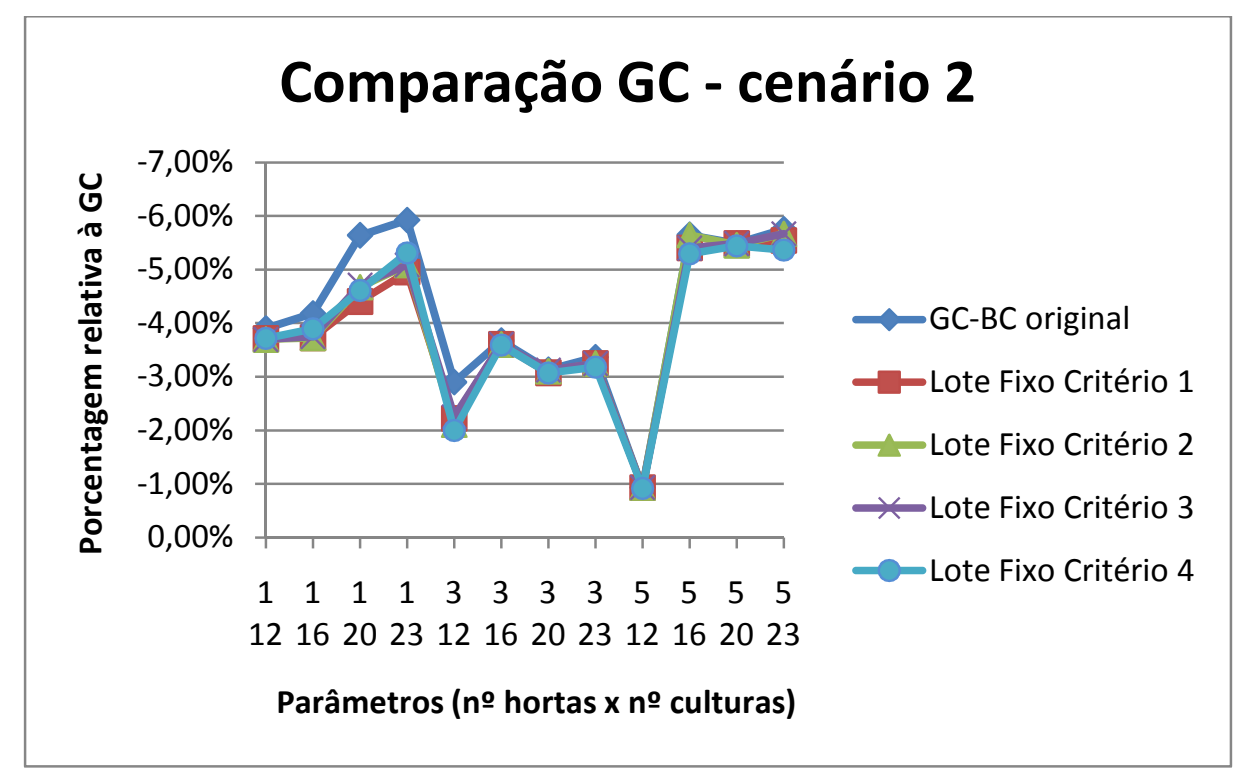

Figura 5.34: Redução de lucro da solução exata aplicado ao cenário de demanda 2

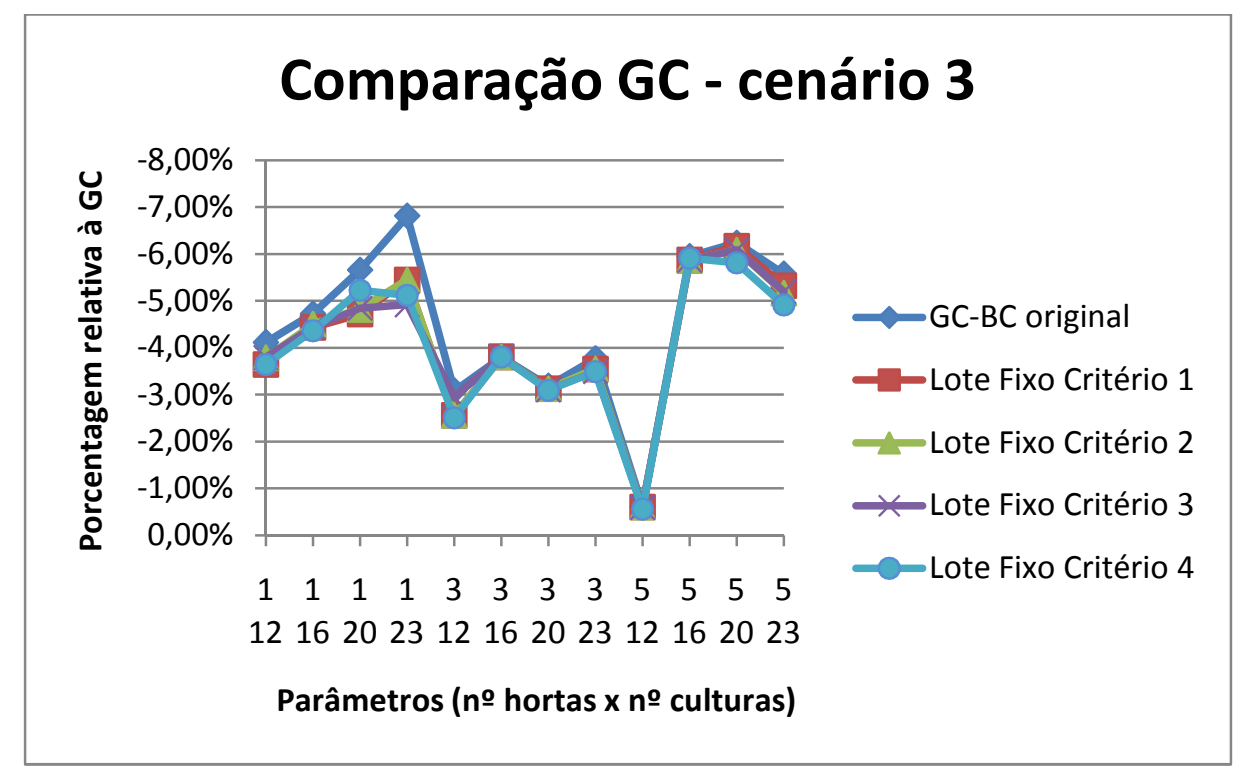

Figura 5.35: Redução de lucro da solução exata aplicado ao cenário de demanda 3

Os cenários de demanda 4 e 5 não ofereceram resultados significativos, mantendo as soluções muito próximas e variações muito pequenas com pouquíssimas exceções, então foram omitidos para evitar redundância.

Devido aos valores próximos, algumas regiões dos gráficos são de difícil comparação. Para visualizar em mais detalhes, listamos a seguir as tabelas com os resultados obtidos. Por questão de facilidade de leitura, o critério com o melhor solução para cada classe de problema possui seu valor destacado nas tabelas abaixo. 
Tabela 5.14: redução de lucro de cada critério para o cenário de demanda 1

\begin{tabular}{|c|c|cccccc|}
\hline \multicolumn{1}{|c}{ hortas } & cult. & GC-BC & Critério 1 & Critério 2 & Critério 3 & Critério 4 \\
\hline \multirow{4}{*}{$\mathbf{1}$} & $\mathbf{1 2}$ & $-0,97 \%$ & $-0,60 \%$ & $-0,74 \%$ & $-0,72 \%$ & $-0,42 \%$ \\
& $\mathbf{1 6}$ & $-1,35 \%$ & $-0,69 \%$ & $-0,68 \%$ & $-0,65 \%$ & $-0,70 \%$ \\
& $\mathbf{2 0}$ & $-1,51 \%$ & $-1,25 \%$ & $-1,05 \%$ & $-1,25 \%$ & $-1,41 \%$ \\
& $\mathbf{2 3}$ & $-3,96 \%$ & $-1,32 \%$ & $-1,18 \%$ & $-1,15 \%$ & $-1,88 \%$ \\
\hline \multirow{4}{*}{$\mathbf{3}$} & $\mathbf{1 2}$ & $-0,91 \%$ & $-0,50 \%$ & $-0,49 \%$ & $-0,49 \%$ & $-0,30 \%$ \\
& $\mathbf{1 6}$ & $-1,07 \%$ & $-1,07 \%$ & $-1,07 \%$ & $-1,07 \%$ & $-0,98 \%$ \\
& $\mathbf{2 0}$ & $-1,18 \%$ & $-0,97 \%$ & $-0,97 \%$ & $-1,01 \%$ & $-1,05 \%$ \\
& $\mathbf{2 3}$ & $-4,43 \%$ & $-3,98 \%$ & $-3,95 \%$ & $-3,82 \%$ & $-3,88 \%$ \\
\hline \multirow{5}{*}{$\mathbf{5}$} & $\mathbf{1 2}$ & $-0,17 \%$ & $-0,16 \%$ & $-0,16 \%$ & $-0,16 \%$ & $-0,16 \%$ \\
& $\mathbf{1 6}$ & $-1,46 \%$ & $-1,46 \%$ & $-1,46 \%$ & $-1,46 \%$ & $-1,46 \%$ \\
& $\mathbf{2 0}$ & $-1,43 \%$ & $-1,37 \%$ & $-1,38 \%$ & $-1,37 \%$ & $-1,20 \%$ \\
& $\mathbf{2 3}$ & $-2,21 \%$ & $-2,19 \%$ & $-2,17 \%$ & $-2,18 \%$ & $-1,95 \%$ \\
\hline
\end{tabular}

Tabela 5.15: redução de lucro de cada critério para o cenário de demanda 2

\begin{tabular}{|c|c|cccccc|}
\hline \multicolumn{1}{|c}{ hortas } & cult. & GC-BC & Critério 1 & Critério 2 & Critério 3 & Critério 4 \\
\hline \multirow{4}{*}{$\mathbf{1}$} & $\mathbf{1 2}$ & $-3,90 \%$ & $-3,71 \%$ & $-3,70 \%$ & $-3,70 \%$ & $-3,72 \%$ \\
& $\mathbf{1 6}$ & $-4,18 \%$ & $-3,73 \%$ & $-3,73 \%$ & $-3,75 \%$ & $-3,89 \%$ \\
& $\mathbf{2 0}$ & $-5,64 \%$ & $-4,40 \%$ & $-4,67 \%$ & $-4,71 \%$ & $-4,61 \%$ \\
& $\mathbf{2 3}$ & $-5,92 \%$ & $-4,95 \%$ & $-5,09 \%$ & $-5,08 \%$ & $-5,31 \%$ \\
\hline \multirow{5}{*}{$\mathbf{3}$} & $\mathbf{1 2}$ & $-2,90 \%$ & $-2,22 \%$ & $-2,10 \%$ & $-2,26 \%$ & $-1,99 \%$ \\
& $\mathbf{1 6}$ & $-3,67 \%$ & $-3,60 \%$ & $-3,60 \%$ & $-3,60 \%$ & $-3,59 \%$ \\
& $\mathbf{2 0}$ & $-3,13 \%$ & $-3,07 \%$ & $-3,10 \%$ & $-3,13 \%$ & $-3,07 \%$ \\
& $\mathbf{2 3}$ & $-3,36 \%$ & $-3,25 \%$ & $-3,25 \%$ & $-3,25 \%$ & $-3,18 \%$ \\
\hline \multirow{5}{*}{$\mathbf{5}$} & $\mathbf{1 2}$ & $-0,93 \%$ & $-0,93 \%$ & $-0,93 \%$ & $-0,93 \%$ & $-0,92 \%$ \\
& $\mathbf{1 6}$ & $-5,65 \%$ & $-5,41 \%$ & $-5,65 \%$ & $-5,40 \%$ & $-5,29 \%$ \\
& $\mathbf{2 0}$ & $-5,49 \%$ & $-5,49 \%$ & $-5,46 \%$ & $-5,49 \%$ & $-5,45 \%$ \\
& $\mathbf{2 3}$ & $-5,75 \%$ & $-5,54 \%$ & $-5,67 \%$ & $-5,67 \%$ & $-5,36 \%$ \\
\hline
\end{tabular}

Tabela 5.16: redução de lucro de cada critério para o cenário de demanda 3

\begin{tabular}{|c|c|cccccc|}
\hline \multicolumn{1}{|c}{ hortas } & cult. & GC-BC & Critério 1 & Critério 2 & Critério 3 & Critério 4 \\
\hline \multirow{4}{*}{$\mathbf{1}$} & $\mathbf{1 2}$ & $-4,11 \%$ & $-3,64 \%$ & $-3,79 \%$ & $-3,79 \%$ & $-3,65 \%$ \\
& $\mathbf{1 6}$ & $-4,72 \%$ & $-4,43 \%$ & $-4,51 \%$ & $-4,43 \%$ & $-4,36 \%$ \\
& $\mathbf{2 0}$ & $-5,66 \%$ & $-4,72 \%$ & $-4,82 \%$ & $-4,84 \%$ & $-5,22 \%$ \\
& $\mathbf{2 3}$ & $-6,81 \%$ & $-5,44 \%$ & $-5,45 \%$ & $-4,92 \%$ & $-5,12 \%$ \\
\hline \multirow{4}{*}{3} & $\mathbf{1 2}$ & $-3,09 \%$ & $-2,56 \%$ & $-2,56 \%$ & $-2,95 \%$ & $-2,51 \%$ \\
& $\mathbf{1 6}$ & $-3,81 \%$ & $-3,81 \%$ & $-3,81 \%$ & $-3,81 \%$ & $-3,81 \%$ \\
& $\mathbf{2 0}$ & $-3,18 \%$ & $-3,12 \%$ & $-3,12 \%$ & $-3,10 \%$ & $-3,09 \%$ \\
& $\mathbf{2 3}$ & $-3,77 \%$ & $-3,54 \%$ & $-3,55 \%$ & $-3,49 \%$ & $-3,49 \%$ \\
\hline
\end{tabular}




\begin{tabular}{|c|c|ccccc|}
\hline & $\mathbf{1 2}$ & $-0,61 \%$ & $-0,60 \%$ & $-0,60 \%$ & $-0,59 \%$ & $-0,56 \%$ \\
5 & $\mathbf{5}$ & $-5,94 \%$ & $-5,87 \%$ & $-5,87 \%$ & $-5,87 \%$ & $-5,91 \%$ \\
& $\mathbf{2 0}$ & $-6,23 \%$ & $-6,16 \%$ & $-6,09 \%$ & $-6,09 \%$ & $-5,81 \%$ \\
& $\mathbf{2 3}$ & $-5,57 \%$ & $-5,32 \%$ & $-5,17 \%$ & $-5,20 \%$ & $-4,91 \%$ \\
\hline
\end{tabular}

Observamos nos gráficos que o algoritmo GC-BC original sempre possui as soluções mais distantes em relação ao problema relaxado, enquanto a heurística Lote Fixo gera algumas melhorias nestas soluções. Isto é esperado, pois a heurística gera colunas adicionais ao problema restrito, portanto a nova solução é sempre melhor ou igual que a obtida pelo algoritmo GC-BC. Uma comparação entre os critérios se tornae difícil devido aos resultados próximos, portanto analisamos os valores discretizados nas tabelas 5.14-16 para tirarmos conclusões.

Em algumas classes de problemas esta melhoria é ínfima, porém há casos de ganhos mais significativos. Os quatro critérios de seleção de variável demonstram comportamento bem similar, porém o critério 4 (baseado em demanda) mostrou-se mais errático, podendo acarretar em mudanças mais notáveis, tanto gerando soluções finais de melhor qualidade em relação aos outros critérios (ocorrência mais comum nas classes de problemas com 3 e 5 áreas de cultivo) quanto de pior qualidade (observado mais frequentemente nas classes de problemas com 1 área de cultivo). De fato, apenas duas instâncias com 1 área de cultivo obteve o melhor resultado com o uso do critério baseado em demanda, como visto nas tabelas 5.14 e 5.16.

Em geral, o uso da heurística Lote Fixo para gerar colunas adicionais ao problema mestre restrito traz melhorias relativamente baixas comparadas ao resultado prévio do algoritmo GC-BC, e entre os critérios as diferenças são ínfimas, não oscilando mais que $0,5 \%$. Porém, considerando-se o baixo custo computacional envolvido nas instâncias verificadas este esforço adicional mostra-se válido, podendo trazer soluções de melhor qualidade para um planejamento a longo prazo, com um tempo de execução levemente maior mas sem impacto. 


\section{CONCLUSÕES E PERSPECTIVAS}

Este trabalho abordou o problema de planejamento de rotações de culturas, mais especificamente hortaliças, com atendimento de demanda periódica. Este problema é aplicado a cooperativas e associações que reúnem pequenos e médios agricultores que precisam definir o tamanho de cada produção de cada agricultor visando cumprir uma demanda conhecida, porém cada produtor isoladamente possui limitações como pouca área de plantio que levam a dificuldades de planejamento e logística associadas à produção reduzida

As hortaliças possuem a característica de ciclos curtos de cultivo, além de colheitas parciais. Diferente de cultivos extensivos como cana e laranja, o plantio e a produção são variados ao longo de um período (por exemplo, um ano). Focando nos critérios ecológicos que reduzem o uso de fertilizantes e agrotóxicos, este trabalho utilizou o modelo matemático proposto inicialmente em Santos et al. (2007), cuja base se manteve nos trabalhos subsequentes da autora, mas com uma abordagem de atendimento de demanda.

Embora uma abordagem inicial para o problema de demanda tenha sido estudada na tese de doutorado de Santos (2009), a dificuldade prática decorrente deste modelo foi a obtenção de soluções que utilizam lotes de plantio muito pequenos. Indepedente dos recursos disponíveis a um agricultor, o manuseio e administração de um lote muito pequeno tornam a solução ótima do modelo não aplicável na prática. Os estudos aqui realizados visaram obter formas de refinar esta solução, incluindo-se restrições adicionais de lote mínimo para as variáveis de decisão. Tais restrições, entretanto, não estão disponíveis ao problema mestre restrito, pois dependem das colunas geradas que, por sua vez, dependem das restrições de lote mínimo. Esta interdependência foi contornada com heurísticas que geram colunas em uma primeira fase, e incluem as restrições de lote mínimo em uma segunda fase. As restrições de lote mínimo modificam o problema, de forma que os resultados aqui obtidos não são passíveis de comparação com outros trabalhos, inclusive o de Santos: apesar de similares, os problemas abordados são distintos.

Os testes realizados utilizaram um modelo mestre, que caracteriza o problema de demanda, e um subproblema responsável por gerar rotações factíveis perante os critérios impostos, traduzidos em colunas para o problema mestre. O subproblema teve parte do 
conjunto de restrições simplificada sem perda de generalidade, além de resultar em um desempenho computacional levemente melhor, conforme descrito na Seção 5.1.3.

Para impor a condição de lote mínimo, foi proposto um par de restrições adicionais para cada variável de decisão. Este par de restrições requer a inclusão de uma variável de decisão binária referente a cada variável original, representado o uso ou não da variável em questão. Esta inclusão torna o modelo linear em um modelo inteiromisto, o que aumenta a complexidade de resolução do problema.

Devido à natureza do problema relaxado original, um método de geração de colunas mostra-se atrativo. Porém, tal método é aplicado apenas a problemas lineares, e as restrições adicionais de lote mínimo possuem variáveis binárias. Um método branchand-price, embora intuitivo perante a uma situação de geração de colunas com variáveis discretas, possui dificuldades intrínsecas de implementação que incentivam uma abordagem heurística. Como a geração de todas as colunas possíveis é computacionalmente inviável, propomos o algoritmo GC-BC, que consiste em adicionar as restrições de lote mínimo apenas para as colunas geradas pelo problema linear, e então resolver o novo modelo inteiro-misto por um método de branch-and-cut tradicional, para o qual foi utilizado o pacote de otimização IBM CPLEX 12.1.

A seção 5.1.1 descreve uma visão panorâmica dos resultados obtidos pelo algoritmo GC-BC. A resolução do problema inteiro-misto, entretanto, pode adquirir níveis de complexidade maiores caso características de simetria surjam nas colunas geradas. Isso pode ocorrer mais facilmente caso múltiplas áreas de cultivo possuam características similares. Caso as características sejam idênticas ou uma leve relaxação do problema seja aceitável, áreas similares podem ser tratadas como uma única área de cultivo para remover a simetria, o que acelera em muito a resolução do problema, conforme descrito na Seção 5.1.6.

Além da utilização de um tamanho mínimo ao lote, pode ser de interesse aos produtores reduzir o total de lotes utilizados. Por ser um interesse conflitante com o objetivo de maximizar o lucro obtido, uma ponderação entre eles ou a criação de uma curva de Paretto podem auxiliar na tomada de decisão de quantos lotes utilizar. As seções 5.1.2 e 5.1.4 descrevem a construção dessas ferramentas, e fica claro que uma redução significativa no número de lotes criados pode ser obtida sem grandes perdas no lucro, porém o custo computacional envolvido é alto devido às várias resoluções necessárias e dificuldade de resolução associada à inclusão de novas restrições para a obtenção das informações desejadas. 
Utilizar um valor de custo mínimo maior que zero para definir a parada precoce da geração de colunas, apesar de reduzir o tempo de execução, não mostrou ser uma abordagem capaz de trazer resultados interessantes ao problema tratado. Descrevemos na Seção 5.1.5 como o tempo computacional reduzido com esta mudança não justifica sua aplicação.

Com o enfoque deste trabalho em tratar a condição de lote mínimo, analisamos na Seção 5.1.7 o comportamento do modelo com diferentes valores de lote mínimo. Observamos que este valor apenas resulta em dificuldades significativas caso a área de cultivo disponível seja suficientemente limitada, o que sugere que valores diferentes de lote mínimo para cada área de cultivo podem ser aplicados sem perda de generalidade e sem agravar a complexidade do problema.

Considerando a possibilidade de problemas com dimensões que os tornem impraticáveis para uma resolução exata, propomos a Heurística Lote Fixo para simular a utilização de lotes mínimos a partir de um modelo linear. Seu conceito é definir qual variável fixar ao valor mínimo estipulado, e resolver novamente o modelo com sua demanda e área disponível atualizadas, considerando a fixação realizada, potencialmente gerando novas colunas. Esse processo é repetido até que algum critério de parada seja satisfeito, com o ideal sendo parada por atendimento de demanda ou todas as variáveis não-nulas possuírem valor maior que o lote mínimo desejado: além de factível, tal solução seria também um limitante inferior para o problema mestre.

A heurística Lote Fixo tem o critério de seleção de variável a ser fixada como o ponto chave: diversos critérios podem ser definidos, podendo gerar soluções de diferentes qualidades. Foram propostos quatro diferentes critérios, com os focos voltados aos lotes menores, aos lotes maiores, um balanço entre os dois e às demandas não-atendidas. Os detalhes da heurística e dos diferentes critérios de escolha foram definidos ao longo da Seção 5.2

Apesar da inexistência de trabalhos na literatura que tratem o mesmo problema para efeitos comparativos, é plausível afirmar que o algoritmo GC-BC mostrou-se um procedimento efetivo. O tempo computacional de resolução manteve médias baixas, e a qualidade da solução obtida não esteve muito abaixo do problema linear original.

Concluímos também que os resultados obtidos pela heurística Lote Fixo são similares para todos os critérios de seleção com exceção do critério com enfoque na demanda pendente, que gerou soluções de má qualidade. Ainda assim, as soluções heurísticas geradas não se mostraram muito melhor que as obtidas pelo algoritmo GC- 
BC. Porém, considerando o tempo computacional de execução baixo, a heurística se mostrou útil em gerar novas colunas para o problema mestre restrito, permitindo refinar ainda mais as soluções iniciais pela resolução exata do modelo mestre restrito.

Um método exato, que garanta a obtenção da solução ótima considerando as restrições de lote mínimo, do tipo branch-and-price, é ainda um desafio para pesquisas futuras. Estratégias para a construção de métodos tipo branch-and-price consistem em escrever uma formulação compacta para auxiliar nas ramificações da árvore branchand-bound, ou passar informações para os subproblemas relativas às restrições de lote mínimo, as quais não são explicitamente conhecidas. Ambas as estratégias não são, aparentemente, triviais.

As abordagens propostas neste trabalho podem ser estendidas a outros estudos que envolvam restrições de lote mínimo como as únicas restrições com variáveis discretas, como em problemas de corte que exigem que um número mínimo de placas de metal sejam cortadas conforme um padrão de corte. O algoritmo GC-BC por si só mostrou-se uma estratégia razoável para um branch-and-price e auxiliado pela heurística Lote Fixo permite um refinamento ainda maior da solução obtida. Para problemas simétricos, a heurística Lote Fixo pode fornecer limitantes inferiores de qualidade com tempo de execução reduzido. 


\section{Referências Bibliográficas}

[1] ALFANDARI, L.; LEMALADE, J.; NAGIH, A.; PLATEAU, G. A mip flow model for crop-rotation planning in a context of forest sustainable development. Annals of Operations Research, v. DOI: 10.1007/s10479-0090553-0, 2009.

[2] ALtiERI, M. A.; FARRELl, J. G.; HECHT, S. B.; LIEBMAN, M.; MAGDOFF, F.; MURPHY, W.; NORGAARD, R. B.; SIKOR, T. O. Agroecology: the science of sustainable agriculture. 1995.

[3] CAMPANHOLA, C.; VALARINI, P. J. A agricultura orgânica e seu potencial para o pequeno agricultor. Caderno de Ciência e Tecnologia, v. 18, n.3, p. 69 101, 2001.

[4] CLARKE, H. Combinatorial aspects of cropping pattern selection in agriculture. European Journal of Operational Research, v. 40, p. 70 - 77, 1989.

[5] COSTA, A. M.; DOS SANTOS, L. M. R.; ALEM, D. J.; SANTOS, R. H. S. Sustainable vegetable crop supply problem with perishable stocks. Annals of Operation Research, v. DOI: 10.1007/s10479-010-0830-y, 2011.

[6] DETLEFSEN, N.; JENSEN, A. Modelling optimal crop sequences using network flows. Agricultural Systems, v. 94, p. 566 - 572, 2007.

[7] DogliotTi, S.; ROSSING, W.; ITTERSUM, M. V. Rotat, a tool for systematically generating crop rotations. European Journal of Agronomy, v. 19, p. 239 - 250, 2003.

[8] EL-NAZER, T.; MCCARL, B. The choice of crop rotation: A modeling approach and case study. American Journal of Agricultural Economics, v. 68(1), p. 127 - 136, 1986.

[9] GLIESSMAN, S. R. Agroecology: ecological processes in sustainable agriculture. 2000.

[10] GOMES, R.M.; ARENALES, M.N. Otimização linear aplicada ao plantio sustentável de vegetais. Anais do XLII Simpósio Brasileiro de Pesquisa Operacional, p. $331-342,2010$.

[11] HANEVELD, W.; STEGEMAN, A. Crop succession requirements in agricultural production planning. European Journal of Operations Research, v. 166, p. 406 - 429, 2005. 
[12] HILDRETH, C.; REITER, S. On the choice of a crop rotation plan. TC Koopmans, p. 177 - 188, 1951. Proceedings of the Conference on Linear Programming held in Chicago in 1949.

[13] KANTOROVICH, L. Mathematical methods of organizing and planning production (traduzido do original em russo, datado 1939). Management Science, v. 6, p. 366 - 422, 1960.

[14] ONG'WEN, O.; WRIGHT, S. Small farmers and the future of sustainable agriculture. Ecofair Trade Dialogue, Discussion Paper, v. 7, 2007.

[15] SANTOS, L. M. R.; SANTOS, R. H.; ARENALES, M. N.; RAGGI, L. A. Um modelo para a programação de rotações de culturas. Pesquisa Operacional, v. 27, p. 535 - 547, 2007.

[16] SANTOS, L. M. R.; MICHELON, P.; ARENALES, M. N.; SANTOS, R. H. S. Crop rotation scheduling with adjacency constraints. Annals of Operations Research, v. DOI: 10.1007/s10479-008-0478-z, 2008.

[17] SANTOS, L. M. R. Programação de rotação de culturas modelos e métodos de solução. 2009. (Tese de Doutorado) - Universidade de São Paulo - campus São Carlos, 2009.

[18] SANTOS, L. M. R.; ARENALES, M. N.; COSTA, A. M.; SANTOS, R. H. A linear optimization approach for increasing sustainability in vegetable crop production. Computational Methods for Agricultural Research: Advances and Applications (Editores: Dr. Prado, Dr. Barreto Luiz e Dr. Chaib Filho), v. 1, p. 234 - 265, 2010a.

[19] SANTOS, L. M. R.; COSTA, A. M.; ARENALES, M. N.; SANTOS, R. H. S. Sustainable vegetable crop supply problem. European Journal of Operational Research, v. 204, p. 639 - 647, 2010 b.

[20] VANDERMEER, J. H. The ecology of intercropping. Cambridge University Press, 1992. 


\section{Apêndice A}

Para os experimentos computacionais realizados neste trabalho foram selecionadas 23 culturas cultivadas em uma horta orgânica em Barbacena - MG. As culturas 20 a 23 são leguminosas para adubação verde. Os dados de plantio produtividade das culturas são apresentadas nas tabelas a seguir. A unidade de tempo utilizada para definir os ciclos é de uma semana. O ciclo de cultivo de cada cultura inclui o tempo estimado para plantio e colheita.

Tabela A.1 - Dados de plantio e ciclo de 23 culturas

\begin{tabular}{|c|c|c|c|c|c|c|}
\hline \multicolumn{2}{|r|}{ CULTURA } & \multicolumn{2}{|r|}{ FAMILIA } & \multicolumn{2}{|c|}{ ÉPOCA PLANTIO } & CICLO \\
\hline 1 & Alface americana & 1 & Compositae & \multicolumn{2}{|c|}{ ano todo } & 7 \\
\hline 2 & Alface mimosa & 1 & Compositae & \multicolumn{2}{|c|}{ ano todo } & 7 \\
\hline 3 & Alface lisa & 1 & Compositae & \multicolumn{2}{|c|}{ ano todo } & 7 \\
\hline 4 & Almeirão & 1 & Compositae & \multicolumn{2}{|c|}{ ano todo } & 7 \\
\hline 5 & Couve & 2 & Brassicaceae & fevereiro & setembro & 32 \\
\hline 6 & Brócolis & 2 & Brassicaceae & fevereiro & outubro & 20 \\
\hline 7 & Couve-Flor & 2 & Brassicaceae & março & outubro & 18 \\
\hline 8 & Beterraba & 3 & Chenopodiaceae & fevereiro & setembro & 11 \\
\hline 9 & Espinafre & 3 & Chenopodiaceae & fevereiro & setembro & 20 \\
\hline 10 & Abobrinha & 4 & Cucurbitaceae & outubro & fevereiro & 14 \\
\hline 11 & Moranga & 4 & Cucurbitaceae & novembro & janeiro & 19 \\
\hline 12 & Pepino & 4 & Cucurbitaceae & setembro & março & 13 \\
\hline 13 & Alho & 5 & Liliaceae & março & abril & 24 \\
\hline 14 & Cebola & 5 & Liliaceae & março & julho & 24 \\
\hline 15 & Alho porró & 5 & Liliaceae & abril & abril & 12 \\
\hline 16 & Quiabo & 6 & Malvaceae & novembro & janeiro & 27 \\
\hline 17 & Tomate & 7 & Solanaceae & \multirow{2}{*}{\multicolumn{2}{|c|}{$\begin{array}{l}\text { ano todo } \\
\text { ano todo }\end{array}$}} & 24 \\
\hline 18 & Cenoura & 8 & Umbelliferae & & & 16 \\
\hline 19 & Salsinha & 8 & Umbelliferae & outubro & fevereiro & 21 \\
\hline 20 & Mucuna preta & 9 & Leguminosae & outubro & janeiro & 16 \\
\hline 21 & Feijão-de-porco & 9 & Leguminosae & outubro & fevereiro & 12 \\
\hline 22 & Tremoço & 9 & Leguminosae & março & julho & 18 \\
\hline 23 & Ervilha Peluda & 9 & Leguminosae & março & julho & 20 \\
\hline
\end{tabular}


Tabela A.2. Dados sobre colheitas parciais de 19 culturas: nome,unidade de medida, número de períodos de 1 semana até a primeira colheita (representada por $o_{i}$, e produção esperada nos sucessivos períodos de colheita.

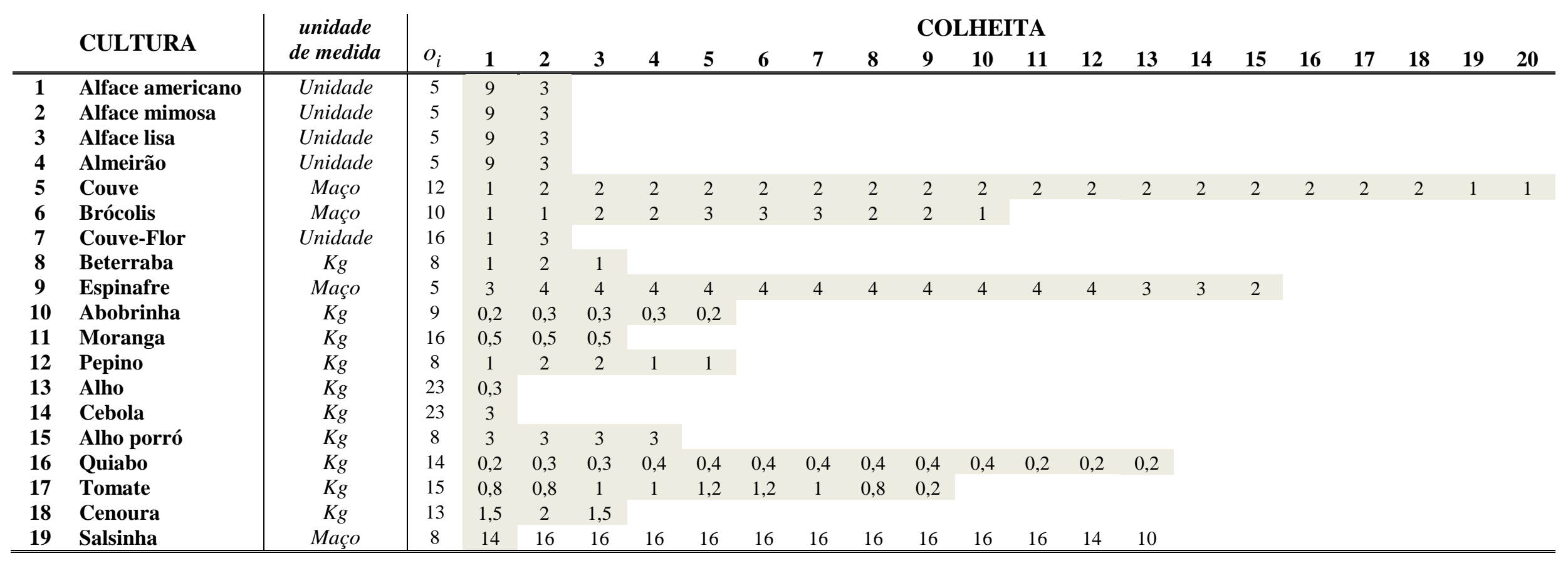

